Portland State University

PDXScholar

Summer 8-14-2019

\title{
Evaluation of Low and High Frequency Dynamic Response for Condition Assessment of Reinforced Concrete Structures
}

Ali Hafiz

Portland State University

Follow this and additional works at: https://pdxscholar.library.pdx.edu/open_access_etds

Part of the Civil Engineering Commons

Let us know how access to this document benefits you.

Recommended Citation

Hafiz, Ali, "Evaluation of Low and High Frequency Dynamic Response for Condition Assessment of Reinforced Concrete Structures" (2019). Dissertations and Theses. Paper 5122.

https://doi.org/10.15760/etd.7001

This Dissertation is brought to you for free and open access. It has been accepted for inclusion in Dissertations and Theses by an authorized administrator of PDXScholar. Please contact us if we can make this document more accessible: pdxscholar@pdx.edu. 
Evaluation of Low and High Frequency Dynamic Response for Condition Assessment of Reinforced Concrete Structures

by

Ali Hafiz

A dissertation submitted in partial fulfillment of the requirements for the degree of

Doctor of Philosophy

in

Civil and Environmental Engineering

Dissertation Committee:

Thomas Schumacher, Chair

Peter Dusicka

Arash Khosravifar

Hormoz Zareh

Portland State University

2019 
(C) 2019 Ali Hafiz 


\begin{abstract}
Concrete is widely used for civil infrastructure structures and they experience deterioration and degradation due to aging, increases in the traffic loads, harsher environmental conditions, use of deicing chemicals, etc. Therefore, evaluating the integrity of reinforced concrete structures has become of increasing interest for infrastructure owners and managers. A number of non-destructive testing (NDT) and structural health monitoring (SHM) methods have been developed in recent decades to aid in evaluating structures and provide input for asset management. One family of these methods uses the dynamic response of a structural member: stress waves (high frequency) and structural vibrations (low frequency). Both the high and low dynamic response frequencies were studied in this $\mathrm{PhD}$ dissertation for NDT and SHM purposes resulting in three novel tools.
\end{abstract}

First, an ultrasonic coda wave comparison (CWC) method was developed, which is a new method to monitor stresses in reinforced concrete members. An ultrasonic wave, representing the high frequency dynamic response (stress wave), was used in this method. Magnitude-squared coherence (MSC) was used to estimate the similarity between two recorded ultrasonic waveforms: a reference waveform under initial stress and one taken at a certain level of applied stress. Through a series of laboratory experiments and an inservice bridge test, the method was found capable of capturing minute changes in the internal stresses in a concrete member.

Second, the modal parameters of the structural vibration response (low frequency) of a reinforced concrete girder was investigated as a means to detect service-level flexural 
cracking. In addition, this investigation emphasized the important effects of elastic support conditions on the modal parameters. The experimental testing of a large-scale reinforced concrete girder suggests that elastic supports have a significant effect on modal parameters. Also, natural frequencies of higher modes (higher that three) can be used to detect flexural cracks, unlike the natural frequency of the first and second modes that might give a wrong indication of cracking.

Finally, a nonlinear vibration index (NVI) method is proposed to detect degradation and delaminations in a reinforced concrete bridge deck. The novelty of this method is that it is reference-free, i.e. no measurements from the undamaged state are required. The approach was simulated numerically using a finite element model and evaluated on an in-service concrete bridge deck. The results show that the proposed NVI method has the ability to detect degradation and delaminations. The availability of visual inspection data, concrete cores, and depth of removed concrete from ultra-high-pressure hydro-blasting provided further confirmation of the method. 


\section{Acknowledgments}

Acknowledgments I would like to express my deepest appreciation to my adviser Dr. Thomas Schumacher who has the attitude and the substance of a genius. This work would not have been possible without his guidance and persistent help.

I'm deeply indebted to committee members Dr. Peter Dusicka, Dr. Arash Khosravifar and Dr. Hormoz Zareh for their valuable comments and suggestions.

I also want to thank all of my colleagues and friends Aqeel Lamy, Anas Yusifany, Salih Mohamed, Wesam Aulse, Anower Mohamed and Alaa Hameed.

I am indebted to my wife Abeer Al-Shammari for her patience, sacrifice, support and understanding throughout my Ph.D. journey. 


\section{Table of Contents}

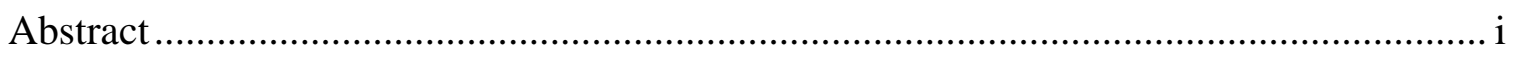

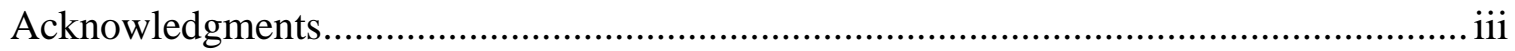

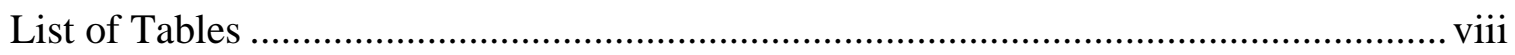

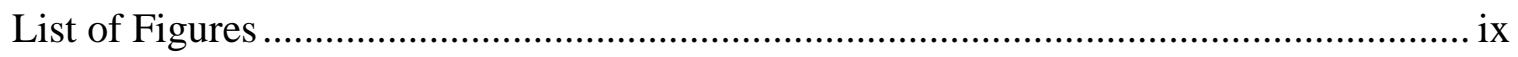

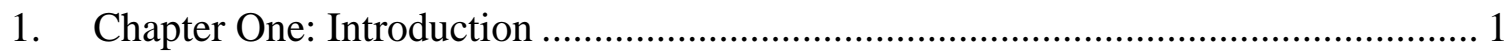

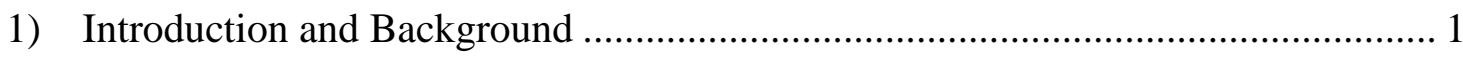

1.1. Non-Destructive Testing .......................................................................... 1

1.2. Structural Health Monitoring ………………….......................................... 2

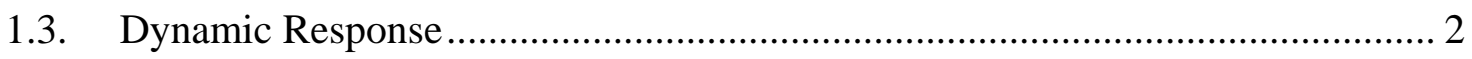

1.3.1. Stress Wave Propagation ....................................................................... 3

1.3.2. Structural Vibrations .......................................................................... 5

1.4. Frequency Domain Analysis of Sig4nals ........................................................ 6

1.5. Outline of Dissertation ............................................................................... 7

2. Chapter Two: Monitoring of Stresses in Concrete Using Ultrasonic Coda Wave

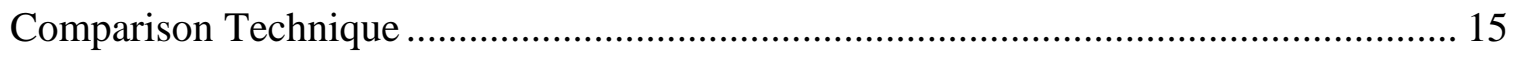

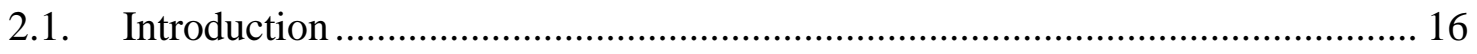

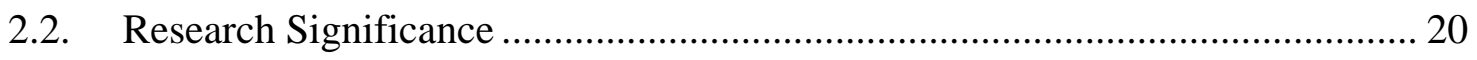


2.3. Methodology

2.3.1. Monitoring Methodology ……………………......................................... 20

2.3.2. Coda Wave Comparison ......................................................................... 21

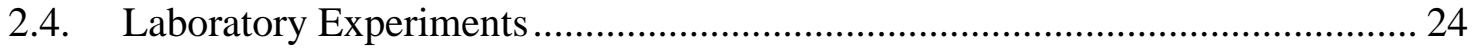

2.4.1. Test Specimens and Loading Protocols ................................................... 25

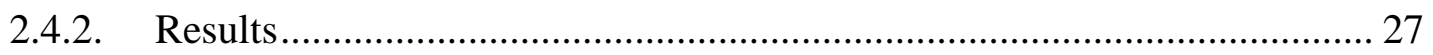

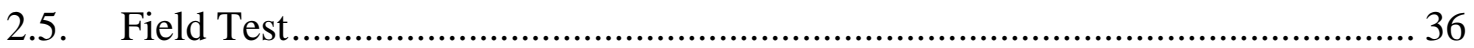

2.5.1. Description of Load Test .................................................................... 36

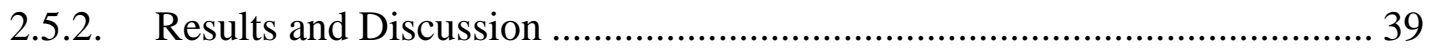

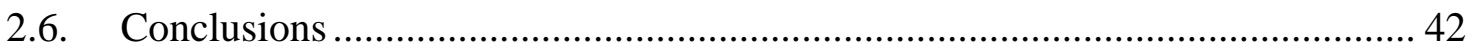

3. Chapter Three: Effects of Elastic Supports and Flexural Cracking on Low and High Order Modal Properties of a Reinforced Concrete Girder................................................ 50

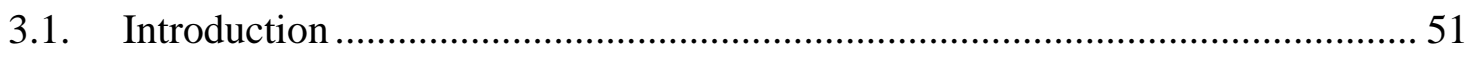

3.2. Research Significance and Objectives ......................................................... 57

3.3. Experimental Setup and Data Processing ...................................................... 58

3.3.1. Experimental Test Setup ………………………............................... 58

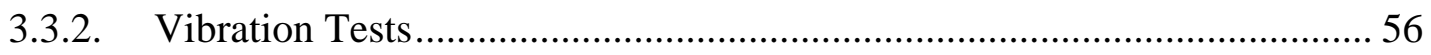

3.3.3. Loading to Induce Flexural Cracking ………………............................... 58

3.3.4. Data Processing .................................................................................. 59 
3.4. Numerical Model.

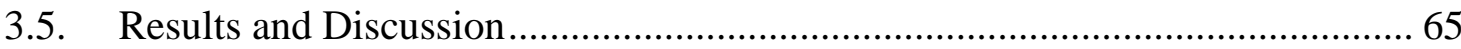

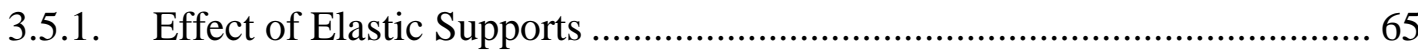

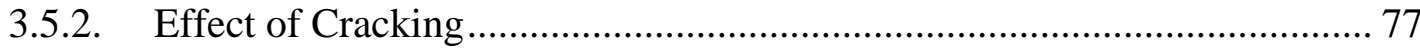

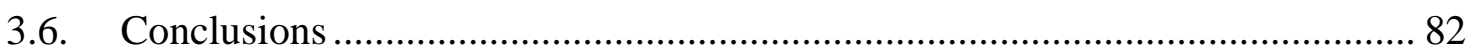

4. Chapter Four: A Reference-Free Non-Destructive Testing Method to Detect Deterioration in Concrete Bridge Decks Based on Non-Linear Vibration Characteristics

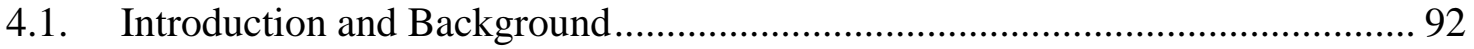

4.2. Research Significance and Objective ………................................................ 96

4.3. Proposed Nonlinear Vibration Index (NVI) Method ........................................ 97

4.4. Numerical Study .................................................................................... 100

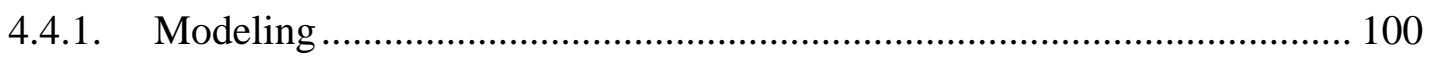

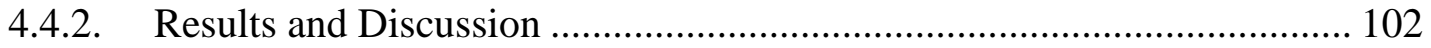

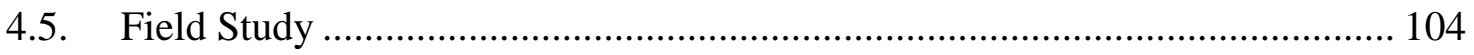

4.5.1. Description of Selected Bridge ………………................................... 104

4.5.2. Test Setup and Procedure....................................................................... 105

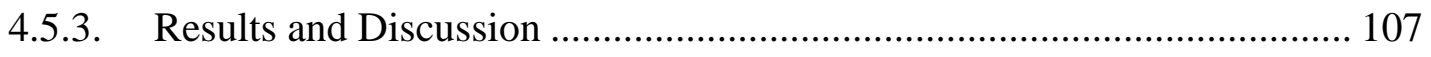

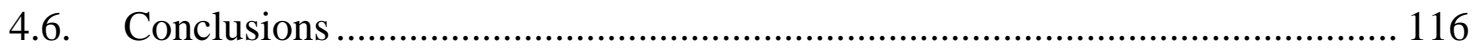


5. Chapter Five: Conclusions and Outlook ..................................................... 122

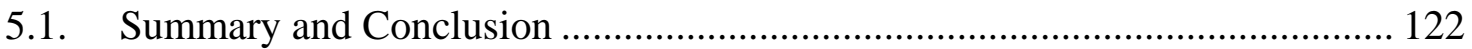

5.2. Outlook and Recommended Future Work ................................................... 124 


\section{List of Tables}

Table 2-1 The regression results for Specimens C1 and C2 34

Table 2-2 The regression results for concrete prisms 36

Table 2-3 Weight information for test trucks 38

Table 2-4 Truck stop locations for girder test 38

Table 2-5 Truck stop locations for column test 39

Table 3-1 Comparison of natural vibration frequencies for modes, $n=1 \quad 67$ to 13

Table 3-2 Comparison of natural vibration frequencies between 76 experimental and $2^{\text {nd }}$ numerical model results

Table 3-3 Natural frequencies of reference and cracked girders 80

Table 4-1 Six selected test location coordinates and their NVI values $\quad 110$ 


\section{List of Figures}

Figure 1-1 Illustration of the frequency range of structural vibration and 3 stress waves

Figure 1-2 Snapshot of a stress wave with its three modes propagating $\quad 4$ in a solid

Figure 1-3 Modal properties for the first four modes of a bridge 5

$\begin{array}{lll}\text { Figure 1-4 Example of a synthetic discrete signal } & 7\end{array}$

Figure 2-1 Illustration of proposed ultrasonic monitoring methodology 21

Figure 2-2 Photo of experimental test setup for Test 1. 27

Figure 2-3 Illustration of experimental setup for Test 2 and the results 25 of FE simulation at an applied load, $P=P$ ult

Figure 2-4 Three samples of recorded waveforms from Specimen C2 28 for different levels of applied stress.

Figure 2-5 $\Delta$ TOF vs. normalized stress for Specimen $\mathrm{C} 2$

Figure 2-6 $\quad$ (a) Transmitted pulse in the time domain. (b) Waveforms in 30 frequency domain

Figure 2-7 Different waveform comparison parameters vs. normalized 31 applied stress for Specimen C2

Figure 2-8 MSC $(\lambda)$ vs. normalized applied stress 32

Figure 2-9 The effect of decreasing the sampling frequency on the 33

CWC results for Specimen C2

Figure 2-10 Results of the linear regression for $\operatorname{MSC}(\lambda)$ vs. normalized 34 applied stress

Figure 2-11 MSC $(\lambda)$ vs. normalized applied stress for Specimens P1 and 36 $\mathrm{P} 2$

Figure 2-12 In-service load test on I-84 Bridge near Echo, Oregon 37

$\begin{array}{lll}\text { Figure 2-13 } & \mathrm{MSC}(\lambda) \text { vs. test time }\end{array}$

Figure 2-14 Normalized $\operatorname{MSC}(\lambda)$ vs. steering axle position 41 
Figure 2-15 Normalized $\operatorname{MSC}(\lambda)$ vs. normalized $\Delta \sigma$

Figure 3-1 Test setup showing loading configuration to induce flexural 56 cracking.

Units: $1 \mathrm{ft}=12$ in $=0.305 \mathrm{~m}$

Figure 3-2 The setup of dynamic test. Units: $1 \mathrm{ft}=12 \mathrm{in}=0.305 \mathrm{~m} \quad 57$

Figure 3-3 Sample: (a) Impact force and (b) Acceleration response 58

Figure 3-4 Sample measured vibration response in the frequency 61

domain for $x=x^{\prime}=8 \mathrm{ft}=2.44 \mathrm{~m}$

Figure 3-5 Three sample FRF for $x=x^{\prime}=3 \mathrm{ft}=0.914 \mathrm{~m}$

Figure 3-6 Coefficient of determination $\left(R^{2}\right)$ vs. vibration frequency 62

Figure 3-7 FE model of girder supported by elastic springs 65

Figure 3-8 Two sample FRF for the reference girder at (a) $x=x^{\prime}=8 \mathrm{ft} \quad 66$ $(2.438 \mathrm{~m})$ and $(\mathrm{b}) \mathrm{x}=\mathrm{x}^{\prime}=3 \mathrm{ft}(0.914 \mathrm{~m})$

Figure 3-9 Experimental vs. numerically-predicted natural vibration $\quad 69$ frequencies

Figure 3-10 FRF for roving hammer: (a) Accelerometer at $3 \mathrm{ft}(0.914 \mathrm{~m}) \quad 69$ and (b) accelerometer at $8 \mathrm{ft}(2.44 \mathrm{~m})$

Figure 3-11 Comparison of experimental and numerical results for first $\quad 70$ sixth modes

Figure 3-12 Numerical model results of mode shapes of the non-linear 71 regime

Figure 3-13 Natural vibration frequency for the first 13 modes vs. 73 support stiffness

Figure 3-14 Mode shape of second mode for varying support stiffness $\quad 74$

Figure 3-15 Four sample FRF for reference and cracked girders 78

Figure 3-16 First mode shape for reference (red dots) and cracked (green 79 dots) girders

Figure 3-17 Flexibility change in mode 1 between undamaged and 81 cracked girder

Figure 4-1 Illustration of impulse response (IR) test setup 97 
Figure 4-2 Sample for test location A1 on the selected bridge deck

Figure 4-3 Example $R^{2}$ for FRFs very soft and very strong vs. frequency

Figure 4-4 Illustration of the finite element model.

Figure 4-5 Two samples of FRFs for decks with and without

102 delaminations

Figure 4-6 Three samples of FRF (first peak) for impact force

103 magnitude $=0.5,4$ and $15 \mathrm{kN}$

Figure 4-7 Maximum peak value of FRF corresponding to first peak

104 frequency for both models vs. peak impact force value

Figure 4-8 Bridge in Branchport, NJ: (a) Google map image showing 105 selected slab (\#2) used as part of this study, (b) photo from a driver's perspective, and (c) cross-section with dimensions in (in)

Figure 4-9 (a) Plan view photo of Deck \#2 with test grid (red '+'), sample results (A1, B1, B2, C1, C2), and cores (full black circles) and (b) peak impact forces for all 270 test locations

Figure 4-10 Samples of: (a) Four impact forces and (b) four 107 corresponding acceleration responses for one select test point

Figure 4-11 Empirical Stress-Strain relationship [21] and generated 108 stress ranges due to very soft (grey) and very strong (green) impact forces. The black dashed line represents the assumed linearity limit for this concrete

Figure 4-12 (a) FRF response of test location $\mathrm{A} 2$ and (b) $R^{2}$ - frequency relationship

Figure 4-13 Photos of extracted concrete cores: (a) Cr1 (near A2) and (b) 111 $\mathrm{Cr} 2$ (near B1)

Figure 4-14 $\quad$ (a) FRF response of test location $\mathrm{B} 1$ and (b) $R^{2}$ - frequency 112 relationship

Figure 4-15 $\quad$ (a) FRF response of test location $\mathrm{B} 2$ and (b) $R^{2}$ - frequency 112 relationship 
Figure 4-16 (a) FRF response of test location C1 and (b) $R^{2}$ - frequency relationship

Figure 4-17 (a) FRF response of test location C2 and (b) $R^{2}$ - frequency 113 relationship

Figure 4-18 (a) NVI values and (b) depth of removed concrete for Deck 115 \#2 


\section{Chapter One: Introduction}

\section{1) Introduction and Background}

Structures such as buildings and bridges begin to deteriorate as soon as they are built and taken into service [1]. In addition to deterioration due to aging and environmental effects, they can also experience fatigue and overloading from natural hazards like earthquakes, tornadoes, and hurricanes, which can introduce both small and large-scale damage. Generally, the term "damage" can be defined as a change in the structure that adversely affects its performance in the present or future [2]. Therefore, evaluating a structure's integrity, without further damaging it, is of greatest importance. This process is called nondestructive evaluation (NDE). NDE has been employed for many decades and researchers have developed a variety of methods and techniques for assessing structural integrity [1]. These techniques may be further sub-categorized: Non-destructive testing (NDT) and structural health monitoring (SHM). Subsequently, NDT and SHM are defined in detail, as used in this dissertation.

\subsection{Non-Destructive Testing}

Non-destructive testing (NDT) includes the in-situ testing, examination, or evaluation performed of a test object in order to determine internal damage (or changes thereof) that may have an effect on its performance or serviceability. NDT is an active process whereby

the test equipment is deployed temporarily to perform the test. A known source is used as the stimulus, e.g. an ultrasonic pulse, hammer impact, or vibration generator. The response of the system is measured using a sensor. The measured signals are then digitized, stored, 
and analyzed using digital signal processing (DSP) techniques. Some common NDT methods for concrete include visual inspection, infrared thermography, impulse response testing, impact echo testing, ultrasonic testing, ground penetrating radar (GPR), half-cell potential, and electrical resistivity [3]. NDT on concrete is mainly employed to locate steel reinforcing bars and tendons, locate voids, cracks, and honeycombing, determine member thickness, estimate the level of corrosion, but it can also be used to estimate material properties such as modulus of elasticity, Poisson's ratio, and strength [4].

\subsection{Structural Health Monitoring}

Structural health monitoring (SHM) can be defined as a process of monitoring and predicting structural integrity [2] at frequent intervals during the life (or partial life) of a structure [1]. Also, it is used to assess the nature of damage in a structure by determining the location and severity of the damage [1]. SHM is a passive process whereby the response of the structure is monitored over time using fixed sensors, often due to unknown and uncontrollable stimuli. Generally, the concept of comparison between two different states is used in structural health monitoring by comparing the current state with an initial (often undamaged, reference) state [2].

\subsection{Dynamic Response}

The dynamic response of structures is widely used for NDE purposes. Generally, an external stimulus (or excitation) is applied on structures and the dynamic response of the structure is measured using displacement, velocity, or acceleration sensors. According to 
the excitation frequency, the dynamic response can be divided into two classes: structural vibrations and stress wave propagation, as illustrated in Figure 1-1 [5][6][7].

Both structural vibrations and stress waves can be described as the vibrational motion of particles due to an external excitation. This motion is initiated by displacing particles from their static equilibrium position [8]. The velocity at which particles oscillate and propagate are a function of the system's geometry, boundary conditions, and material properties such as modulus of elasticity, Poisson's ratio, and mass density.

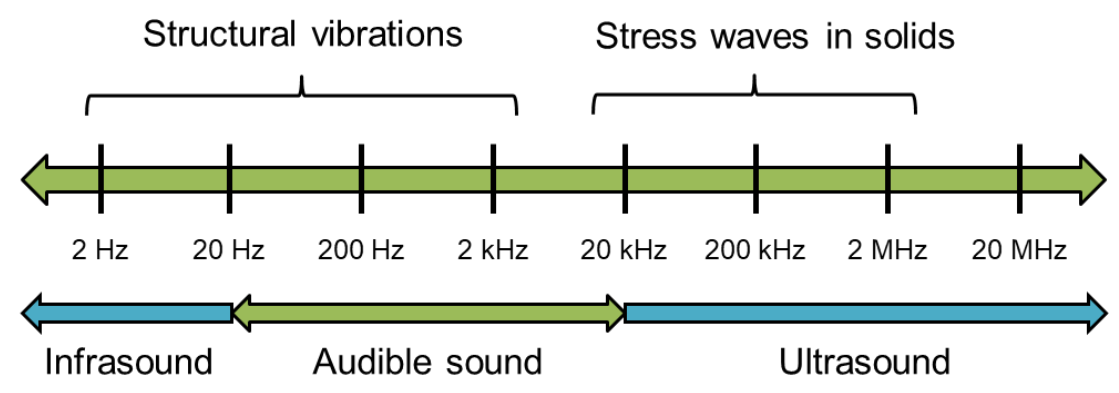

Figure 1-1. Illustration of the frequency range of structural vibration and stress waves [8].

\subsubsection{Stress Wave Propagation}

Stress wave propagation is the result of high-frequency input excitation where its frequency content is within the range of a kilohertz $(\mathrm{kHz})$ or higher [6]. Moreover, the dynamic response of this type of motion causes oscillations in material by particles around their equilibrium positions [9], and as a result, an elastic wave is initiated, propagating radially away from the source through the material (see Figure 1-2). In a solid medium, two socalled modes exist for stress waves: compression and shear waves. For compression waves, the particle oscillation is parallel to the direction of wave propagation; conversely, the 
particle oscillation of shear waves is perpendicular to it. A third wave mode exists that propagates at a surface that is called surface wave. Stress waves in the ultrasonic range have been widely used for NDT purposes and is known as ultrasonic testing (UT). Since material properties directly affect wave characteristics, changes in the recorded waveforms can be associated with changes in the material.

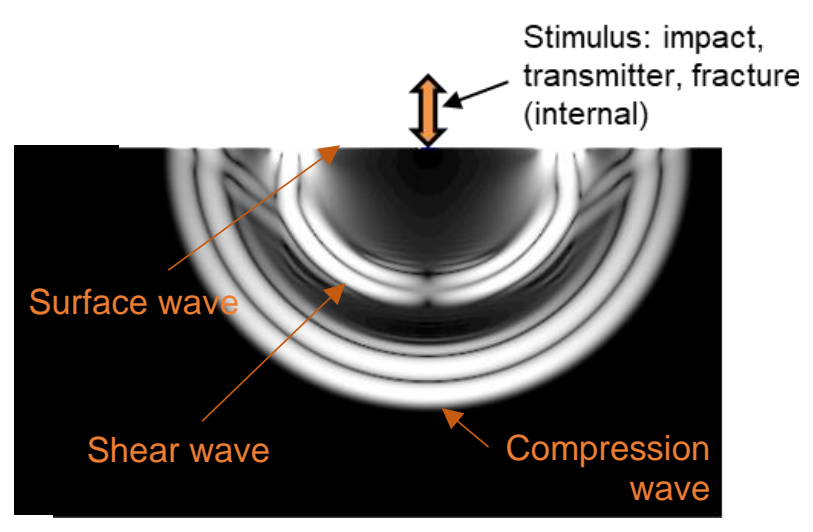

Figure 1-2. Snapshot of a stress wave with its three modes propagating in a solid [8].

Generally, a piezoelectric ultrasonic transducer is used as a transmitter to send a pulse that propagates through the structure. Selecting an appropriate pulse frequency depends on the material properties and the necessary propagation wavelength relative to the size of the material sample. For example, a $1 \mathrm{MHz}$ (or higher) pulse frequency is used for steel members, but for concrete, the typical pulse frequency is within a range of 30 to $150 \mathrm{kHz}$, because concrete is a highly scattering material due to its heterogeneity. Finally, one or more receiving transducers are used to record the response (propagated wave). Further details about UT and a novel methodology of analyzing and interpreting ultrasonic waves for stress monitoring are presented in Chapter 2. 


\subsubsection{Structural Vibrations}

Structural dynamics is associated with a low frequency dynamic load where the frequency content of an excitation is in range of few hundred $\mathrm{Hertz}(\mathrm{Hz})$ [6]. Additionally, in this type of response, all parts of the system move sinusoidally with the same frequency and with a fixed phase relation as shown in Figure 1-3. Typically, for NDE applications to civil structures, a force impact or harmonic force is used as excitation in order to initiate vibrations. Based on the dynamic response of the structure, measurements such as natural frequencies, mode shapes, and damping ratios can be extracted, which are called modal parameters. Any damage or abnormality in the structure has an influence on these parameters. Generally, the modal parameters of the lower modes are used since exciting the structure in the higher modes requires significant energy [5]. Moreover, the wavelength of the lower modes is on the order of the length of the structural member and thus much larger than the size of the aggregates in the concrete. Therefore, the interaction between the waves and the local cracks is mostly negligible [10]. Structural vibrations in this dissertation research are divided into two categories: linear and nonlinear response. Further details about structural vibrations and two studies looking at modal properties and the nonlinear response characteristics are presented in Chapters 3 and 4, respectively.

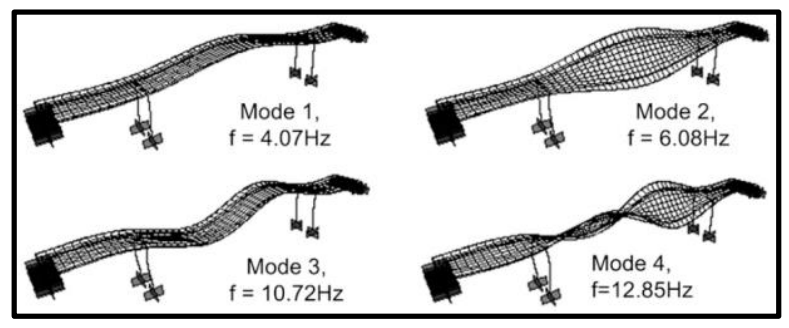

Figure 1-3. Modal properties for the first four modes of a bridge [11]. 


\subsection{Frequency Domain Analysis of Sig4nals}

A signal is defined as a physical quantity that varies over an independent variable such as time or space [12]. Generally, data acquisition systems sample and digitize analog signals in the time domain. Discrete signals are discrete signals and can be decomposed into a series of sines and cosines that, when appropriately scaled and shifted, represent the original signal. The tool used to compute the scaling and shifting parameters is called the discrete Fourier transform (DFT) [13]. Sines and cosines are used in this analysis because they represent orthogonal and Eigen functions [13]. Figure 1-4 shows an example of a discrete signal in both the time and frequency domains. The scaling parameter of the frequency domain (Figure 1-4.b) has useful information regarding frequency content, which would not be possible to observe looking only at hte time domain. 

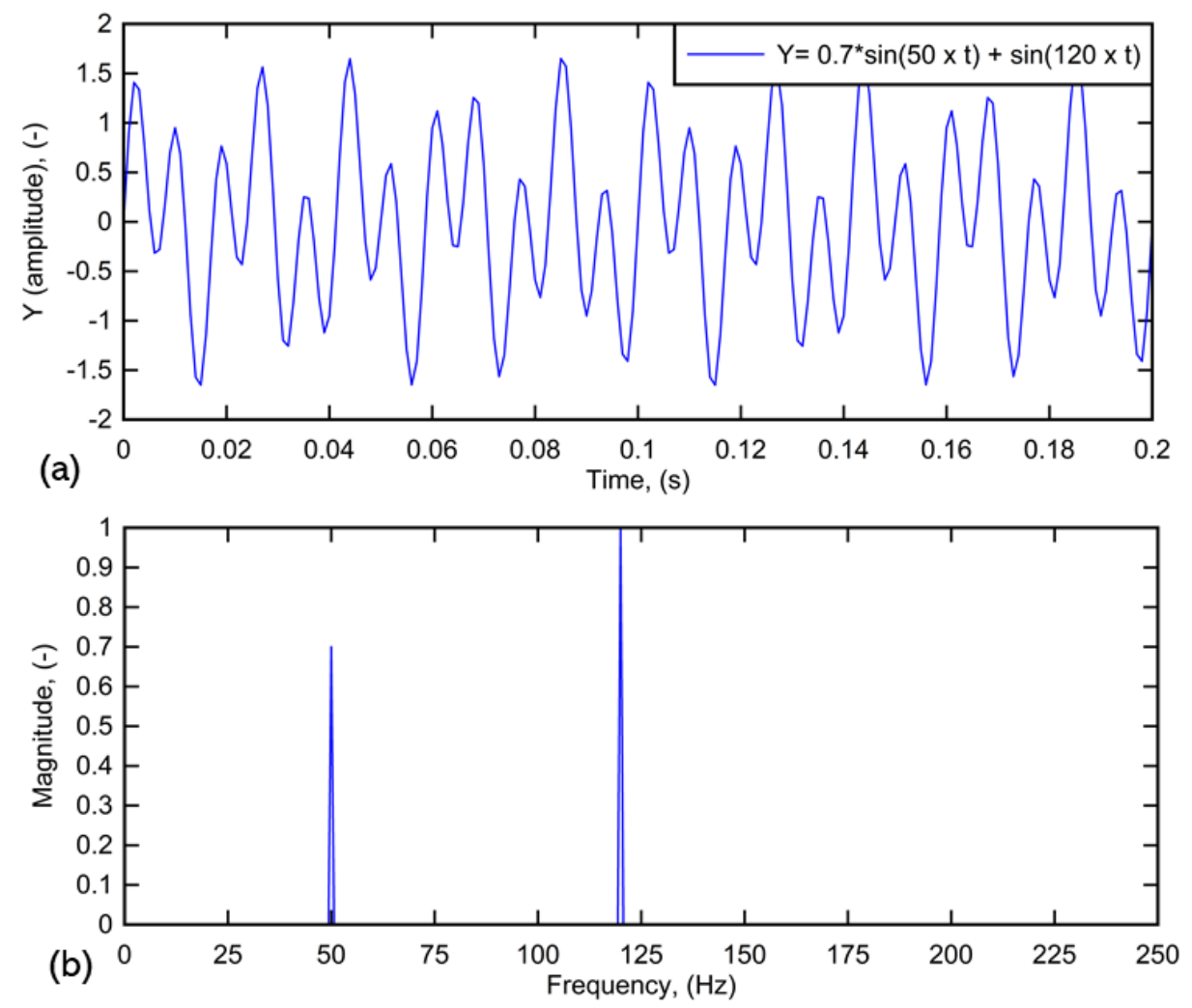

Figure 1-4. Example of a synthetic discrete signal in the: (a) time domain and (b) the frequency domain (only scaling parameter shown for simplicity).

Transform of the signal into the frequency domain is widely used in engineering and science applications, especially for periodic signals. Because of the interpretability of the frequency domain, the DFT is at the core of all analyses in this PhD dissertation research.

\subsection{Outline of Dissertation}

This dissertation research evaluates the use of the high and low frequency dynamic response of reinforced concrete structures to lay the foundation for novel non-destructive evaluation (NDE) tools. Advanced signal processing techniques are used to analyze and 
interpret the recorded response in the frequency domain. This dissertation follows the multi-paper format per PSU OGS guidelines and is organized as follows:

\section{Chapter One: Introduction}

\section{Chapter Two: Monitoring of Stresses in Concrete Using Ultrasonic Coda Wave} Comparison Technique. Abstract: Condition or health monitoring of concrete structures has experienced increasing interest over the last decade. While conventional sensors such as strain gauges are accurate and reliable, they only allow for surface observations. In contrast, ultrasonic waves propagate through the thickness of a member and can thus detect internal changes. In this paper we present an ultrasonic monitoring approach that uses a coda wave comparison (CWC) technique, which makes use of the highly sensitive diffuse (or coda) portion of a recorded ultrasonic waveform. In this study, the changes in the applied stress were correlated to the changes observed in the ultrasonic waveforms, which were estimated using magnitude-squared coherence (MSC). The CWC technique was evaluated by investigating key influence parameters that affect the relationship between MSC and the applied stress. First, two concrete cylinders were cast and tested to study the effect of maximum aggregate size. Second, two concrete prisms were used to study the effect of the frequency of the transmitted pulse. Finally, we discuss a field test involving a prestressed concrete bridge girder and a column. The results show that MSC is capable of discriminating minute stress changes in a laboratory as well as a field setting.

This paper is published and can be found using the following citation: 
Hafiz, A. and Schumacher, T. (2018). Monitoring of Stresses in Concrete Using Ultrasonic Coda Wave Comparison Technique. Journal of Nondestructive Evaluation. Vol. 37(73). DOI: https://doi.org/10.1007/s10921-018-0527-8.

\section{Chapter Three: Effects of Elastic Supports and Flexural Cracking on Low and High} Order Modal Properties of a Reinforced Concrete Girder. A number of nondestructive evaluation (NDE) methods are available to detect cracks and damage in reinforced concrete structures. Methods such as ultrasonic, impact echo, or X-ray testing have high resolution but are time consuming to perform and therefore only used locally. Since the early 1970s, researchers have also studied the modal properties of structures for damage detection and identification. In this paper, we discuss the effects of elastic supports and flexural cracking on the dynamic response of a large-scale laboratory reinforced concrete girder. For this purpose, an instrumented hammer used for impulse response testing was employed to initiate vibrations and to subsequently estimate the natural frequencies and modes of a large-scale laboratory concrete girder. Natural frequencies up to the 13th mode were successfully extracted from the frequency response function (FRF). In addition, the mode shapes were extracted up to the 6th mode due to the limitation of the linearity of the FRF response. These modal properties were determined from the measured accelerations of two points on the girder using a roving hammer. The test procedure was performed on the uncracked beam and repeated after the beam had been cracked. The experimental measurements were verified with a finite element (FE) model consisting of onedimensional beam elements that consider both flexural and shear deformations. Support flexibility was modeled as linear-elastic springs, and was found critical in order to explain 
experimentally-obtained measurements. The effects of cracking were found to be most obvious in the higher modes. Additionally, utilizing the modal flexibility method on the first mode (natural vibration frequency and mode shape) was an accurate predictor of flexural crack locations.

This paper is published and can be found using the following citation:

Hafiz, A. and Schumacher, T. (2019). Effects of Elastic Supports and Flexural Cracking on Low and High Order Modal Properties of a Reinforced Concrete Girder. Engineering Structures. Vol. 178, pp. 573-585. DOI: https://doi.org/10.1016/j.engstruct.2018.10.041.

\section{Chapter Four:A Reference-Free Non-Destructive Testing Method to Detect Deterioration in Concrete Bridge Decks Based on Non-Linear Vibration} Characteristics. A number of non-destructive evaluation (NDE) methods have been developed in recent decades to detect deterioration such as delaminations in concrete bridge decks. These methods, namely visual inspection (i.e. hammer sounding and chain drag), impulse response testing, impact echo testing, ultrasonic (array) echo testing, and under certain conditions ground penetrating radar (GPR) can be used to detect and estimate the extent of delaminations. Since the early 1970s, researchers have also investigated using the dynamic response properties of a structure, which is generally referred to as the vibration-based method. For damage detection, the vibration-based method requires a comparison with reference data, which is unavailable in most cases. Generally, the vibration response due to an impact force can be measured using accelerometers. The frequency response function (FRF) is computed by dividing the measured response by the 
input force, both in the frequency domain. In this paper, we present a simple reference-free method based on impulse response (IR) testing to detect deterioration in concrete bridge decks using non-linear vibration characteristics. The hypothesis is that for an undamaged deck, varying the impact force does not affect the corresponding FRFs for frequencies that lie within the accelerometer's operating range. On the other hand, the FRFs of a deteriorated slab change when the impact force is increased with the delamination resulting a non-linear vibration response. Finite element modeling was first used to demonstrate that the method will work in theory. We then evaluated its performance on an in-service bridge deck. Finally, ultra-high-pressure hydro-blasting was performed on the deck for rehabilitation, providing an opportunity to compare results.

This manuscript will be submitted to the Journal of Mechanical Systems and Signal Processing.

\section{Chapter 5: Conclusion and Outlook.}




\section{References}

[1] Chang, P. C., Flatau, A., and Liu, S. C., 2003, "Review Paper: Health Monitoring of Civil Infrastructure," Structural Health Monitoring, 2(3), pp. 257-267.

[2] Farrar, C. R., and Worden, K., 2007, “An Introduction to Structural Health Monitoring.," Philosophical transactions. Series A, Mathematical, physical, and engineering sciences, 365(1851), pp. 303-315.

[3] ACI 228.2R-98, 2013, "Nondestructive Test Methods for Evaluation of Concrete in Structures," ACI Committee 228.

[4] S. S. Udpa, P. O. M., 2004, "Nondestructive Testing Handbook , Third Edition," Nondestructive Testing Handbook, Third Edition, pp. 5-6.

[5] Nickell, R. E., 1972, A Survey of Direct Integration Methods in Structural Dynamics, BROWN UNIV PROVIDENCE RI DIV OF ENGINEERING.

[6] Gopalakrishnan, S., Chakraborty, a., and Mahapatra, D. R., 2007, Spectral Finite Element Method: Wave Propagation, Diagnostics and Control in Anisotropic and Inhomogeneous Structures.

[7] Gopalacrishnan, S., and Narendar, S., 2013, "Wave Propagation in Nanostructures."

[8] Schumacher, T., "CE 510/610 Sensing and Monitoring of Structures," Lecture notes;Portland State University. 
[9] Walley, S. M., and Field, J. E., 2005, "Elastic Wave Propagation in Materials," Encyclopedia of Materials: Science and Technology, p. 7.

[10] Planès, T., and Larose, E., 2013, "A Review of Ultrasonic Coda Wave Interferometry in Concrete," Cement and Concrete Research, 53, pp. 248-255.

[11] Siringoringo, D. M., Fujino, Y., and Nagayama, T., 2011, “Dynamic Characteristics of an Overpass Bridge in a Full-Scale Destructive Test," Journal of Engineering Mechanics.

[12] Proakis, J. G., and Manolakis, D. G., 1996, "Digital Signal Processing Principoles, Algorithms and Applications," Digital Signal Processing.

[13] Santamarina, J. C., and Fratta, D., 2006, Discrete Signals and Inverse Problems: An Introduction for Engineers and Scientists. 


\title{
Chapter Two:
}

\section{Monitoring of Stresses in Concrete Using Ultrasonic Coda Wave Comparison}

\section{Technique}

\begin{abstract}
Ali Hafiz ${ }^{1}$ and Thomas Schumacher ${ }^{2}$
Journal of Nondestructive Evaluation

Springer Nature Publications

Switzerland $A G$

This paper is published and can be found using the following citation:

Hafiz, A. and Schumacher, T. (2018). Monitoring of Stresses in Concrete Using Ultrasonic Coda Wave Comparison Technique. Journal of Nondestructive Evaluation. Vol. 37(73). DOI: https://doi.org/10.1007/s10921-018-0527-8.
\end{abstract}

${ }^{1} \mathrm{PhD}$ Candidate, Civil and Environmental Engineering, Portland State University 1930 SW 4th Avenue, Portland, OR 97201, USA, E-mail: hafiz@pdx.edu

${ }^{2} \mathrm{PhD}$, PE, Associate Professor, Civil and Environmental Engineering, Portland State University 1930 SW 4th Avenue, Portland, OR 97201, USA, E-mail:

thomas.schumacher@pdx.edu 


\title{
2. Chapter Two: Monitoring of Stresses in Concrete Using Ultrasonic Coda Wave Comparison Technique
}

\author{
Ali Hafiz and Thomas Schumacher
}

\begin{abstract}
Condition or health monitoring of concrete structures has experienced increasing interest over the last decade. While conventional sensors such as strain gauges are accurate and reliable, they only allow for surface observations. In contrast, ultrasonic waves propagate through the thickness of a member and can thus detect internal changes. In this paper we present an ultrasonic monitoring approach that uses a coda wave comparison (CWC) technique, which makes use of the highly sensitive diffuse (or coda) portion of a recorded ultrasonic waveform. In this study, the changes in the applied stress were correlated to the changes observed in the ultrasonic waveforms, which were estimated using magnitude-squared coherence (MSC). The CWC technique was evaluated by investigating key influence parameters that affect the relationship between MSC and the applied stress. First, two concrete cylinders were cast and tested to study the effect of maximum aggregate size. Second, two concrete prisms were used to study the effect of the frequency of the transmitted pulse. Finally, we discuss a field test involving a prestressed concrete bridge girder and a column. The results show that MSC is capable of discriminating minute stress changes in a laboratory as well as a field setting.
\end{abstract}

Keywords: ultrasound; coda wave comparison; concrete; stress; magnitude-squared coherence. 


\subsection{Introduction}

Concrete is the most widely used building material in the world [1]. Monitoring the performance of concrete structures has increased in the last two decades [2] due to aging and deterioration and limited funds available for maintenance and repair. Structural health monitoring provides a range of useful information related to the short and long-term performance of a structure such as changes in stress, ongoing cracking, chloride levels, corrosion potential, etc. This information can support maintenance and repair decisions and may also help improving design and construction standards.

Overloading and fatigue are the most common causes of cracking in concrete structures and may lead to deterioration such as rebar corrosion. Therefore, monitoring the stress conditions in concrete members provides important information regarding structural performance. A number of sensors have been developed to monitor stress conditions, such as strain gauges, accelerometers, or displacement sensors, etc. All of these sensors are attached to the surface and, therefore, they only represent a surface observation. Another limit of these sensors is that they can measure stress only at the point of their location. While distributed sensors exist, they are still bound to the surface. Ultrasonic stress waves have also been found to be sensitive to changes in stress and an advantage over traditional sensors as they travel through the thickness of a member. The challenge lies in the interpretation of the signals, i.e. how changes in the recorded signals are related to changes in stress.

Hughes and Kelly [3] established a relationship between the p-wave velocity of ultrasonic waves and the applied stress inside a solid material, after third-order elastic constants were 
introduced by Murnaghan [4]. In concrete, this theory is not directly applicable since the variation in time of flight (TOF) (or the propagation velocity) is extremely minute and, thus, difficult to measure [4,5]. For example, our previous experiment on a small concrete cylinder did not show any change in p-wave velocity until the applied stress reached $60 \%$ of ultimate stress [7]. This represents a significant level of stress and is well above a typical service-level or cracking stress. Therefore, we have been further investigating the evaluation of the diffuse portion of the ultrasonic signals.

Concrete is a heterogeneous material and is made up of different sizes of materials, such as gravel, sand, and cement paste. Due to this heterogeneity, the ultrasonic stress wave experiences multiple scattering during propagation, making the signal more complex [8]. Generally, an ultrasonic signal can be divided into two portions: the coherent (early portion containing p-wave arrival) and the diffuse (late portion or coda wave) portion. As discussed earlier, the coherent portion is not sensitive to a change in the applied stress. On the other hand, any small change in the material has an effect on the coda wave, such as amplitude, energy, and the local phase [9].

The term coda wave originates from the field of geophysics [10], and has been used in materials science for the last decade. A common technique used in this field is called coda wave interferometry (CWI). A number of applications based on CWI for monitoring changes in concrete have been reported [5]. In addition to using CWI for monitoring stress, it has been used to monitor cracking $[8,10,11,12]$, temperature changes $[13,14]$, and ASR [16]. Typically, the time lag between coda wave signals is estimated by applying cross correlation [5]: 


$$
C C(t, \delta t)=\frac{\int_{t 1}^{t 2} Y_{0}[t] Y_{i}[t+\delta t] d t}{\sqrt{\int_{t 1}^{t 2} Y_{0}^{2} d t \int_{t 1}^{t 2} Y_{i}^{2} d t}}
$$

where $Y_{0}$ and $Y_{i}$ is the waveform in the initial and final state, respectively, and $\left(t_{1}, t_{2}\right)$ is the time window in the coda wave. CWI is much more sensitive than TOF to stress changes in concrete [17]. In addition, the sensitivity of CWI velocities relates to direction of the load respect to direction of wave propagation where the parallel situation shows greater sensitivity [18]. CWI has been successfully used for monitoring stresses in a concrete beam tested under a four-point bending load [1]. In addition, CWI was used to determine the non-linear constants for concrete by obtaining the relative velocity change for a concrete cylinder [19]. Stähler et al. [6] estimated the stress changes in an existing bridge by using CWI. Zhang et al. [2] used the CWI to correlate the velocity change in coda wave with the applied tensile stress in a concrete cylinder. Moreover, CWI and nonlinear acoustic waves can provide potential field applicability for in-situ measurements because of their sensitivity to the microstructural changes in concrete [20]. Questions exist regarding sampling frequency and the type of windowing technique to employ when performing CWI. Since the relative change in velocity is small, a high sampling frequency is required. Sometimes, a sampling frequency of $10 \mathrm{MHz}$ is still not enough to detect a change in stress. The location, length, and number of time windows vary from study to study and no recommendations exist for using a specific time window. Liu et al. [21] applied the Taylor series expansion method on coda waves of a concrete cylinder to avoid signal resampling and time consuming calculations in the traditional CWI analysis.

Over the last decade, the interest in quantifying the similarity between signals has increased. Larose et al. [22] proposed a decorrelation coefficient $(K)$ by using the 
correlation coefficient as shown in Eq. (2). The decorrelation coefficient was used to measure the change in the similarity of the coda wave due to the evolution of cracks inside concrete. Based on the decorrelation coefficient and CWI, the researchers developed the LOCADIFF technique for crack imaging[23].

$$
K=1-\frac{\int_{t 1}^{t 2} Y_{0}[t] Y_{i}[t] d t}{\sqrt{\int_{t 1}^{t 2} Y_{0}^{2} d t \int_{t 1}^{t 2} Y_{i}^{2} d t}}
$$

Niederleithinger et al. [24] applied the squared correlation coefficient $\left(R^{2}\right)$ on a time window in the coda wave and related it with applied stress. The authors of this paper also correlated the $R^{2}$ with applied stress, but they used the entire (or full) waveforms [7]. They also used magnitude-squared coherence (MSC) to compute the similarity between fullwaveforms, where MSC was correlated with applied stress in concrete cylinders [25]. Grosse [26] originally proposed the use of MSC to compare acoustic emission (AE) signals. Finally, Chen and Schumacher [27] applied MSC on the coda wave to correlate it with the length of a notch in a steel plate.

Environmental parameters such as temperature and humidity have been found to have a significant effect on the coda wave portion, and structures such as bridges are fully exposed to environment [28]. Yuxiang Zhang et al. [29] proposed a thermal bias control technique by using a second (reference) specimen. They concluded that their technique could reduce the bias from both stress effects and environmental temperature fluctuations [29]. Fröjd and Ulriksen [28] used the Mahalanobis distance to distinguish between signal changes stemming from damage and the environment. 


\subsection{Research Significance}

This paper proposes a coda wave comparison (CWC) technique based on magnitudesquared coherence (MSC) of ultrasonic signals for monitoring internal stresses in concrete. In this technique, the entire recorded ultrasonic waveform is used, not relying on an arbitrary window. Through a series of laboratory experiments, the proposed technique was found capable of discriminating minute changes in the internal stress in concrete. Additionally, the methodology was evaluated during an in-service bridge load test where the MSC value correlated directly with the internal forces of the tested members. In conclusion, ultrasonic monitoring in conjunction with $\mathrm{CWC}$ represents a promising technique to monitor internal stresses. In this study, the environmental effects were minimal and therefore not considered since the testing time was only on the order of a few minutes.

\subsection{Methodology}

\subsubsection{Monitoring Methodology}

Our proposed monitoring methodology is based on ultrasonic stress wave measurements, which are taken at selected intervals. Figure 2-1 illustrates the fundamental idea on a simple setup with one transmitting $(\mathrm{T})$ and one receiving $(\mathrm{R})$ piezoelectric transducer. The option exists to employ a network of sensors, which would allow for spatial discrimination of changes. While the transmitted pulse is selected by the operator and thus assumed to be constant, the received (or recorded) waveforms will change if the material experiences an internal change. This approach is different from the acoustic emission (AE) monitoring 
technique in that it is an active process. AE monitoring is passive and records stress waves released due to sudden processes such as cracking or friction.

Subsequently, a mathematical framework is presented for our proposed monitoring approach and a waveform comparison technique that allows monitoring for minute and slowly varying changes in concrete.

Transmitted

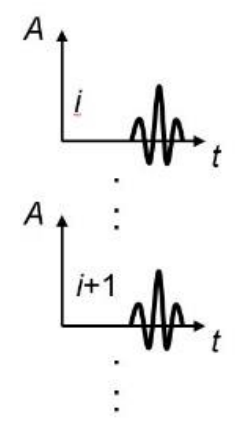

Received

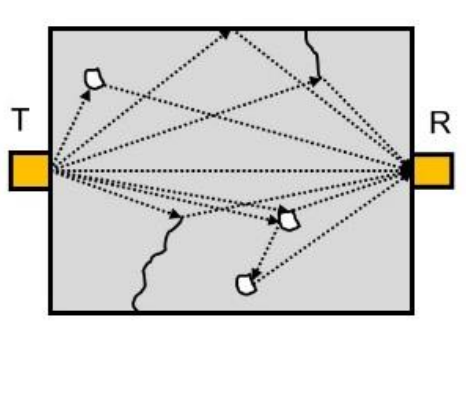

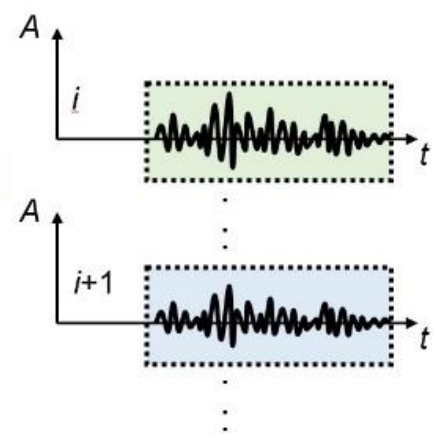

Figure 2-1. Illustration of proposed ultrasonic monitoring methodology. Only one transmitting $(\mathrm{T})$ and one receiving $(\mathrm{R})$ transducer are shown for simplicity.

\subsubsection{Coda Wave Comparison}

Our proposed coda wave comparison (CWC) technique attempts to correlate observed changes in recorded ultrasonic signals with internal structural changes that develop in concrete. This paper focuses on the changes that manifest due to changes in the interior stresses. In this technique, the entire waveform, including both the first arrival and the coda portion of the wave, is used in order to avoid having to select an arbitrary window. The measurements performed in this technique can be mathematically described using a signals and system's framework as a measurement chain of the following form [30]:

$$
R(t)=S(t) * T F_{G}(t) * T F_{T}(t) * T F_{D A Q}(t)
$$


where $R(t)$ is the recorded digitized signal, $S(t)$ describes the transmitted pulse (i.e. source), $T F_{G}(t)$ is the Green's function describing stress wave propagation effects in the medium, and $T F_{T}(t)$ and $T F_{D A Q}(t)$ are the impulse responses of the transducers and the data acquisition unit, respectively. The four elements are linked in the time domain via convolution, which is denoted as “* ”. When high-fidelity components are used that have a flat response over the range of frequencies of interest, the respective element in the measurement chain has a theoretical value of $T F_{x}(t)=1$, which means it can be neglected. Assuming that high-fidelity system components are used, and the coupling of the transducers does not change over time, Eq. (2) reduces to:

$$
R(t)=S(t) * T F_{G}(t)
$$

In the case of our proposed ultrasonic monitoring approach, $S(t)$ does not change over time, and we can therefore attribute the observed differences between measurements, $R(t)$, solely with changes in the Green's function, $T_{F G}(t)$, and hence with changes occurring in the material. The changes in the interior stresses cause minute relocations of the aggregates and eventually micro cracking, which affect the propagation of stress waves through the concrete. This has a particular influence on the coda portion due to the multiple scattering effect seen in concrete, resulting in a change of amplitudes, time shifts, and alteration of frequency content. Mathematically, these changes may be presented as follows:

$$
\Delta T F_{G}(t) \propto \Delta \sigma
$$

where $\Delta T F_{G}(t)$ represents the changes inside the concrete resulting from changes in the interior stress, $\Delta \sigma$. Although micro cracks are randomly generated, we can assume they follow a normal distribution in the propagation path of the stress wave. Also, a change in 
the location of an aggregate is assumed to linearly correlate with interior stress. Therefore, we can assume the changes in concrete vary linearly with stress. Using this assumption and substituting Eq. (4) into Eq. (3) we get:

$$
\Delta R(t) \propto \Delta \sigma
$$

where $\Delta R(t)$ is the change in the recorded signal. In our proposed CWC technique, magnitude-squared coherence (MSC) is used, which estimates the strength of the relationship between two random variables in the frequency domain. In our case, MSC is used to describe the similarity between two waveforms recorded at different levels of stress: $Y_{0}$ is the reference waveform recorded at the initial stress condition of the material and $Y_{i}$ is a waveform recorded at a certain level of interior stress, $\sigma_{i}$. The cross-spectrum $\left[R_{Y 0 Y i}\left(e^{j \omega}\right)\right]$ of any two signals is a complex function of $\omega$, and the normalized cross-power spectrum is known as the coherence function [31]:

$$
\operatorname{MSC}=\left|C_{Y o Y i}\left(e^{j \omega}\right)\right|^{2}=\frac{\left|R_{Y 0 Y i}\left(e^{j \omega}\right)\right|^{2}}{R_{Y 0}\left(e^{j \omega}\right) R_{Y i}\left(e^{j \omega}\right)}
$$

By assuming $\Delta R(t)$ can be represented by MSC at the pulse wavelength, $\lambda$, Eq. (6) can be reformulated as:

$$
\operatorname{MSC}(\lambda) \propto M(\lambda, A) \Delta \sigma
$$

where $M$ is a constant that represents the slope of the linear relationship between the MSC and $\Delta \sigma$. This constant is also function of the wavelength $(\lambda)$ of the source and the aggregate effect $(A)$ for a specific specimen or member. Small wavelengths are more sensitive to micro cracks and relocation of the aggregates and the maximum size of the aggregate influences the interaction of the ultrasonic wave with the aggregates, which is discussed in section "Laboratory Experiments". MSC takes values between one and zero. If $Y_{0}$ is equal 
to $Y_{i}$, the MSC value is equal to one, which implies there is no difference between the signals; otherwise, it is less than one and greater than or equal to zero. In other words, a value of one indicates a perfect match while decreasing values correspond to decreasing similarity between signals. Also, the $M$ value has always a negative sign because the MSC decreases from one at the initial condition with increasing internal stress [25].

For comparison, the change in the recorded ultrasonic signal, $\Delta R(t)$ can be estimated by using the coefficient of determination, $R^{2}$, which is also referred to as the squared correlation coefficient, $\rho^{2}$. The correlation coefficient is also known as the Pearson correlation coefficient and represents a measure of the strength of the relationship between two random variables by using linear regression [32]. It can be calculated by using:

$$
\begin{gathered}
\rho_{Y_{0}, Y_{i}}=\rho=\frac{\operatorname{cov}\left(Y_{0}, Y_{i}\right)}{\sigma_{Y_{0}} \sigma_{Y_{i}}}=\frac{\sigma_{Y_{0}, Y_{i}}}{\sigma_{Y_{0}} \sigma_{Y_{i}}} \\
R^{2}=\rho^{2}=M(\lambda, A) \Delta \sigma
\end{gathered}
$$

Since the coefficient of determination estimates the difference between the signals in the time domain, estimating the time lag between the signals is critical. For this purpose, cross correlation was applied on the full waveform signals by using Eq. (1). The waveforms were adjusted by shifting each signal by its time lag before calculating $R^{2}$, resulting in what we refer to as the adjusted coefficient of determination, $R^{2}$.

\subsection{Laboratory Experiments}

For all experiments, we utilized two Panametrics V103 normal-wave transducers, using one as a transmitter $(\mathrm{T})$ and the other one as a receiver $(\mathrm{R})$, as illustrated in Figure 2-1. The transmitter was connected to a BK Precision 4053 arbitrary waveform generator, which produced a 100 or $50 \mathrm{kHz}$ Morlet-type pulse (see Figure 2-6) at $20 \mathrm{Vpp}$. These frequencies 
have been reported in the literature (see e.g., Fröjd and Ulriksen [33]) and were found suitable for our experiments as well. Both transducers were coupled to the concrete using hot glue and connected to a high-speed data recorder (Elsys TraNET FE) to record both the transmitted and recorded waveforms. The recorder triggered on the transmitted signal in order to record 32,768 samples at a sampling rate of $10 \mathrm{MHz}$ (with $500 \mathrm{kHz}$ low-pass anti-aliasing filters), which ensured that both the coherent as well as the coda portions of the recorded waveforms were fully captured. The number of pre-trigger samples equaled $10 \%$ of the total number of samples. All laboratory specimens were loaded using a programmable 1112-kN-capacity (250-kip-capacity) hydraulic concrete cylinder compression-testing machine (Forney LP) with a loading rate of $0.156 \mathrm{kN} / \mathrm{s}(35 \mathrm{lb} / \mathrm{s})$.

\subsubsection{Test Specimens and Loading Protocols}

\subsubsection{Test 1: Monotonically-Loaded Cylinder}

The goal of this test was to evaluate if the proposed CWC technique is able to capture an applied compressive stress and to investigate the aggregate effect on the results by varying maximum aggregate size. For this purpose, two concrete cylinders (152 x $305 \mathrm{~mm}(6 \mathrm{x} 12$ in)) were cast and tested, and found to exhibit a similar ultimate stress. However, each cylinder had a different maximum aggregate size. These cylinders were named as Specimen C1 and C2. In this test, the cylinders were monotonically loaded in compression up to failure. A pitch-catch setup (illustrated in Figure 2-1) was used during loading and is shown in Figure 2-2. The transducers were attached at mid-height of the cylinders. A pulse with a $100 \mathrm{kHz}$ central frequency was used with a pulse repetition frequency (PRF) of 
$31.74 \mathrm{~Hz}$ to ensure high-resolution continuous monitoring and compatibility with the data acquisition unit on the compression machine.

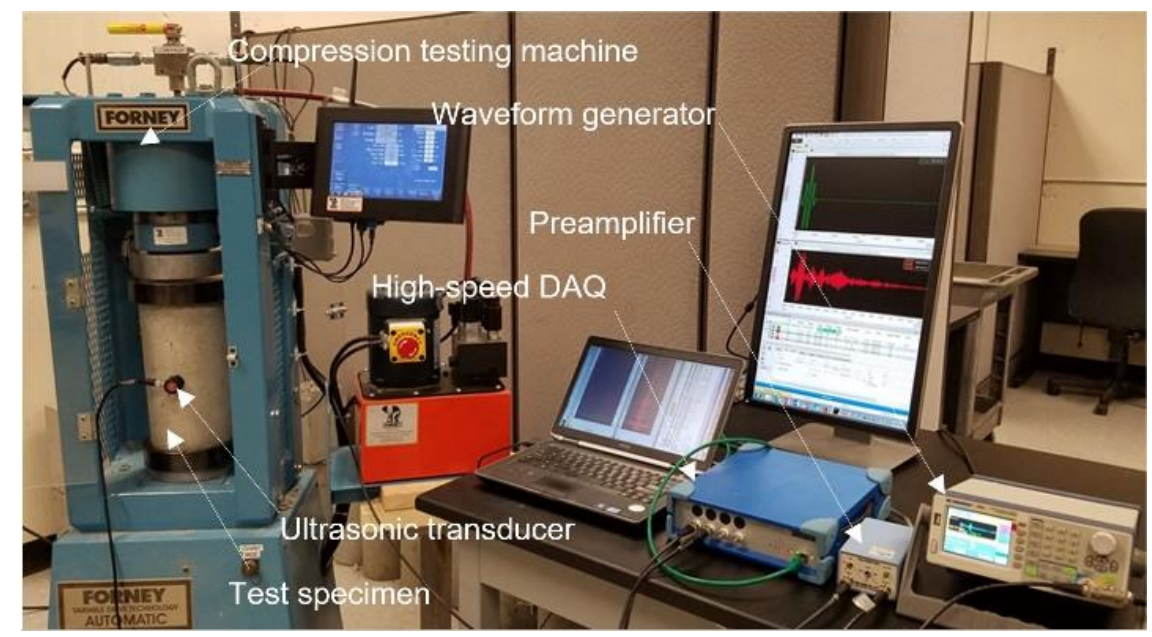

Figure 2-2. Photo of experimental test setup for Test 1.

\subsubsection{Test 2: Stepwise-Loaded Prism}

The goal of this test was to investigate the effect of pulse frequency (or wavelength, $\lambda$ ) on the results of the CWC, as well as to show the ability of the CWC technique to detect changes in internal stresses when the transducers are attached to an unstressed surface. In this test, two concrete prisms with the same dimensions of $152 \times 152 \times 533 \mathrm{~mm}(6 \times 6 \times$ 21 in) were used, coming from the same batch. They were partially loaded about the centerline on a $152 \times 152 \mathrm{~mm}(6 \times 6$ in) loading area and the same pitch-catch and setup as used in Test 1 was employed, as illustrated in Figure 2-3. The result of a finite element (FE) simulation for this specimen showed that the stresses at the location of the transducers are near zero at the ultimate load level, as shown in Figure 2-3. The first prism (P1) was loaded up to $40 \%$ of ultimate stress by four loading steps where each load increment equaled $10 \%$ of ultimate stress. During each loading step, the load was held and six pulses 
were transmitted: three at $50 \mathrm{kHz}$ and three at $100 \mathrm{kHz}$. The second prism (P2) was loaded up to $80 \%$ of ultimate stress. Like the first prism, the load was increased in steps and each step equaled $10 \%$ of ultimate stress. Three pulses at $100 \mathrm{kHz}$ were transmitted during load holding.

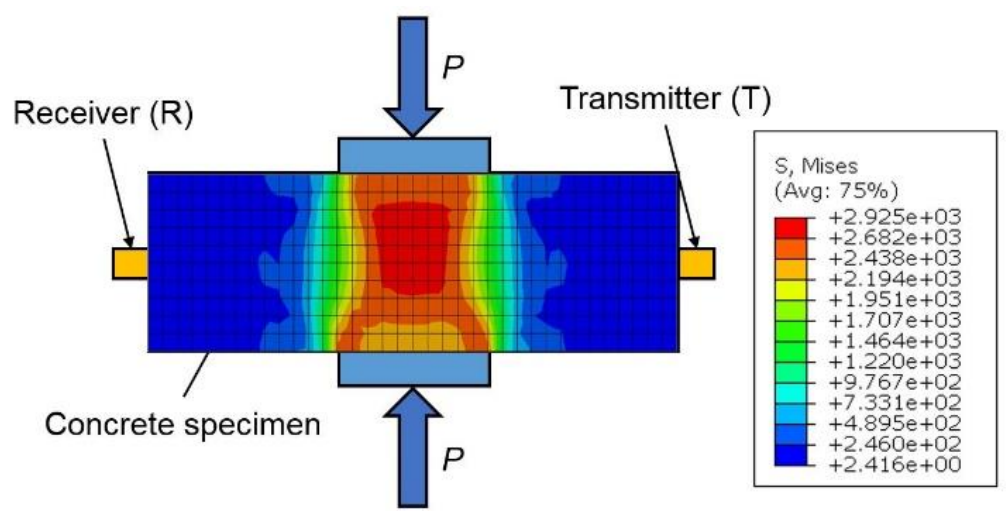

Figure 2-3. Illustration of experimental setup for Test 2 and the results of FE simulation at an applied load, $P=P$ ult.

\subsubsection{Results}

\subsubsection{General Observations}

As expected, the recorded waveforms were found to be longer and more complicated than the transmitted pulse due to the heterogeneity of the concrete and specimen size. Figure 24a shows three waveforms recorded at different levels of applied stress for Specimen C2. It can be observed that not all portions of the wave are affected the same way by an applied stress. The earlier (coherent) portion of the waveform (Figure 2-4b) is less affected by changes in applied stress than the later (coda) portion (Figure 2-4c). The coherent portion does not show any noticeable change due to the increase of the applied stress in low stress cases (up to $40 \%$ of ultimate stress). A phase shift is only apparent at the $80 \%$ of ultimate stress level. Figure 2-5 confirms that there is no change in the time of flight (TOF), which 
considers only the coherent portion of the waveform, until approximately $70 \%$ of ultimate stress (vertical dashed line) is reached. This explains why traditional techniques, for instance the pulse velocity test [34], are not capable of capturing changes in applied stress under service-level conditions.

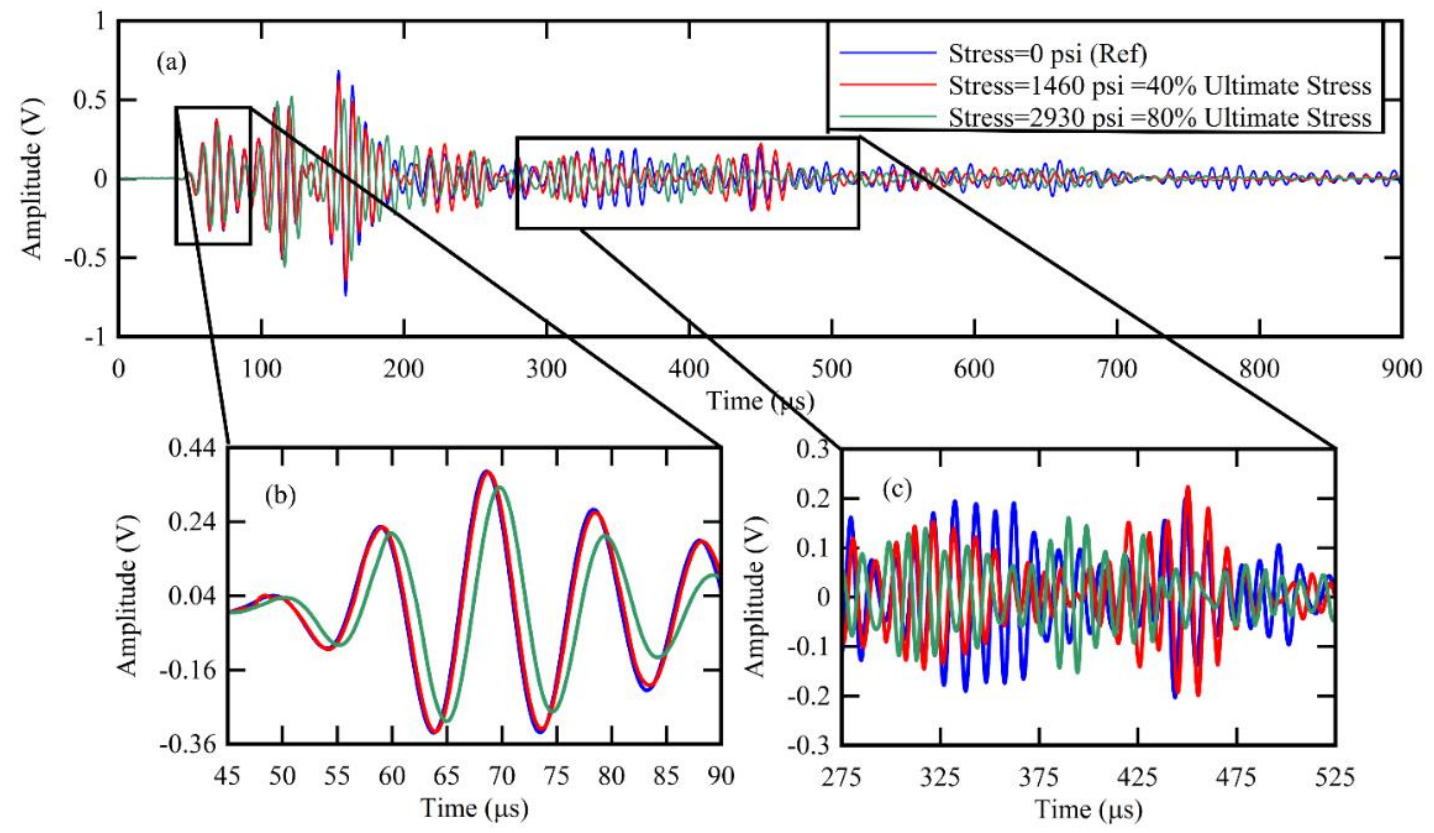

Figure 2-4. Three samples of recorded waveforms from Specimen C2 for different levels of applied stress. (a) Entire recorded waveforms. (b) Sample window from the coherent portion.(c) Sample window from the coda portion. 


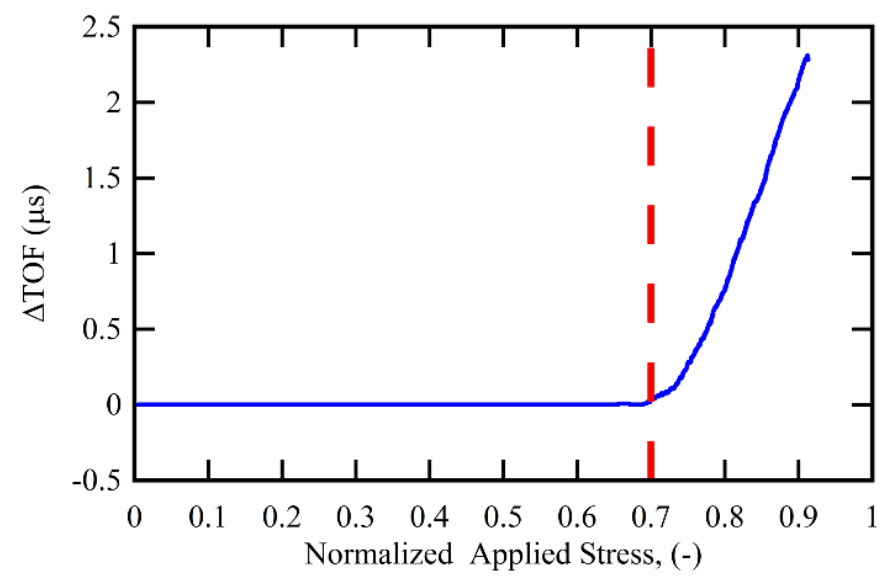

Figure 2-5. $\triangle \mathrm{TOF}$ vs. normalized stress for Specimen C2.

On the other hand, the coda wave portion shows high sensitivity to changes in applied stress for any level (Figure 2-4c) where these changes appear as changes in amplitude, frequency, and time shift. Figure 2-6, in addition to showing the transmitted pulse in the time domain (Figure 2-6a), also shows examples in the frequency domain (Figure 2-6b) of the three recorded signals presented in Figure 2-4. Although the recorded waveforms contain the same range of frequencies as the transmitted pulse, each recorded wave showed an uneven attenuation in this range of frequencies due to the nonlinearity of concrete response as shown in Figure 2-6b. In addition, this attenuation was influenced by the load (stress) level, but the relationship between the load level and amount of the attenuation could not be extracted directly. Therefore, MSC was used to determine and evaluate the changes in the recorded wave (in the frequency domain) due to the stress effects.

In order to evaluate the noise of the system on the MSC calculations, 100 pulses were transmitted at the zero stress level in all specimens and evaluated. The error in the MSC value was found to be 0.0003 ; therefore, the system's noise can be neglected. This also proved that the decrease in the MSC value is a result of the change of applied stress. 

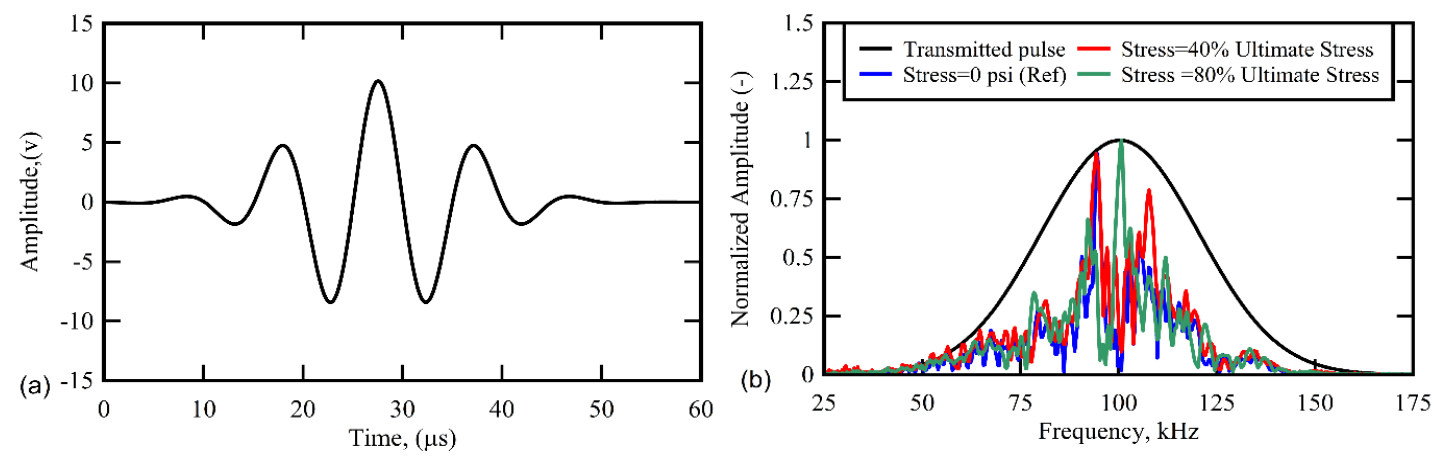

Figure 2-6. (a) Transmitted pulse in the time domain. (b) Waveforms in frequency domain: transmitted pulse and three recorded waveforms at different levels of applied stress. The recorded waveforms were normalized according to the maximum spectra amplitude of the reference signal (blue curve).

\subsubsection{Test 1: Monotonically-loaded Cylinder}

\section{Results of Different Waveform Comparison Parameters}

The ultimate stress of Specimen C1 was 24.1 MPa (3500 psi), which is a typical concrete strength used in reinforced concrete structures. For correlating the applied stress and the changes in the recorded waveforms, Eqs. (7) and (9) were applied and the results are presented in Figure 2-7a. The results show that both $R^{2}$ and $\operatorname{MSC}(\lambda)$ are a function of applied stress, and exhibit a linear relationship up to $30 \%$ of ultimate stress. After this limit, the time shift between the full waveforms has a large influence on the results of $R^{2}$, since the $R^{2}$ compares between signals in the time domain. This time shift was calculated for full waveforms by using Eq. (1), and the results are presented in Figure 2-7b. To conclude, the $R^{2}$ is more sensitive at higher stress levels compared to $\operatorname{MSC}(\lambda)$ due to its sensitivity to the observed time shift in the recorded waveforms. In order to exclude the effect of time shift, the signals were shifted in the time domain, to produce the adjusted coefficient of 
determination $\left(R^{2}\right)$. The results of $R^{2}$ match the $\operatorname{MSC}(\lambda)$ curve almost perfectly, as can be seen in Figure 2-7a. In conclusion, the results of $\operatorname{MSC}(\lambda)$ and $R^{2}$ are the same after excluding the time shift in the signals.

Some recorded signals showed a superposition between the pulse response and spontaneous acoustic emissions due to the imposed loading, which had an unwanted influence on the results of $R^{2}$. In order to exclude the signals that contained the acoustic emission (AE) hits, the energy filter presented in [7] was applied to all recorded signals. On the other hand, AE hits did not affect the $\operatorname{MSC}(\lambda)$ 's results. Therefore, only the $\operatorname{MSC}(\lambda)$ results are presented and discussed subsequently.
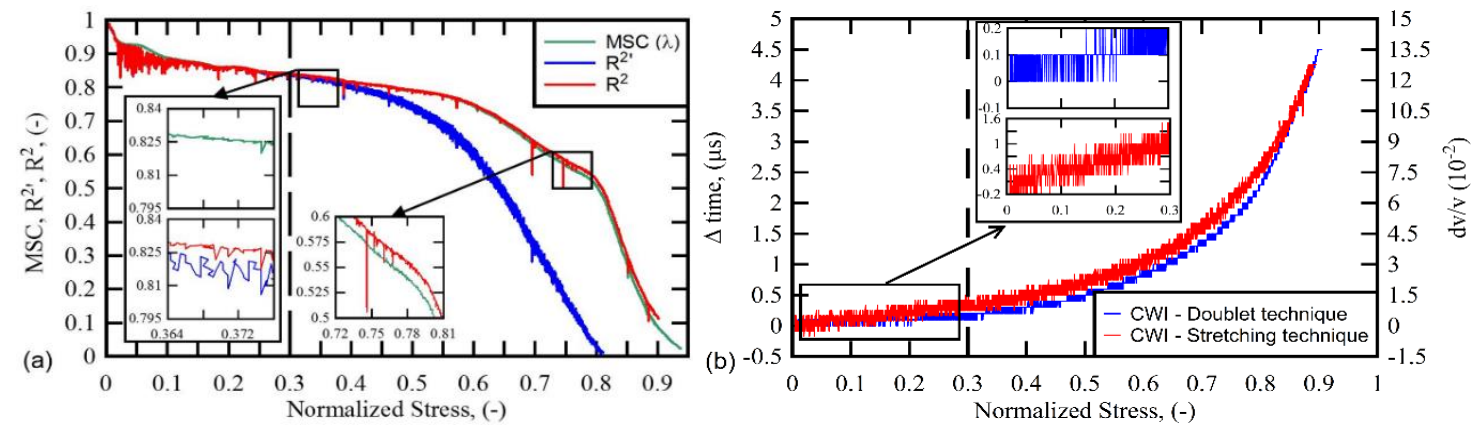

Figure 2-7. Different waveform comparison parameters vs. normalized applied stress for Specimen C2. (a) $R^{2}, \operatorname{MSC}(\lambda)$ and $R^{2}$, vs. normalized stress. (b) Time shift and $d v / v$ vs. normalized stress.

\section{Influence of Mechanical Properties}

The ultimate stress of concrete cylinder Specimens C1 and C2 was 25.3 and 24.1 MPa (3670 and 3500 psi), respectively. Figure 2-8a shows the relationship between $\operatorname{MSC}(\lambda)$ and normalized applied stress for these two concrete cylinders and one specimen from tests described in [25]. These specimens were tested using the same experimental setup, pulse 
frequency, and reached approximately the same compressive strength, but had different maximum aggregate sizes. The results show a linear relationship between $\operatorname{MSC}(\lambda)$ and applied stress up to approximately $55 \%$ of ultimate stress. In addition, each specimen has a particular slope $M$, for the linear portion of the $\operatorname{MSC}(\lambda)$-applied stress relationship. In Figure 2-8b it can be observed that the $\operatorname{MSC}(\lambda)$ curves were similar in the linear portion for specimens (up to $55 \%$ of ultimate) with the same aggregate size and for varying compressive strengths ranging from 22.6 to $29.1 \mathrm{MPa}$ (3280 to $4220 \mathrm{psi}$ ). To conclude, the slope of the linear portion is mainly influenced by the maximum aggregate size and not by compressive strength.
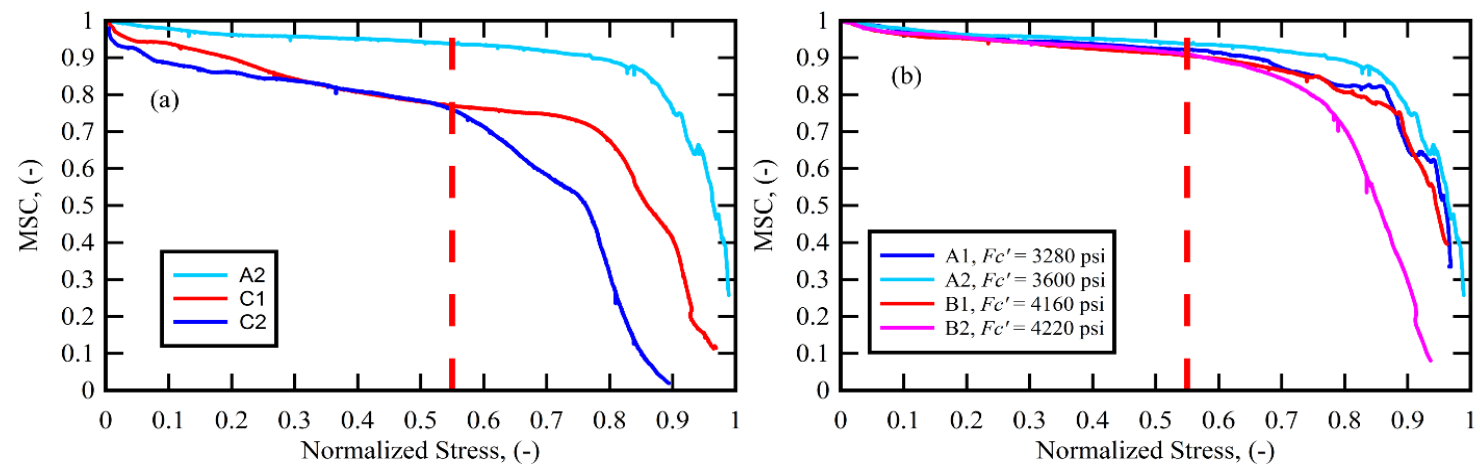

Figure 2-8. MSC( $\lambda$ ) vs. normalized applied stress. (a) Varying maximum aggregate size.

(b) Varying compressive strength [25].

\section{Effect of Sampling Frequency}

A relatively high sampling frequency is required when working with ultrasonic waves in concrete since typical pulse frequencies are in the range of 20 to $150 \mathrm{kHz}$. As discussed earlier, this pulse frequency range is suitable for monitoring the changes of the diffuse portion of signals from concrete [33]. Using a high sampling frequency, however, increases the amount of data and requires high-speed data acquisition systems, thus increasing the 
overall computational cost, which can become prohibitive in a field setting. Decreasing the sampling frequency from $10 \mathrm{MHz}$ to $500 \mathrm{kHz}$ using by numerical downsampling does not influence the $\operatorname{MSC}(\lambda)$ results as shown in Figure 2-9, which is demonstrated by the perfect match between them. To conclude, CWC is able to capture changes with relatively low sampling frequencies, without the need for post-acquisition oversampling.

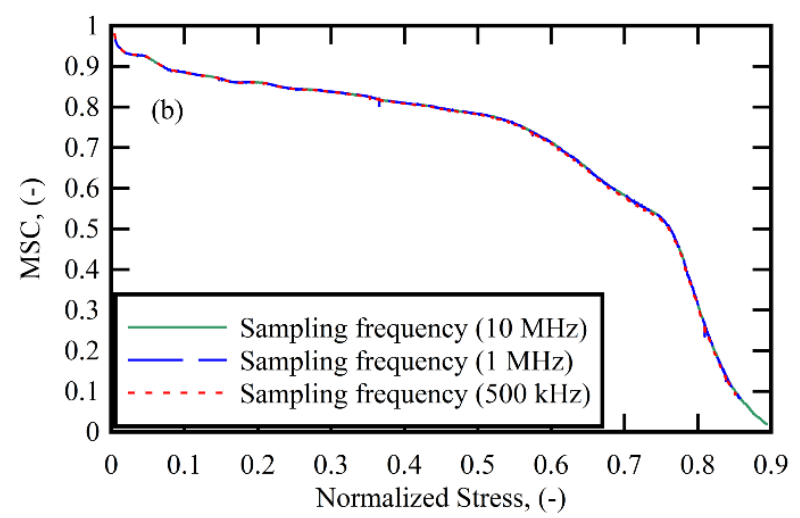

Figure 2-9. The effect of decreasing the sampling frequency on the $\mathrm{CWC}$ results for Specimen C2.

\section{Linear Regression}

A linear regression curve-fit with $95 \%$ confidence intervals was applied to the results of Specimens $\mathrm{C} 1$ and $\mathrm{C} 2$ over the range of 0 to $55 \%$ of ultimate stress, as shown in Figure 210. It can be observed that all data points are in range of the prediction intervals. The confidence intervals are not shown because the large number of samples, which effectively collapses them onto the fitted line. It can be observed that a moderate linear relationship exists between $\operatorname{MSC}(\lambda)$ and applied stress where the $R^{2}$ for the linear fit for Specimens $\mathrm{C} 1$ and $\mathrm{C} 2$ is equal to 0.987 and 0.993 , respectively. In addition, the root-mean-square error 
(RMSE) was negligible for both specimens and the p-value was zero for all specimens, as shown in Table 2-1, which indicates the high statistical relationship.
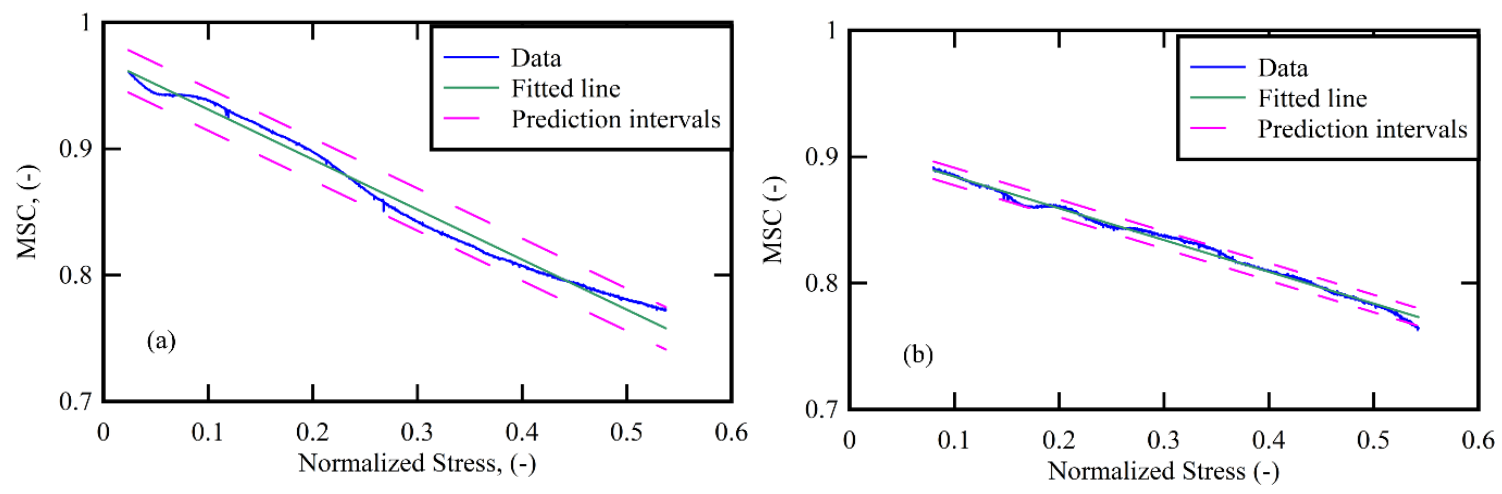

Figure 2-10. Results of the linear regression for $\operatorname{MSC}(\lambda)$ vs. normalized applied stress.

(a) Specimen C1. (b) Specimen C2.

This demonstrates that Eq. (9) is applicable for relating the changes in applied stress with changes in the coda wave for the stress range of approximately 0 to $55 \%$ of ultimate stress. Beyond that value, the time shifts have an over-proportional effect on the changes in the recorded waveform. Table 2-1 shows the results of using the $\mathrm{CWC}$ technique by applying Eq. (9), and presents the computed test coefficient, $M$.

Table 2-1. The regression results for Specimens C1 and C2.

\begin{tabular}{|c|c|c|c|c|c|c|c|}
\hline Specimen & $\begin{array}{c}\text { Max. Size of } \\
\text { Aggregate (in) }\end{array}$ & $M$ & R2 & p-value & RMSE & SE & $\begin{array}{c}\text { Numbers of } \\
\text { Samples }\end{array}$ \\
\hline C1 & $1 / 2$ & -0.3963 & 0.987 & 0 & 0.00683 & 0.00116 & 1692 \\
\hline C2 & $7 / 16$ & -0.2513 & 0.993 & 0 & 0.00283 & 0.00055 & 1500 \\
\hline
\end{tabular}

\subsubsection{Test 2: Stepwise-Loaded Prism}

For the concrete prisms, nine $\operatorname{MSC}(\lambda)$ values were obtained at each load level, consisting of three pulses with the same wavelength. The variance of these values was found very small, as shown in Figure 2-11. Also, there was no noise effect from either inside or outside 
the system since the calculation of $\operatorname{MSC}(\lambda)$ depends on the frequency of the recorded waveforms. This test demonstrates that changes in the interior stress can be detected using our proposed CWC technique when the changes are within the propagation path of the wave. Changes in the interior stress do not have to extend to the surface to which the transducers are attached (see Figure 2-3), which is an advantage compared to sensors that are attached to the surface such as strain gauges. The results of the first prism (P1) show that the sensitivity of the $\operatorname{MSC}(\lambda)$ values was influenced by the wavelength, which is a function of pulse frequency assuming a p-wave velocity of $3600 \mathrm{~m} / \mathrm{s}(141000 \mathrm{in} / \mathrm{s})$. The pulse with the smaller wavelength was more sensitive to changes in interior stress than the larger wavelength, as shown in Figure 2-11a and 11b. When the applied load increased from 10 to $40 \%$ of ultimate stress, the $\operatorname{MSC}(\lambda)$ decreased from 0.88 to 0.6 for $\lambda=36 \mathrm{~mm}$ (1.41 in), where decrease for $\lambda=66 \mathrm{~mm}$ (2.62 in) was from 0.88 to 0.85 . Moreover, the $R^{2}$ of the linear fit for the results of the $\operatorname{MSC}(\lambda)$ for the shorter wavelength was higher, as shown in Table 2-2.

For Specimen P2 (see Figure 2-11c), the results show the high sensitivity of the $\operatorname{MSC}(\lambda)$. Increasing the applied load from 10 to $80 \%$ from ultimate stress, the $\operatorname{MSC}(\lambda)$ decreased from 0.78 to 0.2 . The sensitivity of this test is very close to the sensitivity of Specimen P1 due to wavelength similarity in both cases. The results also show that the relationship is linear between the change in the $\operatorname{MSC}(\lambda)$ value and the change in the applied stress, as shown in Figure 2-11c. Although the linear fit for the results shows one slight deviation at a load of $60 \%$ of ultimate, $R^{2}=0.988$, as shown in Table 2-2. The relationships are statistically highly significant with near-zero p-values. 

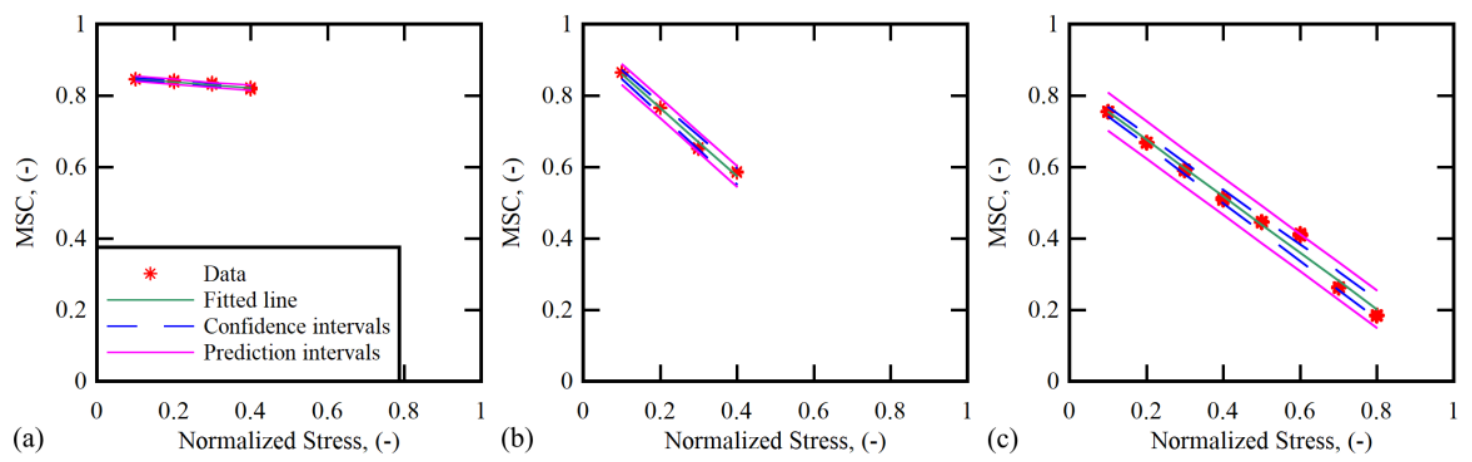

Figure 2-11. $\operatorname{MSC}(\lambda)$ vs. normalized applied stress for Specimens P1 and P2. (a)

Specimen P1, $\lambda=66 \mathrm{~mm}$ (2.61 in). (b) Specimen P1, $\lambda=36 \mathrm{~mm}$ (1.41 in). (c) Specimen

$$
\mathrm{P} 2, \lambda=36 \mathrm{~mm}(1.41 \mathrm{in}) .
$$

Table 2-2. The regression results for concrete prisms.

\begin{tabular}{|c|c|c|c|c|}
\hline Specimen & $\begin{array}{c}\text { Wavelength } \\
\text { (in) }\end{array}$ & $M$ & $\mathrm{R}^{2}$ & p-value \\
\hline P1 & 2.61 & -0.06991 & 0.62 & $1.24 \mathrm{e}-08$ \\
\hline P1 & 1.41 & -0.9496 & 0.99 & $1.12 \mathrm{e}-35$ \\
\hline P2 & 1.41 & -0.7895 & 0.988 & $2.07 \mathrm{e}-68$ \\
\hline
\end{tabular}

\subsubsection{Final Remarks Regarding Laboratory Tests}

The $\operatorname{MSC}(\lambda)$ curves typically show a sharp drop at the initial loading phase. This phenomenon appears only in a laboratory setting when a hydraulic machine is used to apply the load. It is likely associated with the initial contact of the loading cap and settling and in some regard another testament to the sensitivity of our proposed approach.

\subsection{Field Test}

\subsubsection{Description of Load Test}

The objective of the field test was to demonstrate our proposed CWC technique's sensitivity to capturing internal changes in tensile and compression stresses in real 
structural concrete members. A prestressed concrete bridge located on the I-84 Highway near Echo, Oregon undergoing in-service load testing was selected for this purpose. The bridge consists of three non-continuous spans with lengths of 12.2, 24.4, and $12.2 \mathrm{~m}$ (40, 80 , and $40 \mathrm{ft}$.). The superstructure of the bridge is made of prestressed concrete girders and a reinforced concrete deck slab as shown in Figure 2-12a and 12b. This bridge is part of the FHWA Long-Term Bridge Performance (LTBP) program where 42 sensors were already mounted for monitoring the long-term performance of the bridge. In July 2017, FHWA calibrated the monitoring system by performing an in-service load test (see Figure 2-12c) and invited us to participate.

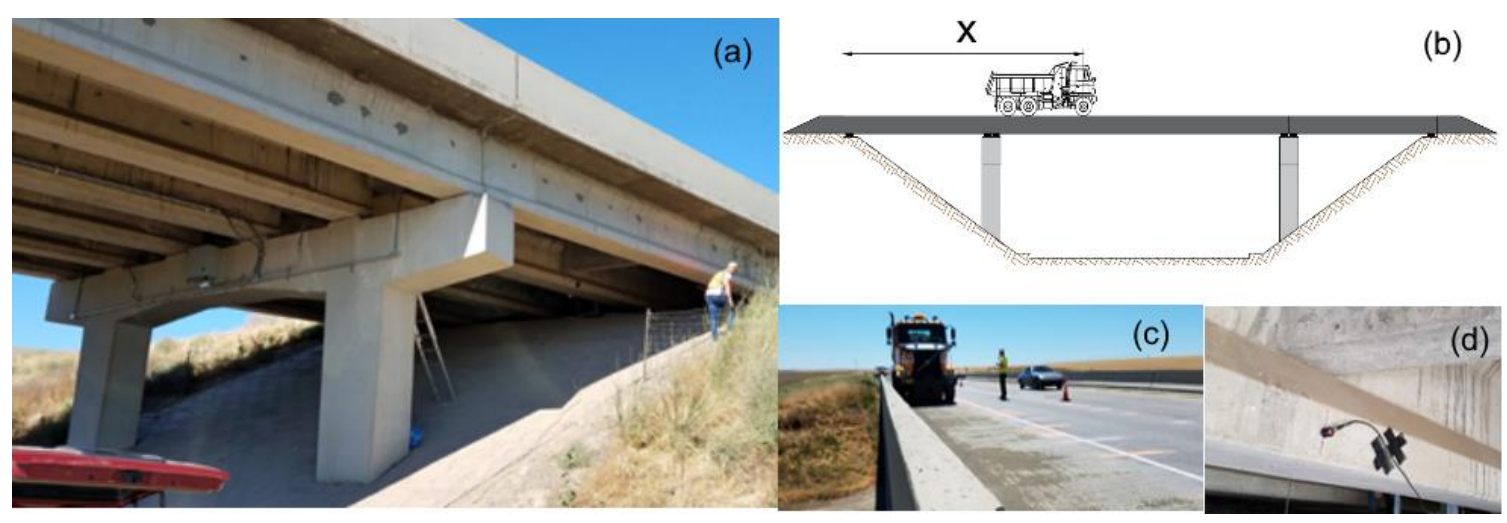

Figure 2-12. In-service load test on I-84 Bridge near Echo, Oregon. (a) Photo from road under the bridge showing bent and girders. (b) Elevation view with test truck. (c) Photo of deck with approaching test truck. (d) Photo of girder with ultrasonic transducer. Loaded water tank and dump trucks were used and weight information are listed in Table 2-3. During the loading process, a pitch-catch setup was used to capture changes in applied stress in one interior girder (Figure 2-12d) that was a part of the external span. Additionally, the stress in one of the bent's columns was monitored (see Figure 2-12a). Consistent with the type of structural member, the tests are subsequently referred to as girder test and 
column test. The same data acquisition setup used for the laboratory tests was used. Power was provided by large uninterruptable power supply (UPS) device battery connected to a fuel-powered generator. The UPS device also ensured a clean power signal.

Table 2-3. Weight information for test trucks.

\begin{tabular}{|c|c|c|c|c|c|c|}
\hline \multirow{4}{*}{ Truck } & \multicolumn{3}{|c|}{ Axle } \\
\cline { 2 - 7 } & \multicolumn{3}{|c|}{ Steer } & \multicolumn{4}{c|}{ Tandem } \\
\cline { 2 - 7 } & Weight & Distance & Weight & Distance & Weight & Distance \\
& $(\mathrm{kN})$ & $(\mathrm{m})$ & $(\mathrm{kN})$ & $(\mathrm{m})$ & $(\mathrm{kN})$ & $(\mathrm{m})$ \\
& $(\mathrm{lbs})$ & $(\mathrm{in})$ & $(\mathrm{lbs})$ & $(\mathrm{in})$ & $(\mathrm{lbs})$ & $(\mathrm{in})$ \\
\hline \multirow{2}{*}{ ODOT Water Truck } & 77.8 & 0 & 81.0 & 5.28 & 79.2 & 6.66 \\
& 17,500 & 0 & 18,200 & 208 & 17,800 & 262 \\
\hline \multirow{2}{*}{ ODOT Dump Truck } & 71.8 & 0 & 75.2 & 4.47 & 72.7 & 5.79 \\
& 16,150 & 0 & 16,900 & 176 & 16,350 & 228 \\
\hline
\end{tabular}

For the girder test, the transmitting and receiving transducers were attached to the midthickness of the bottom flange at the centerline of the girder (see Figure 2-12d). A water tank truck crossed the bridge starting from the beginning of the right exterior span with 13 stop points, as shown in Table 2-4. Throughout the loading process, which consisted of moving and stopping of the truck, a $50 \mathrm{kHz}$ Morlet-type pulse was sent from the transmitter every $20 \mathrm{~ms}$ and recorded at a sampling frequency of $10 \mathrm{MHz}$. This test was performed twice.

Table 2-4. Truck stop locations for girder test (see Figure 2- 2b).

\begin{tabular}{|r|c|c|c|c|c|c|c|c|c|c|c|c|c|}
\hline Stop Case & 1 & 2 & 3 & 4 & 5 & 6 & 7 & 8 & 9 & 10 & 11 & 12 & 13 \\
\hline $\begin{array}{r}\text { Steer Axle } \\
\text { Position, } x \\
(\mathrm{~m})(\mathrm{ft})\end{array}$ & $\begin{array}{c}36.6 \\
120\end{array}$ & $\begin{array}{c}37.8 \\
124\end{array}$ & $\begin{array}{c}39.0 \\
128\end{array}$ & $\begin{array}{c}39.6 \\
130\end{array}$ & $\begin{array}{r}41.5 \\
136\end{array}$ & $\begin{array}{r}42.7 \\
140\end{array}$ & $\begin{array}{r}44.5 \\
146\end{array}$ & $\begin{array}{c}45.7 \\
150\end{array}$ & $\begin{array}{r}47.5 \\
156\end{array}$ & $\begin{array}{c}48.8 \\
160\end{array}$ & $\begin{array}{c}50.6 \\
166\end{array}$ & $\begin{array}{c}53.6 \\
176\end{array}$ & $\begin{array}{c}54.9 \\
180\end{array}$ \\
\hline
\end{tabular}

For the column test, the transducers were located at the mid-height of the column in the short direction, which was $0.91 \mathrm{~m}$ (36 in), as illustrated in Figure 2-12a. A water tank truck 
and dump truck side-by-side crossed the interior span (24.4 m (80 ft span)) nine times and the exterior span (12.2 $\mathrm{m}(40 \mathrm{ft}))$ eight times as shown in Table 2-5. Because of the difficulty of making the trucks moving and stopping together, the dump truck was moved first and stopped at a stopping point and waiting for the water tank truck to catch up. In this test, a $50 \mathrm{kHz}$ Morlet-type pulse was used as well. The pulse repetition frequency and sampling frequency was $3 \mathrm{~Hz}$ and $3.3 \mathrm{MHz}$, respectively.

Table 2-5. Truck stop locations for column test (see Figure 2-12b).

\begin{tabular}{|c|c|c|c|c|c|c|c|c|c|}
\hline $\begin{array}{l}\text { Stop Case (Interior } \\
\text { Span) }\end{array}$ & 1 & 2 & 3 & 4 & 5 & 6 & 7 & 8 & 9 \\
\hline $\begin{array}{r}\text { Steer Axle Position, } \mathrm{x} \\
(\mathrm{m}) \\
(\mathrm{ft})\end{array}$ & $\begin{array}{c}12.2 \\
40\end{array}$ & $\begin{array}{c}15.2 \\
50\end{array}$ & $\begin{array}{c}18.3 \\
60\end{array}$ & $\begin{array}{c}20.1 \\
66\end{array}$ & $\begin{array}{c}23.2 \\
76\end{array}$ & $\begin{array}{c}25.0 \\
82\end{array}$ & $\begin{array}{c}28.7 \\
94\end{array}$ & $\begin{array}{l}32.3 \\
106\end{array}$ & $\begin{array}{r}36.0 \\
118\end{array}$ \\
\hline $\begin{array}{c}\text { Stop Case (Exterior } \\
\text { Span) }\end{array}$ & 10 & 11 & 12 & 13 & 14 & 15 & 16 & 17 & \\
\hline $\begin{array}{r}\text { Steer Axle Position, } \mathrm{x} \\
(\mathrm{m}) \\
(\mathrm{ft}) \\
\end{array}$ & $\begin{array}{l}39.0 \\
128\end{array}$ & $\begin{array}{c}39.6 \\
130\end{array}$ & $\begin{array}{l}41.5 \\
136\end{array}$ & $\begin{array}{r}44.5 \\
146\end{array}$ & $\begin{array}{r}45.7 \\
150\end{array}$ & $\begin{array}{r}48.8 \\
160\end{array}$ & $\begin{array}{r}50.6 \\
166\end{array}$ & $\begin{array}{c}53.6 \\
176\end{array}$ & \\
\hline
\end{tabular}

\subsubsection{Results and Discussion}

The results of the $\operatorname{MSC}(\lambda)$ of these tests as a function of test time are presented in Figure 2-13. The thirteen and the seventeen stops of the trucks can be distinguished in this figure for both girder and column tests, respectively. In addition, several sharp drops in the $\operatorname{MSC}(\lambda)$ curve (highlighted with red circles) can be observed that occur when the truck arrives at a stop location. This phenomenon is likely related to the transient vibrations induced by the truck when the driver hits the brakes to stop. Using a pulse with $50 \mathrm{kHz}$ central frequency was found suitable to monitor the change in applied stress due to the weight of the trucks, where the $\operatorname{MSC}(\lambda)$ varied between 1.0 (unloaded) to 0.57 and 0.3 
(maximum load) for column and girder tests, respectively. The column test and previous tests presented in this paper demonstrate the capability of the proposed CWC technique to monitor minute changes in compression stresses. Additionally, the girder test shows the same the capability to sense a change in tension stresses. Unfortunately, no deformation measurements were available for direct comparison. An estimate of the maximum tensile strain in the girder during loading is $10 \mu \varepsilon$. This was confirmed as a reasonable value with the bridge owner and based on readings available at other locations.
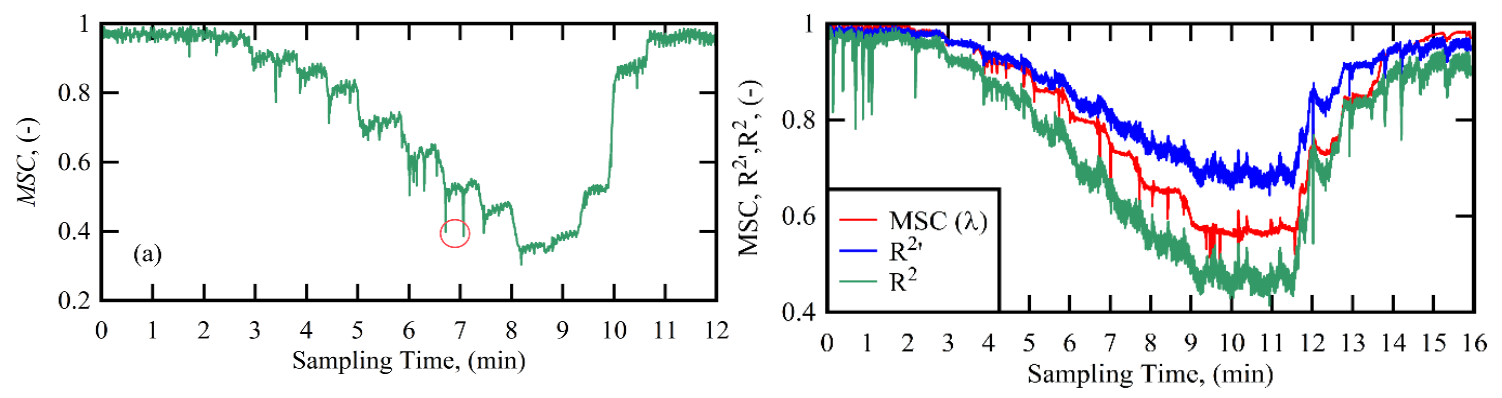

Figure 2-13. MSC( $\lambda$ ) vs. test time. (a) Girder test. (b) Column test. Red circles indicate drops in the $\operatorname{MSC}(\lambda)$ curve when the test trucks arrived at a stop location.

Since the truck is a moving load, the influence line can be used to correlate changes in the internal force and corresponding stresses at that location of the bridge with respect to the truck position. Therefore, the influence line for the bending moment in the girder and the axle force in column for each truck stop location were computed using a conventional moving load analysis. From the influence line for the bending moment, the influence line of the change in tensile force in the bottom flange of the girder was obtained. The influence line of the change in compression force in in the column was determined from the influence line for the steer truck axle load. Figure 2-14 shows the normalized change in stress (column and girder bottom flange) and the normalized change in $\operatorname{MSC}(\lambda)$. The results show 
that the $\operatorname{MSC}(\lambda)$ values correlate very well with changes in the internal stresses, which demonstrates the ability of the proposed CWC technique to capture minute changes in internal stress. The $\operatorname{MSC}(\lambda)$ results for the two girder tests were in excellent matching, as shown in Figure 2- 4a, indicating robustness of the CWC's results. Moreover, CWC can monitor the unloading cases, when the truck passes the maximum stress location. Finally, for the girder test, it can be observed that the $\operatorname{MSC}(\lambda)$ value returns to the original value as shown in Figure 2-13a and 14a, indicating that no residual stress or damage has occurred due to the loading. For the column test, the residual stress could not be investigated because the DAQ ran out its storage memory capacity to complete the test.
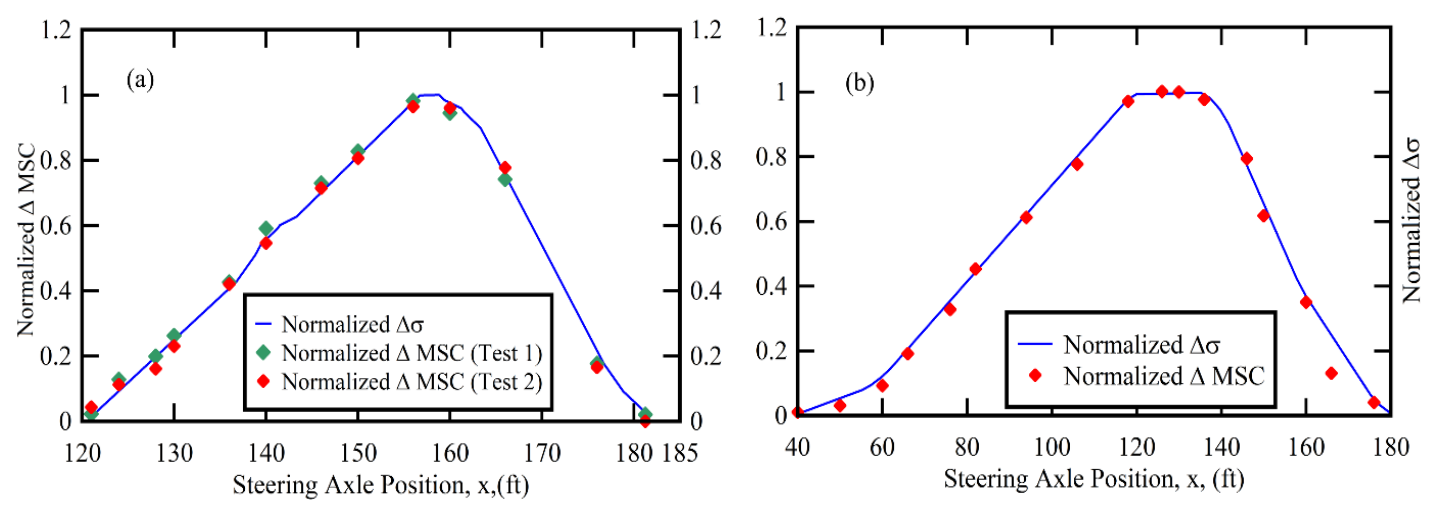

Figure 2-14. Normalized MSC $(\lambda)$ vs. steering axle position. (a) Girder test. (b) Column

test.

Linear regression curve-fits with $95 \%$ confidence intervals were applied to the results to estimate the accuracy of the CWC technique. Figure 2-15. shows that all $\operatorname{MSC}(\lambda)$ results for the column and girder tests are located in the confidence interval limits except for two points of the column test. However, these two points are still located within the prediction intervals. Additionally, a linear relationship between the $\operatorname{MSC}(\lambda)$ results and applied stress 
can be assumed, since the coefficients of determination $R^{2}$, are equal to 0.996 and 0.999 for column and girder tests, respectively, and the root mean square error RMSE, for the column and girder tests are equal to 0.0249 and 0.0129 , respectively. Finally, the p-values were found to be near zero, indicating that statistically significant relationship exists.
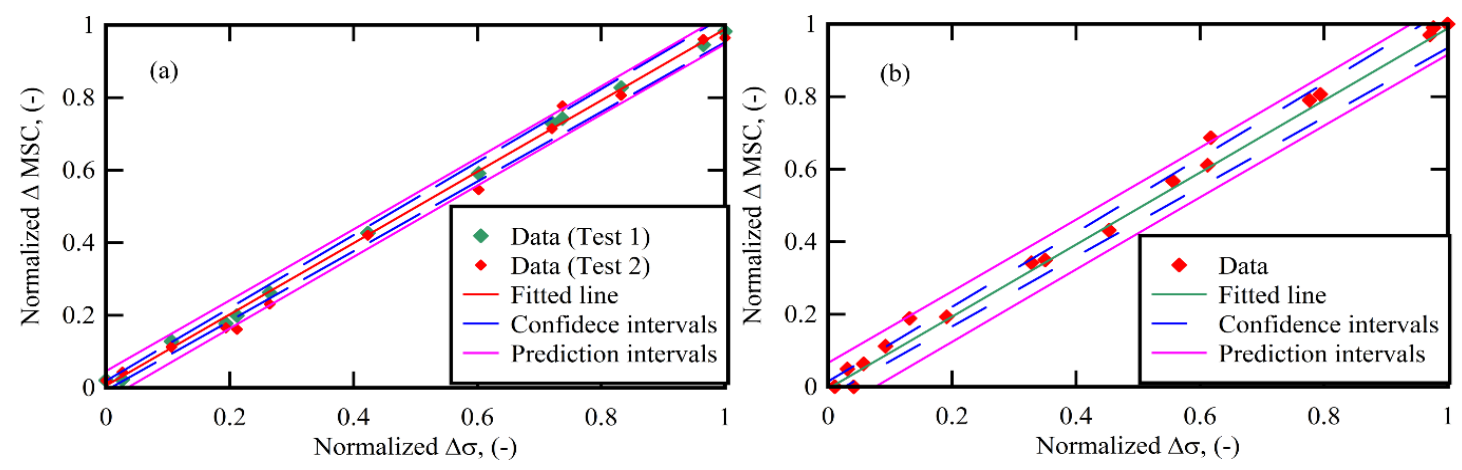

Figure 2-15. Normalized $\operatorname{MSC}(\lambda)$ vs. normalized $\Delta \sigma$. (a) Girder test. (b) Column test.

\subsection{Conclusions}

The results presented in this paper demonstrate the ability of our proposed CWC technique to relate changes in an ultrasonic stress wave to changes that occur in concrete due to internal stresses. In the proposed technique, a wave similarity parameter based on magnitude-squared coherence evaluated at a specific wavelength, $\operatorname{MSC}(\lambda)$ is used to measure the similarity between recorded ultrasonic waveforms in their frequency domain. Similarly, the time-shift-adjusted squared correlation coefficient, $R^{2}$ produces the same results as $\operatorname{MSC}(\lambda)$. Both $\operatorname{MSC}(\lambda)$ and $R^{2}$ show a linear relationship with the applied stress up to a specific limit which depends on a number of variables but can be assumed to be at least $50 \%$ of ultimate stress. Linear regression produced a test constant, $M$, which 
represents the slope of the $\operatorname{MSC}(\lambda)$ vs. applied stress relationship, and can thus be interpreted as a measure of sensitivity. The results showed that $M$ depends on the maximum size of the aggregate more than the compressive strength of concrete, in addition to the dependence on the wavelength of the transmitted pulse. The sensitivity of the $\operatorname{MSC}(\lambda)$ parameter increased with decreasing wavelength. The proposed $\mathrm{CWC}$ technique was also validated in a field setting where it was found to correlate extremely well with the internal stresses at the sensor locations. The CWC technique exhibits two advantages over the more established coda wave interferometry (CWI) approach and traditional deformation measurements such as strain gauges. First, no arbitrary windows need to be selected for CWC since the entire waveform is used. Second, using a sampling frequency equal to five times the pulse frequency is good enough to produce accurate relations between $\operatorname{MSC}(\lambda)$ and applied stress. Finally, compared to traditional deformation sensors, ultrasonic monitoring using the CWC technique can measure changes in the internal stress that are not observable on the surface of a member. Future work includes evaluating the technique's ability to measure residual stresses and other changes such as deterioration mechanisms.

\section{Acknowledgments}

We would like to acknowledge the financial support from the Higher Committee of Education Development in Iraq (HCED), which funded the first author, and the Department of Civil and Environmental Engineering at Portland State University for providing laboratory equipment and specimens. Finally, we thank Mr. Salih Mahmood for assisting with the finite element model illustrated in Figure 2-3. 


\section{References}

[1] Zhang, Y., Planès, T., Larose, E., Obermann, A., Rospars, C., and Moreau, G., 2016, "Diffuse Ultrasound Monitoring of Stress and Damage Development on a 15-Ton Concrete Beam," The Journal of the Acoustical Society of America, 139(4), pp. $1691-1701$.

[2] Zhang, Y., Abraham, O., Grondin, F., Loukili, A., Tournat, V., Duff, A. Le, Lascoup, B., and Durand, O., 2012, "Study of Stress-Induced Velocity Variation in Concrete under Direct Tensile Force and Monitoring of the Damage Level by Using Thermally-Compensated Coda Wave Interferometry," Ultrasonics, 52(8), pp. 10381045.

[3] Hughes, D. S., and Kelly, J. L., 1953, "Second-Order Elastic Deformation of Solids,” Physical Review, 92(5), pp. 1145-1149.

[4] Murnaghan, F. D., and D Murnaghan, B. F., 1937, "Finite Deformations of an Elastic Solid FINITE DEFORMATIONS OF AN ELASTIC SOLID.*," Source: American Journal of Mathematics, 59(2), pp. 235-260.

[5] Planès, T., and Larose, E., 2013, "A Review of Ultrasonic Coda Wave Interferometry in Concrete," Cement and Concrete Research, 53, pp. 248-255.

[6] Stähler, S. C., Sens-Schönfelder, C., and Niederleithinger, E., 2011, "Monitoring Stress Changes in a Concrete Bridge with Coda Wave Interferometry,” The Journal of the Acoustical Society of America, 129(4), pp. 1945-1952.

[7] Hafiz, A., and Schumacher, T., 2017, "Monitoring of Applied Stress in Concrete Using Ultrasonic Full-Waveform Comparison Techniques," Nondestructive Characterization and Monitoring of Advanced Materials, Aerospace, and Civil 
Infrastructure 2017, International Society for Optics and Photonics, p. $101692 Z$.

[8] Grêt, A., Snieder, R., and Scales, J., 2006, "Time-Lapse Monitoring of Rock Properties with Coda Wave Interferometry,” Journal of Geophysical Research: Solid Earth, 111(3).

[9] Legland, J.-B., Zhang, Y., Abraham, O., Durand, O., and Tournat, V., 2017, "Evaluation of Crack Status in a Meter-Size Concrete Structure Using the Ultrasonic Nonlinear Coda Wave Interferometry," The Journal of the Acoustical Society of America, 142(4), pp. 2233-2241.

[10] Snieder, R., 2006, "The Theory of Coda Wave Interferometry," Pure and Applied Geophysics, 163(2-3), pp. 455-473.

[11] Payan, C., Quiviger, A., Garnier, V., Chaix, J. F., and Salin, J., 2013, “Applying Diffuse Ultrasound under Dynamic Loading to Improve Closed Crack Characterization in Concrete," The Journal of the Acoustical Society of America, 134(2), pp. EL211-EL216.

[12] Larose, E., Obermann, A., Digulescu, A., Planes, T., Chaix, J.-F., Mazerolle, F., and Moreau, G., 2015, "Locating and Characterizing a Crack in Concrete with Diffuse Ultrasound: A Four-Point Bending Test," The Journal of the Acoustical Society of America, 138(1), pp. 232-241.

[13] Bui, D., Kodjo, S. A., Rivard, P., and Fournier, B., 2013, "Evaluation of Concrete Distributed Cracks by Ultrasonic Travel Time Shift under an External Mechanical Perturbation: Study of Indirect and Semi-Direct Transmission Configurations," Journal of Nondestructive Evaluation, 32(1), pp. 25-36. 
[14] Schurr, D. P., Kim, J. Y., Sabra, K. G., and Jacobs, L. J., 2011, “Damage Detection in Concrete Using Coda Wave Interferometry," NDT and E International, 44(8), pp. $728-735$.

[15] Moradi-Marani, F., Kodjo, S. A., Rivard, P., and Lamarche, C.-P., 2014, "Effect of the Temperature on the Nonlinear Acoustic Behavior of Reinforced Concrete Using Dynamic Acoustoelastic Method of Time Shift," Journal of Nondestructive Evaluation, 33(2), pp. 288-298.

[16] Schurr, D. P., Kim, J. Y., Sabra, K. G., and Jacobs, L. J., 2011, “Monitoring Damage in Concrete Using Diffuse Ultrasonic Coda Wave Interferometry," AIP Conference Proceedings, pp. 1283-1290.

[17] Shokouhi, P., 2013, "Stress-and Damage-Induced Changes in Coda Wave Velocities in Concrete," AIP Conference Proceedings, AIP, pp. 382-389.

[18] Shokouhi, P., Niederleithinger, E., Zoëga, A., Barner, A., and Schöne, D., 2010, "Using Ultrasonic Coda Wave Interferometry for Monitoring Stress Induced Changes in Concrete," Symposium on the Application of Geophysics to Engineering and Environmental Problems 2010, pp. 650-654.

[19] Larose, E., and Hall, S., 2009, "Monitoring Stress Related Velocity Variation in Concrete with a $2 \times 10-5$ Relative Resolution Using Diffuse Ultrasound," The Journal of the Acoustical Society of America, 125(4), pp. 1853-1856.

[20] Jiang, H., Zhang, J., and Jiang, R., 2017, “Stress Evaluation for Rocks and Structural Concrete Members through Ultrasonic Wave Analysis," Journal of Materials in Civil Engineering, 29(10), p. 4017172. 
[21] Liu, S., Zhu, J., and Wu, Z., 2015, "Implementation of Coda Wave Interferometry Using Taylor Series Expansion,” Journal of Nondestructive Evaluation, 34(3).

[22] Larose, E., Planes, T., Rossetto, V., and Margerin, L., 2010, "Locating a Small Change in a Multiple Scattering Environment," Applied Physics Letters, 96(20).

[23] Planès, T., Larose, E., Margerin, L., Rossetto, V., and Sens-Schönfelder, C., 2014, "Decorrelation and Phase-Shift of Coda Waves Induced by Local Changes: Multiple Scattering Approach and Numerical Validation," Waves in Random and Complex Media, 24(2), pp. 99-125.

[24] Niederleithinger, E., Wolf, J., Mielentz, F., Wiggenhauser, H., and Pirskawetz, S., 2015, "Embedded Ultrasonic Transducers for Active and Passive Concrete Monitoring," Sensors (Switzerland), 15(5), pp. 9756-9772.

[25] Hafiz, A., and Schumacher, T., 2017, "Characterizing the Effect of Applied Stress in Concrete by Magnitude-Squared Coherence of Ultrasonic Full-Waveforms," Structural Health Monitoring 2017: Real-Time Material State Awareness and DataDriven Safety Assurance - Proceedings of the 11th International Workshop on Structural Health Monitoring, IWSHM 2017.

[26] Grosse, C., 1996, "Quantitative Zerstörungsfreie Prüfung von Baustoffen Mittels Schallemissionsanalyse Und Ultraschall."

[27] Chen, A., and Schumacher, T., 2014, "Characterization of Flaws in Structural Steel Members Using Diffuse Wave Fields," AIP Conference Proceedings, pp. 761-768.

[28] Fröjd, P., and Ulriksen, P., 2018, "Detecting Damage Events in Concrete Using Diffuse Ultrasound Structural Health Monitoring during Strong Environmental 
Variations," Structural Health Monitoring, 17(2), pp. 410-419.

[29] Zhang, Y., Abraham, O., Tournat, V., Le Duff, A., Lascoup, B., Loukili, A., Grondin, F., and Durand, O., 2013, "Validation of a Thermal Bias Control Technique for Coda Wave Interferometry (CWI)," Ultrasonics, 53(3), pp. 658-664.

[30] Große, C., and Schumacher, T., 2013, “Anwendungen Der Schallemissionsanalyse an Betonbauwerken," Bautechnik, 90(11), pp. 721-731.

[31] Manolakis, D. G., Ingle, V. K., and Kogon, S. M., 2000, Statistical and Adaptive Signal Processing: Spectral Estimation, Signal Modeling, Adaptive Filtering, and Array Processing, McGraw-Hill Boston.

[32] Cohen, J., 1988, "Statistical Power Analysis for the Behavioral Sciences," Statistical Power Analysis for the Behavioral Sciences, 2nd, p. 567.

[33] Fröjd, P., and Ulriksen, P., 2017, "Frequency Selection for Coda Wave Interferometry in Concrete Structures," Ultrasonics, 80, pp. 1-8.

[34] ASTM C597-02, 2002, "Standard Test Method for Pulse Velocity Trough Concrete," Annual Book of ASTM Standards, pp. 3-6. 


\section{Chapter Three:}

\section{Effects of Elastic Supports and Flexural Cracking on Low and High Order Modal Properties of a Reinforced Concrete Girder}

Ali Hafiz ${ }^{1}$ and Thomas Schumacher ${ }^{2}$

Journal of Engineering Structures

Elsevier Publications

This paper is published and can be found using the following citation:

Hafiz, A. and Schumacher, T. (2019). Effects of Elastic Supports and Flexural Cracking on Low and High Order Modal Properties of a Reinforced Concrete Girder. Engineering Structures. Vol. 178, pp. 573-585. DOI: https://doi.org/10.1016/j.engstruct.2018.10.041.

${ }_{1}^{1} \mathrm{PhD}$ Candidate, Civil and Environmental Engineering, Portland State University 1930 SW 4th Avenue, Portland, OR 97201, USA, E-mail: hafiz@pdx.edu ${ }^{2} \mathrm{PhD}, \mathrm{PE}$, Associate Professor, Civil and Environmental Engineering, Portland State University 1930 SW 4th Avenue, Portland, OR 97201, USA, E-mail: thomas.schumacher@pdx.edu 


\title{
3. Chapter Three: Effects of Elastic Supports and Flexural Cracking on Low and High Order Modal Properties of a Reinforced Concrete Girder
}

\author{
Ali Hafiz and Thomas Schumacher
}

\begin{abstract}
A number of nondestructive evaluation (NDE) methods are available to detect cracks and damage in reinforced concrete structures. Methods such as ultrasonic, impact echo, or Xray testing have high resolution but are time consuming to perform and therefore only used locally. Since the early 1970s, researchers have also studied the modal properties of structures for damage detection and identification. In this paper, we discuss the effects of elastic supports and flexural cracking on the dynamic response of a large-scale laboratory reinforced concrete girder. For this purpose, an instrumented hammer used for impulse response testing was employed to initiate vibrations and to subsequently estimate the natural frequencies and modes of a large-scale laboratory concrete girder. Natural frequencies up to the $13^{\text {th }}$ mode were successfully extracted from the frequency response function (FRF). In addition, the mode shapes were extracted up to the $6^{\text {th }}$ mode due to the limitation of the linearity of the FRF response. These modal properties were determined from the measured accelerations of two points on the girder using a roving hammer. The test procedure was performed on the uncracked beam and repeated after the beam had been cracked. The experimental measurements were verified with a finite element (FE) model consisting of one-dimensional beam elements that consider both flexural and shear deformations. Support flexibility was modeled as linear-elastic springs, and was found
\end{abstract}


critical in order to explain experimentally-obtained measurements. The effects of cracking were found to be most obvious in the higher modes. Additionally, utilizing the modal flexibility method on the first mode (natural vibration frequency and mode shape) was an accurate predictor of flexural crack locations.

Keywords: modal analysis; high order modal properties; natural vibration frequencies and modes; mode shape; elastic support; flexural cracking; reinforced concrete girder; flexibility method; roving hammer technique.

\subsection{Introduction}

A number of non-destructive evaluation (NDE) methods have been developed in the recent decades to detect cracks and other kind of damage in reinforced concrete girders. Some of these methods, namely visual inspection, ultrasonic testing, and X-ray can be used to detect and locate cracks [1]. Since the early 1970, researchers have also investigated using the modal properties of a structure, which is generally referred to as the vibration-based method [2]. While this approach is able to detect the presence of damage and cracks, challenges remain locating them.

The fundamental idea of the vibration-based method is that local damage causes an local increase in the flexibility (or decrease in stiffness) of a member [3], which in turn changes the properties of modal parameters, namely the natural vibration frequencies, natural modes, and modal damping values [1]. These properties can be obtained by measuring the dynamic response due to an external stimulus, such as an excitation force. An low-energy impact-type force is typically used to make the structural member vibrate and produce a 
measurable response [4]. Considering the effects of cracks on both natural vibration frequencies and modes, this method can be further divided into frequency-based and mode shape-based methods [1].

In the frequency-based method, a change in the natural vibration frequencies is the basic feature used to detect damage. Using this method is attractive because the natural vibration frequencies can be extracted from the dynamic response from only a few accessible points on the structure [1]. However, the change in the natural vibration frequencies may be not sufficient for a unique identification of the damage location in the structure because the amount of change may be the same for a similar crack length at a different location [4]. Moreover, there are two additional limitations in using this method. First, the structure may exhibit a small change in the natural frequencies due to significant damage, especially for large structure [5]. Additionally, these changes cannot always be detected because of measurement restrictions or processing errors [2]. Farrar et al [6] found that there is no significant reduction in natural frequencies when the stiffness of the overall bridge crosssection decreased by $21 \%$. The experimental results of Eccles [7] showed that increases in the natural frequencies were observed for some mode when introducing damage. Secondly, environmental and operational conditions can also affect the natural vibrations frequencies [1]. Generally, the environmental effects on the frequency response can be as high as 5$10 \%$ [4]. As a result, this method can only be used to estimate the global condition of a member. 
The mode shape-based method is based on the idea that any damage changes the natural mode shapes of a structure. The mode shapes are much more sensitive to local damage than the natural vibration frequencies [2] and are less sensitive to environmental effects [1]. However, there are some drawbacks to using the mode shape-based method. First, the mode shapes of the lower modes may not be significantly influenced by local damage [2]. Second, the mode shapes are subject to noise contamination [1]. Finally, using this method requires a series of sensors in order to adequately capture the mode shapes [2].

Frequency Response Function (FRF) usually is used to extract the mode shapes from experimental measurements in two ways. Means to initiate natural vibrations to reliably extract mode shapes include: (a) loading the structure with a harmonic vibration generator or (b) imposing an impact force. The impact force can be created using an instrumented hand-held hammer [8] or, for the case of bridges, a falling weight deflectometer (FWD) [9]. Impact forces can be employed in two ways. First, a hammer impact force (roving hammer) can be employed at multiple locations with an acceleration sensor located at one location (= roving hammer technique) [10]. Second, a hammer impact at a fixed location can be used with multiple acceleration sensors placed in different locations (= single excitation point technique) [10]. This method is called single excitation point impact test technique. Theoretically, both approaches should produce the same result; however, there is a small percentage of error between them experimentally [8]. The roving hammer technique has the advantage that it requires only a few accelerometers to extract most modes. Therefore, only a small number of recording channels are required. Additionally, in order to increase the resolution of the measured modes, increasing the number of the 
excitation points can be achieved easily. On the other hand, a large number of sensors and hence recording channels, are required when using the single excitation point technique. One disadvantage of the roving hammer technique is that accessibility to some members for sensor installation is more difficult than accessibility for imposing the impact force.

In addition to the mechanical properties of the structure (i.e., stiffness, mass, and damping), support conditions, or the degree of restraint offered by the support, has an influence on the modal parameters [11]. A number of researchers have investigated the effect of the support condition on the dynamic response. Thomas and Dohrmann [12] studied the effect of support stiffness on the measured natural vibration frequencies and concluded that the support condition must be considered in the model, unless a free-free test is performed. Therefore, some researchers have used the free-free test in their work. For example, Lin and $\mathrm{Ng}$ [13] used soft nylon ropes to suspend their beams in order to simulate the free-free test. Wei-Ren and Roeck [14] also used the technique of suspending a beam. This technique has been used to avoid any imperfections in support behavior [15].

Elastic bearings are often used to support bridge girders [11] because they allow for horizontal thermal deformations [16]. Fayyadh and Razak [17] investigated the effect of elastic bearing deterioration on the modal parameters using reinforced concrete girders with different levels of deterioration of the elastic bearing pads. They extracted the natural vibration frequencies up to the $6^{\text {th }}$ mode and mode shapes up to $3^{\text {rd }}$ mode. However, they did not use a numerical model to validate their experimental results. They found that the natural vibration frequency of the $3^{\text {rd }}$ mode gave a good indication for deterioration while 
the first mode showed higher sensitivity to changes in support conditions. Dai et al. [16] used a three-dimensional structural model with various rubber pad stiffness and found that the natural vibration frequency decreases with decreasing stiffness of the rubber pad. Additionally, they extracted natural vibration frequencies up to the $5^{\text {th }}$ mode and did not study the mode shapes and effect of cracking. Analogously, Lin and $\mathrm{Ng}$ [13] found the natural vibration frequency increased when the stiffness of the support increased. They investigated the effects of elastic supports on the first five natural vibration frequencies and mode shapes. However, they did not study these effects for reinforced concrete beams or cracked beams. Aydin [18] used the effect of the support's characteristic on dynamic response to optimize the stiffness and location of the springs while minimizing the tip of a cantilever beam supported by springs. The researcher used only a numerical model in his investigation and did not simulate a beam with two elastic supports. Also, he did not investigate the effects of cracking on modal parameters. Hamad et al. [19] presented an improved crack model for reinforced concrete beams by incorporating non-linearity of flexural damage. They found that the changes in the natural vibration frequencies were more sensitive for stiffer than softer supports. However, they investigated the effects of flexural cracking and elastic supports on only the first four natural vibration frequencies without studying the effects on the mode shapes. Dilena et al. [20] investigated damage identification in a single-span reinforced concrete bridge. In their numerical model, they considered longitudinal flexibility from the supports by inserting a linear elastic spring. They found the fundamental mode to be most sensitive to spring stiffness, while changes 
in the higher modes were almost negligible. However, they did not study the vertical flexibility of the supports in their study.

For damage detection, both the frequency-based as well as the mode shape-based method require a comparison with baseline data. These data can be obtained from the experimental dynamic response of the reference (or undamaged, intact) structure [1]. When experimental baseline data are not available, a numerical (e.g., FE-based) model of the baseline structure can be established. Usually, Euler-Bernoulli beam theory is employed for modeling beamtype structures [1]. For short beams, Lele and Maiti [21] took in their model the effect of shear deformations by employing Timoshenko beam theory. Dilena and Morassi [22] investigated steel-concrete composite beams with partially degraded connections using both theories. They found that by using the Timoshenko beam model, improved accuracy in representing the experimental data was achieved. Finally, Hamad et al. [19] ignored the effect of the shear deformations in their model but ultimately identified that as a weak point in their model.

To locate damage, a number of methods have been presented including modal strain energy based on damage index [23] and modal flexibility method [24]. In this paper, the modal flexibility method is discussed and was applied to the experimental data (see Section 5.2.3). The influence of both the mode shapes and the natural vibration frequencies can be studied using this method, as shown in Eq. (1). Theoretically, structural deterioration manifests in a local increase in the flexibility of a member, which is used as the indicator [25]. One of the advantages of the modal flexibility method is that it requires only lower mode data to detect and locate damage [24]. The governing equations are as follows: 


$$
\begin{aligned}
& F=\sum_{i=1}^{n} \frac{1}{f^{2}} \Phi_{i} \Phi_{i}^{T} \\
& \Delta F=F_{h}-F_{d}
\end{aligned}
$$

where $F$ is modal flexibility; $f$ is the natural vibration frequency at mode $n ; \Phi$ is the mode shape; $F_{h}$ and $F_{d}$ are modal flexibilities for the healthy and damaged case, respectively.

\subsection{Research Significance and Objectives}

The objective of this research were to study the effects of elastic supports and flexural cracking on the modal properties of a large-scale reinforced concrete girder. Typically, civil engineering researchers investigate modal properties up to the $5^{\text {th }}$ mode. In this paper, we consider natural vibration frequencies up to the $13^{\text {th }}$ mode and mode shapes up to the $6^{\text {th }}$ mode, which were extracted and investigated from the frequency response function (FRF). The roving hammer technique with two fixed sensors was employed to induce structural vibrations, even though most researchers employ multiple sensors with a moving hammer. Additionally, a numerical model was created and their parameters estimated to explain the experimental results of the baseline (i.e., uncracked) girder. The numerical model was used to investigate the effect of varying support stiffness from the free-free to the simply-supported beam case. Finally, the modal flexibility method was used to locate cracking after the girder had been loaded to induce flexural cracks.

Different levels of damage and presence of shear cracks were not investigated. Also, environmental effects such as temperature and humidity changes were assumed to be negligible since the test was conducted in a laboratory. Finally, while the effect of varying 
elastic support stiffnesses on the modal parameters was only investigated numerically, but not experimentally.

\subsection{Experimental Setup and Data Processing}

\subsubsection{Experimental Test Setup}

The reinforced concrete T-girder used for this study was simply-supported with a span length of $15 \mathrm{ft}(4.57 \mathrm{~m})$. Cuboid ends were used to increase the support areas to ensure stability during loading, as shown in Figure 3-1. Ultra-high strength Neoprene rubber strips $($ width $\times$ thickness $=2 \times 0.5$ in $(50.8 \times 12.7 \mathrm{~mm})$, tensile strength $=2500 \mathrm{psi}(17.2 \mathrm{MPa}))$ were placed between the steel supports and the concrete girder representing bearing pads commonly used beneath precast bridge girders. The concrete had an average cylinder compressive strength, $f^{\prime \prime}{ }_{c}=4 \mathrm{ksi}(27.6 \mathrm{MPa})$ and Grade $60\left(f_{y}=414 \mathrm{MPa}\right)$ steel reinforcing bars were used. A monotonic load to produce service-level type cracking was applied at the girder's mid-span location. Impacts using an instrumented impulse response hammer were used for the dynamic testing, before (= intact, baseline condition) and after cracking (= cracked condition) . 

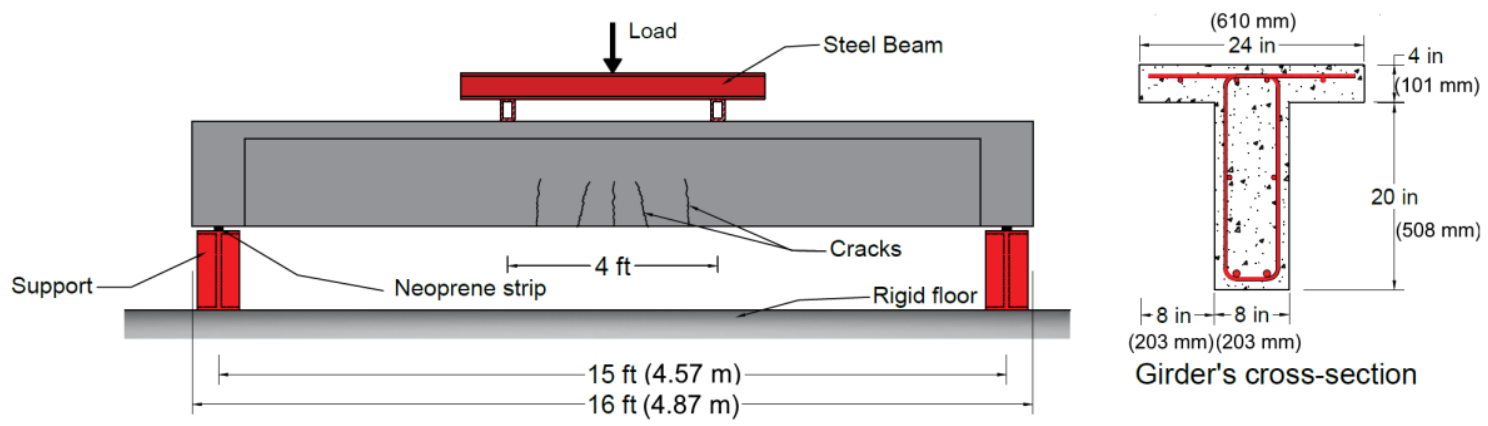

Figure 3-1. Test setup showing loading configuration to induce flexural cracking.

$$
\text { Units: } 1 \mathrm{ft}=12 \text { in }=0.305 \mathrm{~m} \text {. }
$$

\subsubsection{Vibration Tests}

Vibration tests were performed on the girder before and after the beam was cracked to service-level conditions (see Section 3.3). The hydraulic ram as well as the steel beam shown in Figure 3-1 were removed for the dynamic tests. To induce vibrations, an impact was generated by hitting the girder with a $1.5 \mathrm{lb}(0.68 \mathrm{~kg})$ hammer (PCB-Model-086D20) using a medium plastic hammer tip (1500 Ib pk (6.67 kN pk)), as illustrated in Figure 3-2. The girder was hit with the hammer at fifteen different locations, starting from $\mathrm{x}^{\prime}=1$ to 15 $\mathrm{ft}(0.305$ to $4.57 \mathrm{~m})$ from the left support in $1 \mathrm{ft}(0.305 \mathrm{~m})$ increments. Each hit was repeated three times to evaluate measurement repeatability. The hammer is used for impulse response tests [8] and has a piezoelectric sensor that measures the generated impact force. The signal from the hammer impact was amplified and sampled by the data acquisition system. 


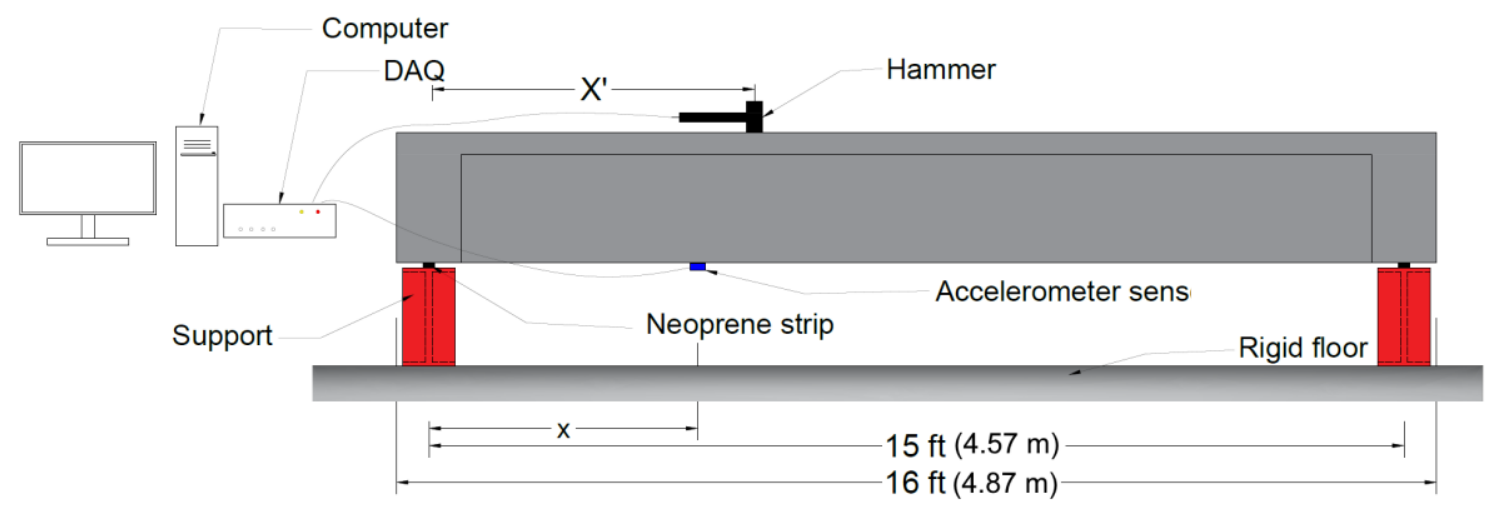

Figure 3-2. The setup of dynamic test. Units: $1 \mathrm{ft}=12 \mathrm{in}=0.305 \mathrm{~m}$.

The girder's vibration response due to the hammer impact was captured by a capacitive accelerometer (Silicon Designs-Model-2260-010), which was fixed at the girder soffit. The accelerometer has a flat frequency response within $3 \mathrm{~dB}$ over the range of 0 to $1 \mathrm{kHz}$, which was deemed adequate for this study. For this study, a total of three accelerometers were available; therefore, five separate location configurations were used to cover the fifteen measurement locations. Hence, for each impact location, measurements of the dynamic response from fifteen different locations were available. This test procedure allows extracting modal properties via two techniques. First, the single excitation point technique uses a fixed hammer impact location and the measured vibration response from multiple locations along the girder. Second, the roving hammer technique uses the measured vibration response from one location with multiple impact locations along the girder.

Both signals, one from the hammer and the other from the accelerometer, were sampled and stored by a high-speed data acquisition system (Model: Elsys TraNET 204s). The sampling frequency was set at $100 \mathrm{kHz}$ with a low-pass anti-aliasing filter at a cutoff 
frequency of $2 \mathrm{kHz}$. A constant threshold trigger was defined to start data sampling for a duration of $1.5 \mathrm{~ms}$. Figure 3-3 shows sample time histories for both impact force (a) acceleration response (b).
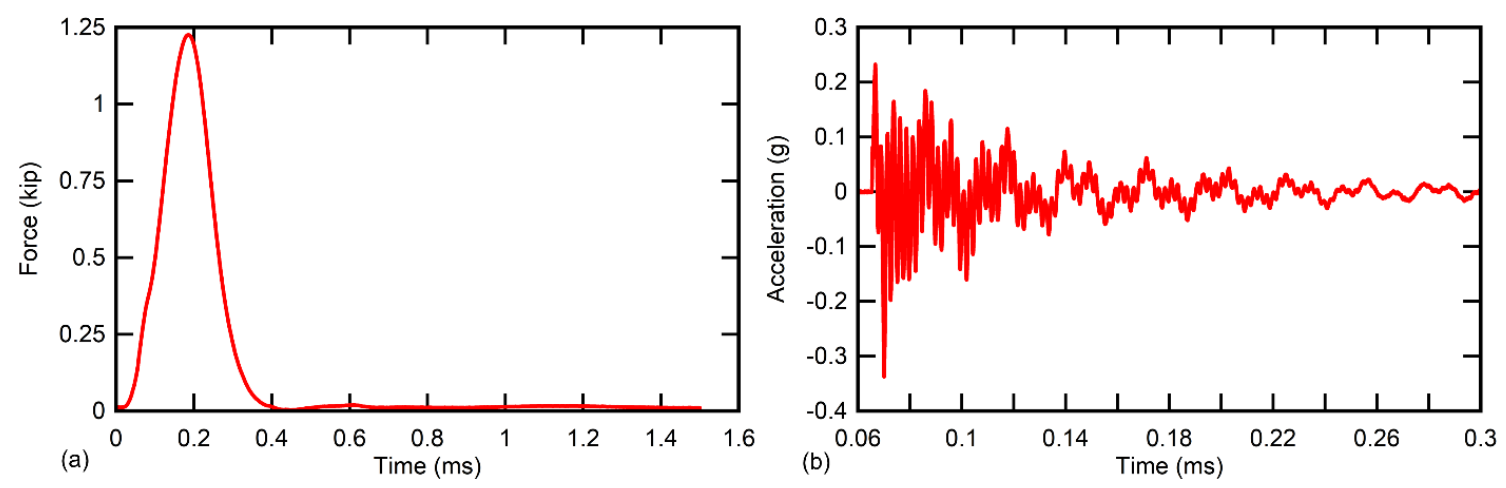

Figure 3-3. Sample: (a) Impact force and (b) Acceleration response.

\subsubsection{Loading to Induce Flexural Cracking}

Following the initial vibration test (see Section 3.2) to collect baseline data, the girder was loaded in a four-point bending test configuration to introduce flexural cracking representative of typical in-service conditions. The setup for this test is shown in Figure 31. A 100-ton (224-kip) capacity hydraulic ram with hand-pump-control was used to apply the load to the steel spreader beam (see Figure 3-1). The girder was loaded monotonically up to $156 \mathrm{kN}$ (35 kip), which was sufficient to generate service-level-type cracking at the girder mid-span location. Flexural tension cracks appeared around mid-span. The applied load corresponds to approximately $56 \%$ of the ultimate load, which was estimated theoretically since the girder has not been loaded to failure. 


\subsubsection{Data Processing}

\subsubsection{Windowing}

In order to reduce unwanted discontinuity effects on the discrete Fourier transform (DFT) response of a discrete time signal, a window function with smooth transitions can be multiplied point-wise with the discrete signal [26], [27]. In this study, a Hanning window was employed as part of the computation of the frequency response function (FRF), producing acceptable results. The Hanning window is named after its originator (Julius von Hann) [27] and is characterized by the highest side lobe level and side lobe roll-off ratio, compared to rectangular (= original discrete signal), triangular, and sine lobe windows [26]. The Hanning window function is defined in the time domain as [27]:

$$
w(n)=\left\{\begin{array}{r}
\frac{1}{2}\left(1-\cos \frac{2 \pi n}{M}\right), 0 \leq n \leq M \\
0, \text { elsewhere }
\end{array}\right.
$$

\subsubsection{Frequency Response Function (FRF)}

The frequency response function (FRF) was utilized to enable a direct comparison between the measured vibration responses. The FRF is also called transfer function, $H(f)$ and completely describes the response of a system in the frequency domain due to a unit impulse force [28]. $H(f)$ can be computed by dividing the measured system response, $Y(f)$ by the measured impact force, $X(f)$ as follows [10]:

$$
F R F=H(f)=\frac{Y(f)}{X(f)}=\frac{G_{x y}(f)}{G_{x x}(f)}
$$


$Y(f)$ and $X(f)$ are the frequency domain representations of the time domain signals, $y(t)$ and $x(t)$, respectively, obtained by the forward DFT. In order to directly compare the measured vibration responses to hammer impacts with variable amplitudes, the FRF was used, since it represents the response of the system itself. A comparison between DFT and FRF results for a select impact and measurement location is shown in Figure 3-4. The main difference between DFT and FRF is that DFT represents the vibration response of the girder due to a given impact force, but FRF represents the true system response (or impulse response) of the girder, which is independent of the type of impact. As such, it excludes the bias a force introduces on the vibration response [29]. It can be observed that the FRF differs in two significant ways from the DFT: first, the FRF shows strong peaks around 750, 1200, 1400, 1700, and $1900 \mathrm{~Hz}$ compared to small peaks of present in the DFT. Note that each peak represents a natural vibration frequency. Figure 3-4 also shows that peak amplitudes in the FRF for higher frequencies are much larger than for low frequencies (less than $200 \mathrm{~Hz}$ ). To conclude, the vibration response of this girder is dominated by the higher natural vibration frequencies, which can also be seen qualitatively in Figure 3-3 (b) where the first portion of the response showed large amplitudes having high frequency content. Therefore, this research focused on studying the higher frequencies. 


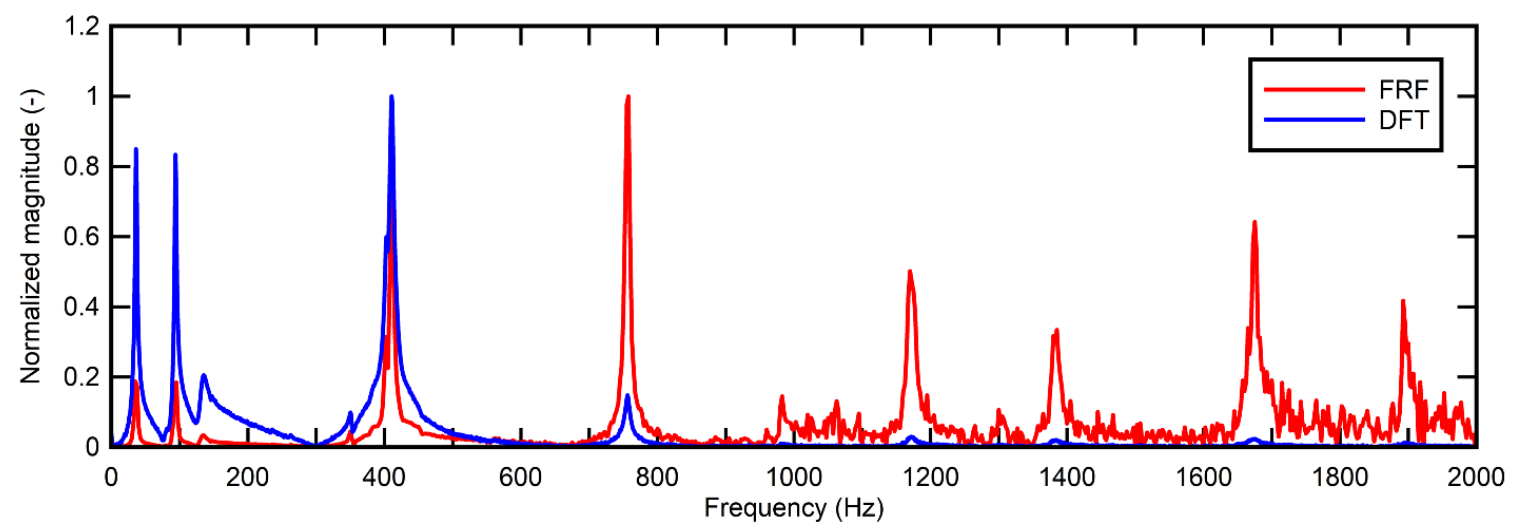

Figure 3-4. Sample measured vibration response in the frequency domain for $x=x^{\prime}=8 \mathrm{ft}$ $=2.44 \mathrm{~m}$.

Next, the importance of using the FRF rather than the DFT is discussed for the case when a fixed measurement location is used in conjunction with a moving impact having variable force amplitudes, which is the case in this study. Figure 3-5 shows the FRF for three different hammer impacts, all measured at the same location. Figs. 5 (b) and 5 (c) show that, although the hammer impacts were not the same, there is excellent match between their frequency magnitudes. For frequencies higher than $750 \mathrm{~Hz}$, the FRF starts to show some discrepancies, as is shown in Figure 3-5 (d). This may be attributed to loss of linearity in the higher frequency response. Linear regression was utilized in order to estimate the linear frequency limit. The coefficient of determination $\left(\mathrm{R}^{2}\right)$ from linear regression was used to evaluate the similarity between the FRF's responses of the three impacts, as shown in Figure 3-6. A sharp reduction in the $\mathrm{R}^{2}$ value after $750 \mathrm{~Hz}$ can be observed, indicating a deviation from linear behavior. Therefore, the FRF of the girder was divided into a linear and a nonlinear regime with $750 \mathrm{~Hz}$ assumed as the separating frequency. To conclude, mode shapes 
can be extracted for natural vibration frequencies within the linear regime, i.e. below 750 $\mathrm{Hz}$.

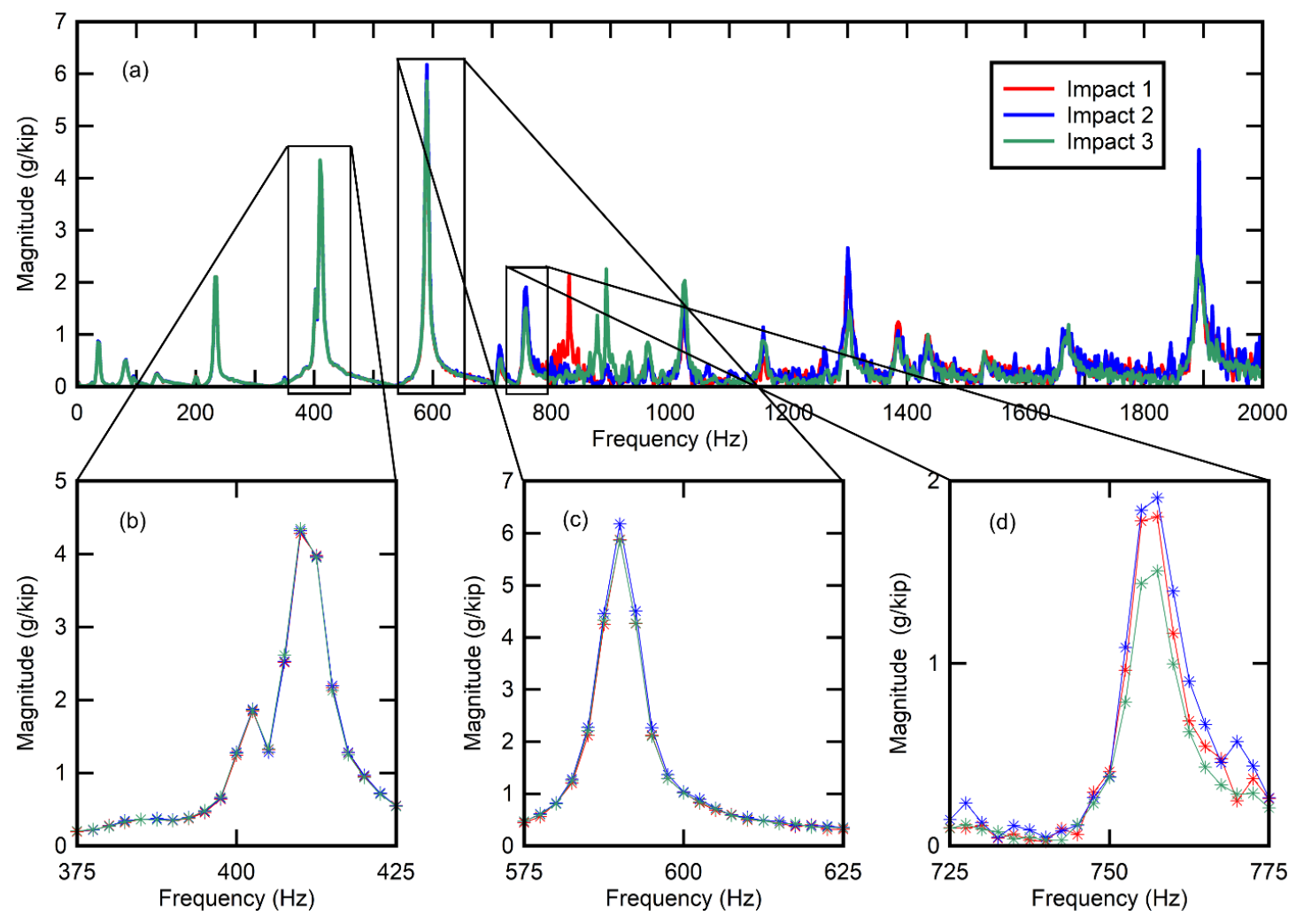

Figure 3-5. Three sample FRF for $x=x^{\prime}=3 \mathrm{ft}=0.914 \mathrm{~m}$.

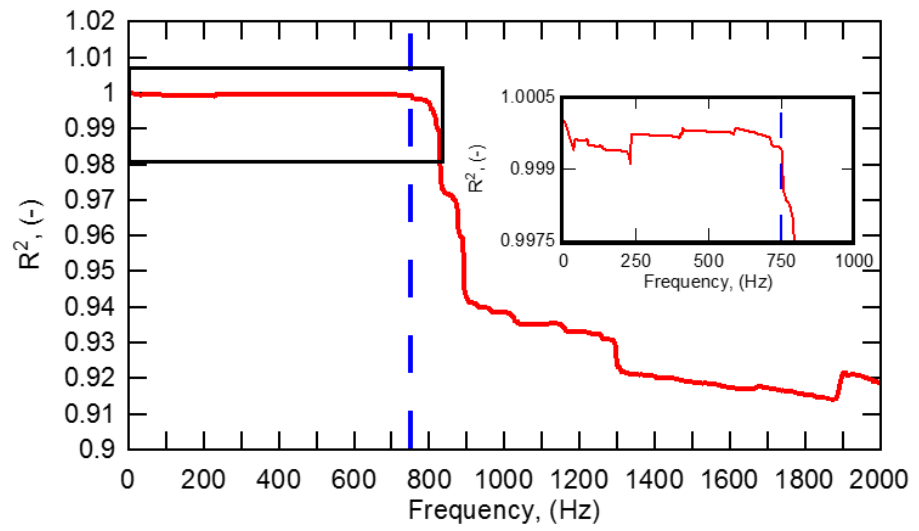

Figure 3-6. Coefficient of determination $\left(\mathrm{R}^{2}\right)$ vs. vibration frequency. 


\subsection{Numerical Model}

The numerical model was utilized in this study to model the intact girder in order to gain a better understanding of the experimental results as well discriminate spurious results. Model parameters were estimated using a pattern search algorithm. The frequency response function (FRF) for the acceleration showed a number of peaks, as discussed in Section 3.4.2 Not all of these peaks are of interest to this study because some of them represent non-flexural modes. Finally, the experimental data is compared to the numerical model and is presented Section 5.1 .

The finite element (FE) method, implemented using MATLAB [30], provided the numerical model in this study. In this model, the girder was modeled as a beam having two elastic supports, which were modeled as elastic springs, as shown in Figure 3-7. The girder was divided into 192 finite elements for high accuracy. The beam elements used also account for shear deformations, i.e. using Timoshenko beam theory. The girder properties used in this study were: mass per unit length, $\bar{m}=6.04 \times 10-4 \mathrm{kip}^{*} \mathrm{~s}^{2} / \mathrm{in}^{2}\left(0.396 \mathrm{kN} * \mathrm{~s}^{2} / \mathrm{m}^{2}\right)$ and moment of inertia, $I=14,806 \mathrm{in}^{4}\left(6162 \times 106 \mathrm{~mm}^{4}\right)$, which was computed using gross section properties. In addition, the shear area, $A_{s}$ was determined to be $171.8 \mathrm{in}^{2}=0.11 \mathrm{~m}^{2}$ based on the following equation [31]:

$$
A_{S}=\frac{I^{2}}{\int\left[\frac{S^{2}(z)}{b^{2}(z)}\right] d A}
$$

where $b(z)$ is the width of the cross-section at position $z$ from the principal y-axis, and $\mathrm{S}(\mathrm{y})$ is the elastic section modulus, determined according to the principal $y$-axis [31]. 
Analogous to finite element (FE) model updating, system parameters in the model were estimated to match the experimental data to a sufficient degree of accuracy [32]. In this study, the system parameters included shear modulus $(G)$, modulus of elasticity $(E)$ and elastic spring stiffness $\left(K_{l}\right.$ and $\left.K_{r}\right)$. A pattern search algorithm [33] was used to minimize the difference between experimental data and the system parameters used in the numerical model, where bounds for $E$ and $G$ were set to [3,467 to 3,832] ksi ([23904 to 26420] $\mathrm{N} / \mathrm{mm}^{2}$ ) and [1,444 to 1,569$] \mathrm{ksi}$ ([9956 to 10817$] \mathrm{N} / \mathrm{mm}^{2}$ ), respectively. These limits represent the mean $\pm 5 \%$ of initially estimated values. The mean value of $(E)$ was calculated by using the ACI 318 equation [34] $\left(E_{c}=57,000 \sqrt{f^{\prime} c}\right)$. Moreover, the estimated value of the shear modulus was calculated by assuming a Poisson's ratio, $\square=0.2$. Finally, the elastic spring stiffnesses were bound to initial values of [100 to 900] kip/in ([17512 to 157614] $\mathrm{kN} / \mathrm{m}$ ) where these limits are reasonable values according to the observed mode shape of the second mode. This point is discussed in detail in the Results and Discussion section.

The correlation coefficient $(R)$ between experimental and theoretical natural vibration frequencies was used to estimate the error in the theoretical model. In addition to the correlation coefficient, the maximum error percentage was set in the optimization algorithm to minimize the difference between numerical model and experimental data. The optimization algorithm produced the following parameters: $K_{l}=627$ kip/in $(109,801$ $\mathrm{kN} / \mathrm{m}), K_{r}=612(107,177 \mathrm{kN} / \mathrm{m}), E=3644 \mathrm{ksi}(25.12 \mathrm{GPa})$ and $G=1469 \mathrm{ksi}(10.12 \mathrm{GPa})$. The results of the optimization process and the estimated model parameters are discussed in detail in the Results and Discussion section. 


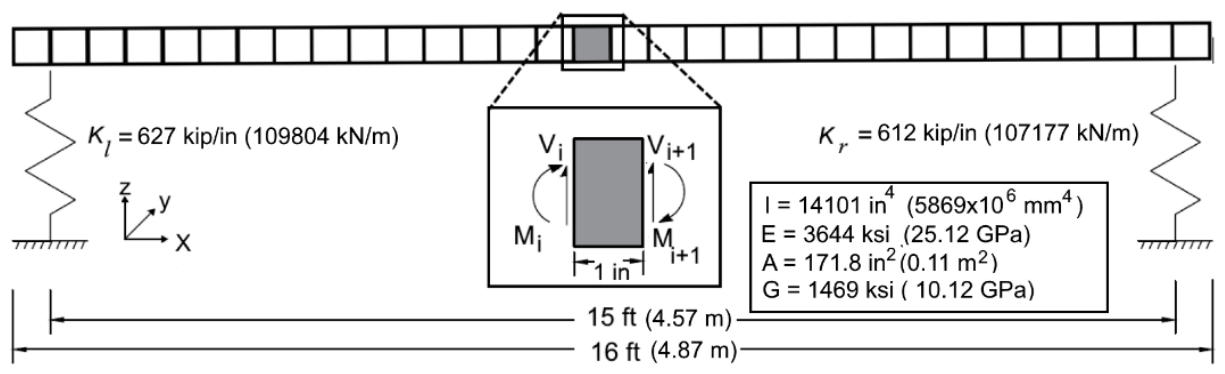

Figure 3-7. FE model of girder supported by elastic springs.

\subsection{Results and Discussion}

\subsubsection{Effect of Elastic Supports}

Figure 3-8. shows two sample FRF of the acceleration response for the reference girder, where (a) and (b) show the response for $x=x^{\prime}=8 \mathrm{ft}(2.438 \mathrm{~m})$ and $x=x^{\prime}=3 \mathrm{ft}(0.914 \mathrm{~m})$, respectively. Each peak represents a natural vibration frequency for a specific mode. For this girder, natural frequencies up to the $13^{\text {th }}$ mode could be identified. It can be observed that additional peaks caused by non-flexural vibration modes are present. Non-flexural vibration modes could include compressional or torsional vibration modes of the girder as well as the steel beam supporting the girder. Typically, compression modes have high frequencies (higher that $800 \mathrm{~Hz}$ ) that match the additional observed peaks. 


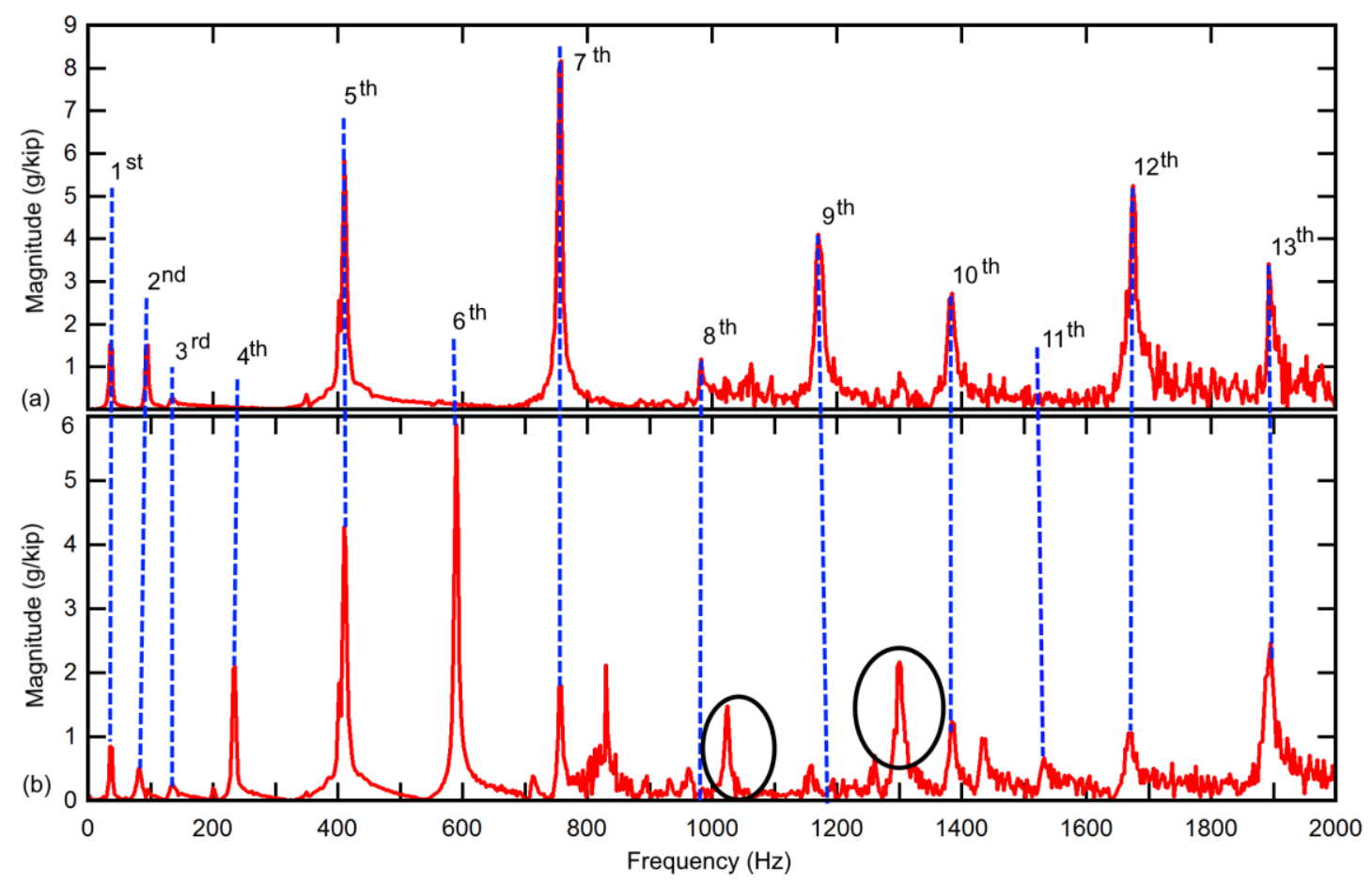

Figure 3-8. Two sample FRF for the reference girder at (a) $x=x^{\prime}=8 \mathrm{ft}(2.438 \mathrm{~m})$ and (b) $\mathrm{x}=\mathrm{x}^{\prime}=3 \mathrm{ft}(0.914 \mathrm{~m})$, the highlighted peaks are discussed in Section 5.1.4.

The numerical model helped identify the natural vibration frequencies associated with the flexural response of the girder. The results from the numerical model are compared with the measured vibration response through the natural frequencies and mode shapes in detail in the following two sub-sections.

\subsubsection{Natural Vibration Frequencies}

The experimentally-determined natural vibration frequencies for both the linear and nonlinear regime are listed in Table $3-1$. The frequency resolution is $\pm 1.25 \mathrm{~Hz}$. In addition, this table shows the values obtained from the numerical model. The results show that a strong 
match exists between experimental and numerical values with a maximum absolute error ranging between 0.01 and $2.8 \%$ for all modes, except for the second and fifth mode where the error was $3.2 \%$. Additionally, a linear regression curve-fit with $95 \%$ confidence intervals was applied to the results, and it is shown in Figure 3-9. This figure shows all data points, linear fit, confidence intervals, and prediction intervals. It can be observed that all data points are in the range of the confidence interval limits. Moreover, the coefficient of determination, $R^{2}=0.999$ and root mean squared (RMS) error was $19.6 \mathrm{~Hz}$.

Table 3-1. Comparison of natural vibration frequencies for modes, $n=1$ to 13 .

\begin{tabular}{|c|c|c|c|c|c|}
\hline \multirow{4}{*}{ FRF regime } & \multicolumn{2}{|c|}{ Experimental } & \multicolumn{3}{|c|}{ Numerical model } \\
\cline { 2 - 6 } & $f^{\#}(\mathrm{~Hz})$ & $n$ & $f(\mathrm{~Hz})$ & $n$ & Error $(\%)$ \\
\hline \multirow{5}{*}{ Linear } & 35.0 & 1 & 35.3 & 1 & 0.8 \\
\cline { 2 - 6 } & 77.5 & 2 & 80.0 & 2 & 3.1 \\
\cline { 2 - 6 } & 132 & 3 & 129.3 & 3 & -2.1 \\
\cline { 2 - 6 } & 232 & 4 & 236.9 & 4 & 2.1 \\
\cline { 2 - 6 } & 412 & 5 & 399.5 & 5 & -3.1 \\
\cline { 2 - 6 } & 595 & 6 & 582.6 & 6 & -2.1 \\
\hline \multirow{5}{*}{ Non-linear } & 757 & 7 & 773.1 & 7 & 2.1 \\
\cline { 2 - 6 } & 982 & 8 & 964.7 & 8 & -1.8 \\
\cline { 2 - 6 } & 1170 & 9 & 1155.2 & 9 & -1.3 \\
\cline { 2 - 6 } & 1382 & 10 & 1343.8 & 10 & -2.8 \\
\cline { 2 - 6 } & 1530 & 11 & 1530.3 & 11 & 0.0 \\
\cline { 2 - 6 } & 1675 & 12 & 1714.9 & 12 & 2.3 \\
\cline { 2 - 6 } & 1892 & 13 & 1897.7 & 13 & 0.3 \\
\hline
\end{tabular}

$f^{\#}$ is the natural frequency. 


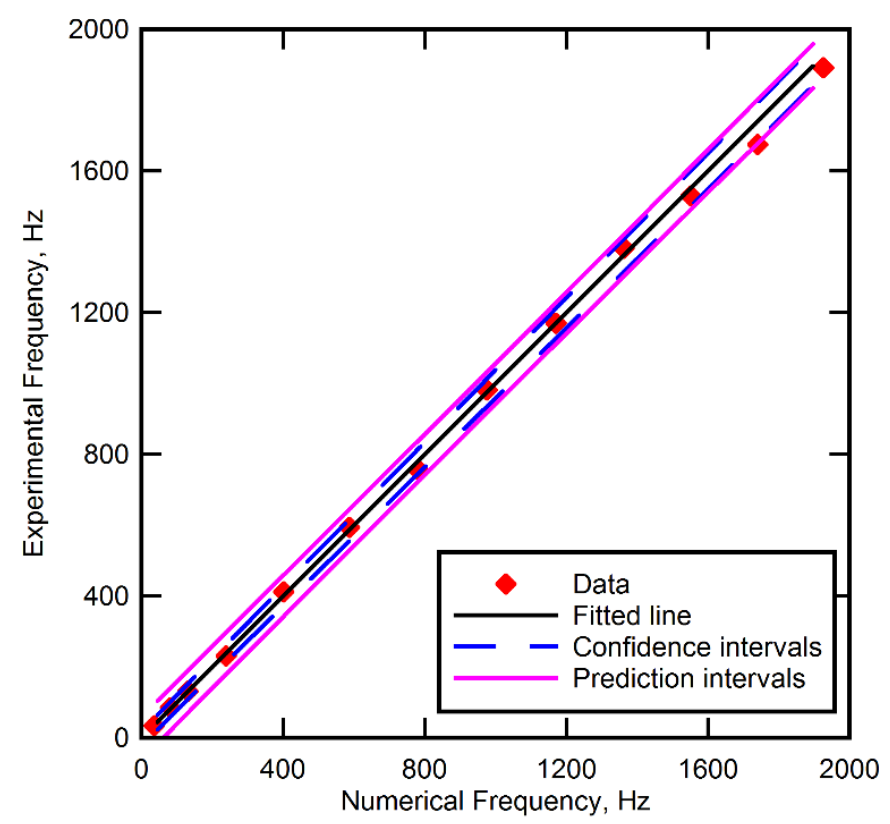

Figure 3-9. Experimental vs. numerically-predicted natural vibration frequencies.

\subsubsection{Mode Shapes}

The linearity of the FRF response plays a crucial role in extracting the mode shapes by using the roving hammer technique because it is based on the assumption that the impact force is the same for all measurements. Additionally, this assumption is needed for using the single excitation point technique, since only three accelerometers were available in this research. As discussed in Section 3.4.2, the FRF was linear until approximately $750 \mathrm{~Hz}$. Therefore, only the first six mode shapes could be extracted from experimental data. Figure 3-10 shows the FRF response for accelerometer were located at $3 \mathrm{ft}(0.914 \mathrm{~m})$ and $8 \mathrm{ft}$ $(2.438 \mathrm{~m})$ where the hammer was roving along the girder. From this figure, it can be observed that the accelerometer cannot capture the mode shape that has a node at the location of the accelerometer. Therefore, the accelerometer at $8 \mathrm{ft}$ can be used to extract 
mode shapes of $n=1,2,3$ and 5 . On the other hand, the $4^{\text {th }}$ and $6^{\text {th }}$ mode shapes can be extracted from the response of the accelerometer at $3 \mathrm{ft}$.
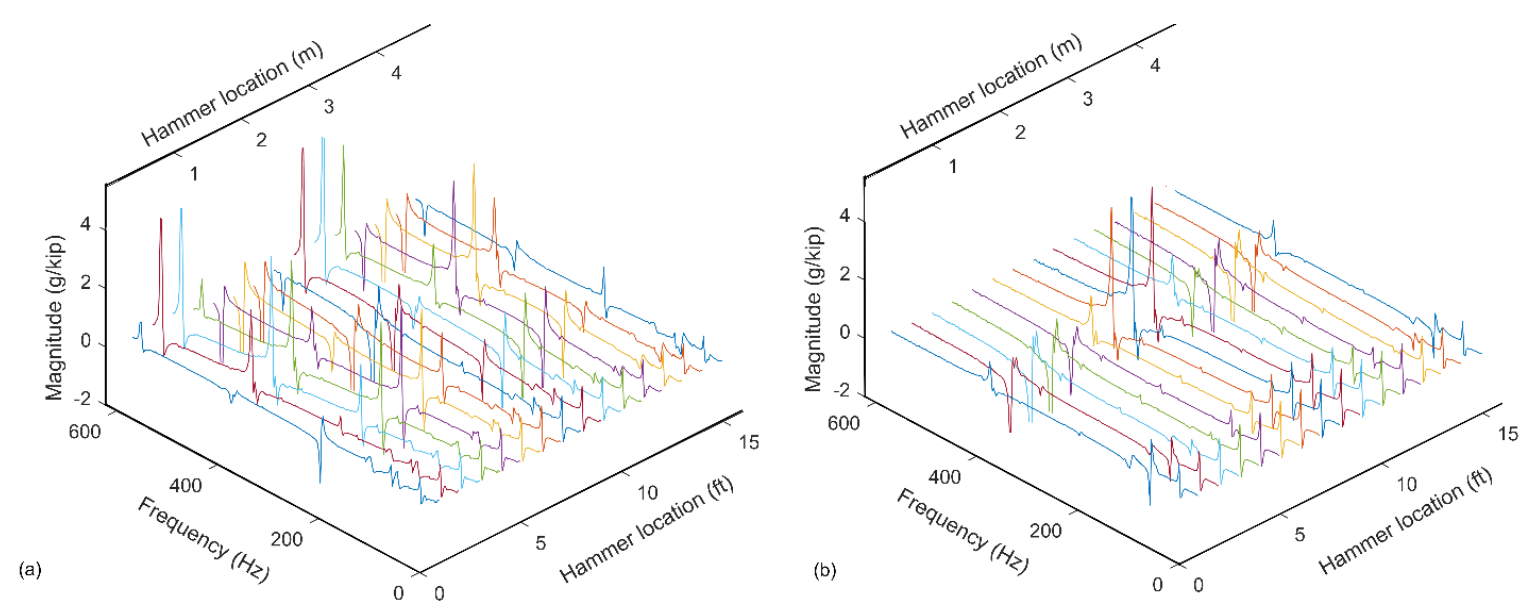

Figure 3-10. FRF for roving hammer: (a) Accelerometer at $3 \mathrm{ft}(0.914 \mathrm{~m})$ and (b) accelerometer at $8 \mathrm{ft}(2.44 \mathrm{~m})$.

For roving hammer technique, the mode shape for each natural frequency was extracted from the magnitudes of FRF response at different location of the hammer. The shape function of the first mode was extracted by both techniques (roving hammer and the single excitation point) as shown in Figure 3-11 (a). It can be observed that a negligible difference exists between the results of the two techniques. As a result, only the results of the roving hammer are presented and discussed in this paper. The effect of elastic support conditions on these mode shapes are evident: first, the value of the mode shape function at the supports was greater than zero because the support did not prevent vertical deformation. Second, the mode shapes of the $2^{\text {nd }}$ and $3^{\text {rd }}$ modes showed the largest value of amplitude at the support and this would not happen for supports that restrain vertical deformation. 
In addition to the verification of the natural vibration frequencies (as shown in Section 5.1.1), the results for the mode shapes are a second verification. The numerical and experimental results offered an acceptable match. The numerical model successfully predicted the experimental measurements. In addition, the model showed the ability to use the numerical model to investigate the effect of support flexibility on the dynamic response characteristics. The numerical model can also be used to extract the mode shapes of the non-linear regime as shown in Figure 3-12, which cannot be extracted experimentally.

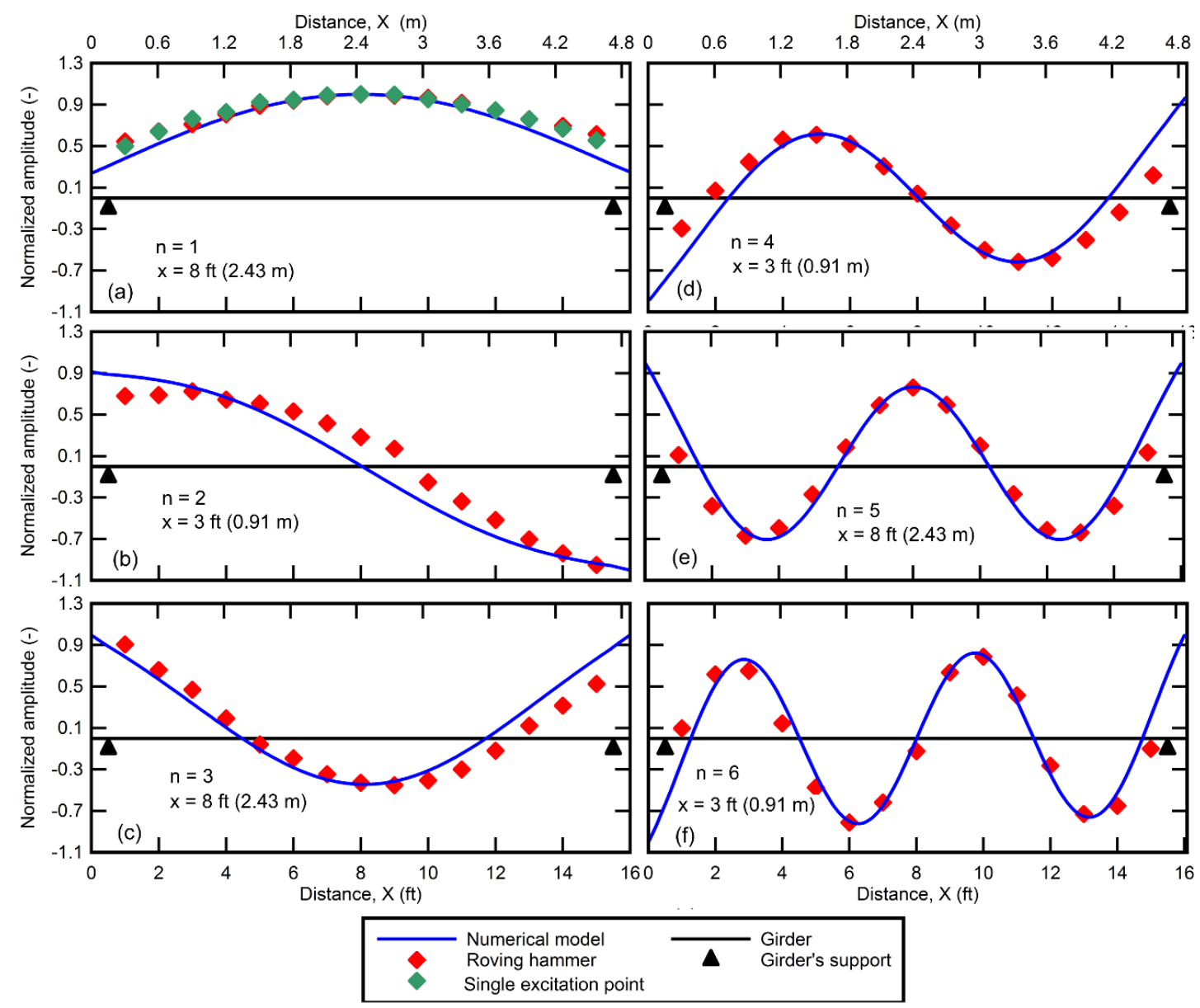

Figure 3-11. Comparison of experimental and numerical results for first sixth modes. 


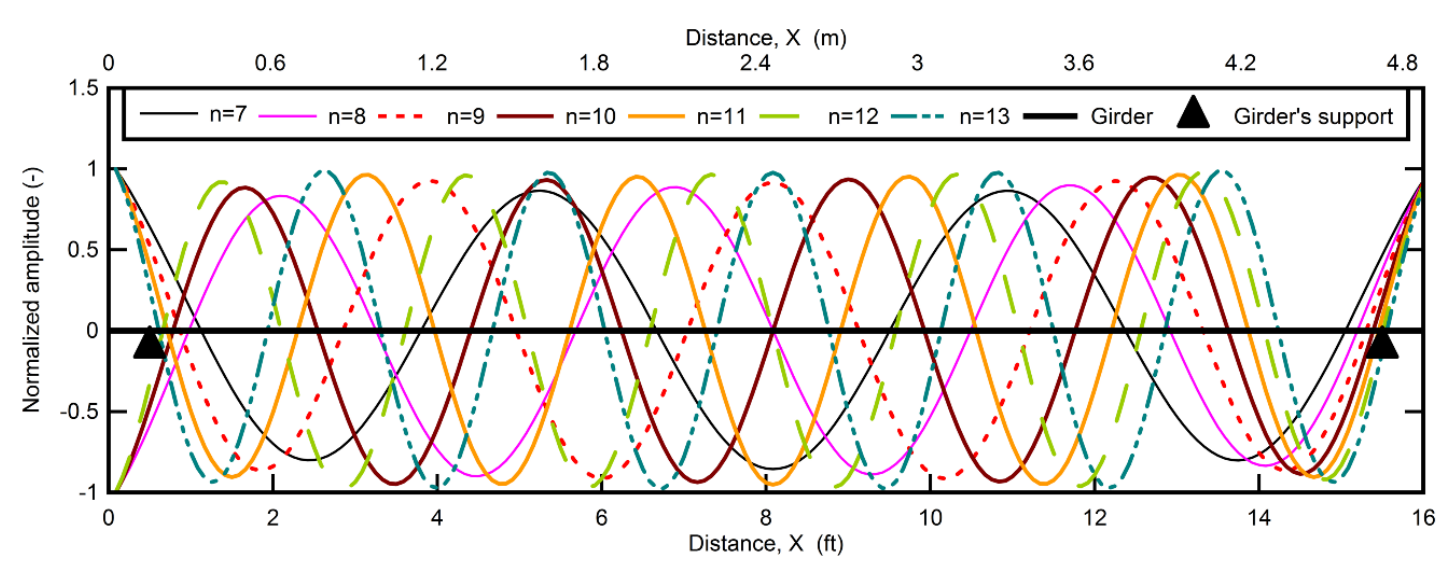

Figure 3-12. Numerical model results of mode shapes of the non-linear regime.

\subsubsection{Parametric Study: Elastic Support Stiffness}

After the numerical model was validated, as shown previously presented in Sections 5.1.1 and 5.1.2, it was used to study the effect of elastic support stiffness by changing the elastic stiffness of the supports on the natural vibration frequency response. This investigation allows us to get better understanding about how the elastic support effect the modal parameters. For this purpose, the stiffness of the supports were varies varied from zero 0 to $1,000,000 \mathrm{kip} / \mathrm{in}$ ( 0 to $175 \mathrm{x} 106 \mathrm{kN} / \mathrm{m}$ ), i.e. from the free-free case up to the rigid simplysupported, i.e. pinned case, respectively. In this new model, the same stiffness was assumed for both girder's supports. All other material properties and constants were unchanged from the numerical model (see Section 4.). Figure 3-13 shows natural vibration frequency against support stiffness for the first 13 modes. It can be observed that the natural vibration frequency of each mode exhibits three phases. The first phase is between free-free case and the point when the natural frequency starts to increase, which are highlighted by red circles in Figure 3-13. The second phase is between the point of increase and when the support 
stiffness plateaus, referred to as maximum stiffness. In this second phase, the natural frequency increases with increasing support stiffness. The third phase is between the maximum stiffness and rigid case, which is when the frequencies reach a final constant. It can be observed that both the threshold stiffness and the maximum stiffness increase with increasing mode number. Finally, the relationship between the natural vibration frequency and support stiffness follows an S-shape curve. 


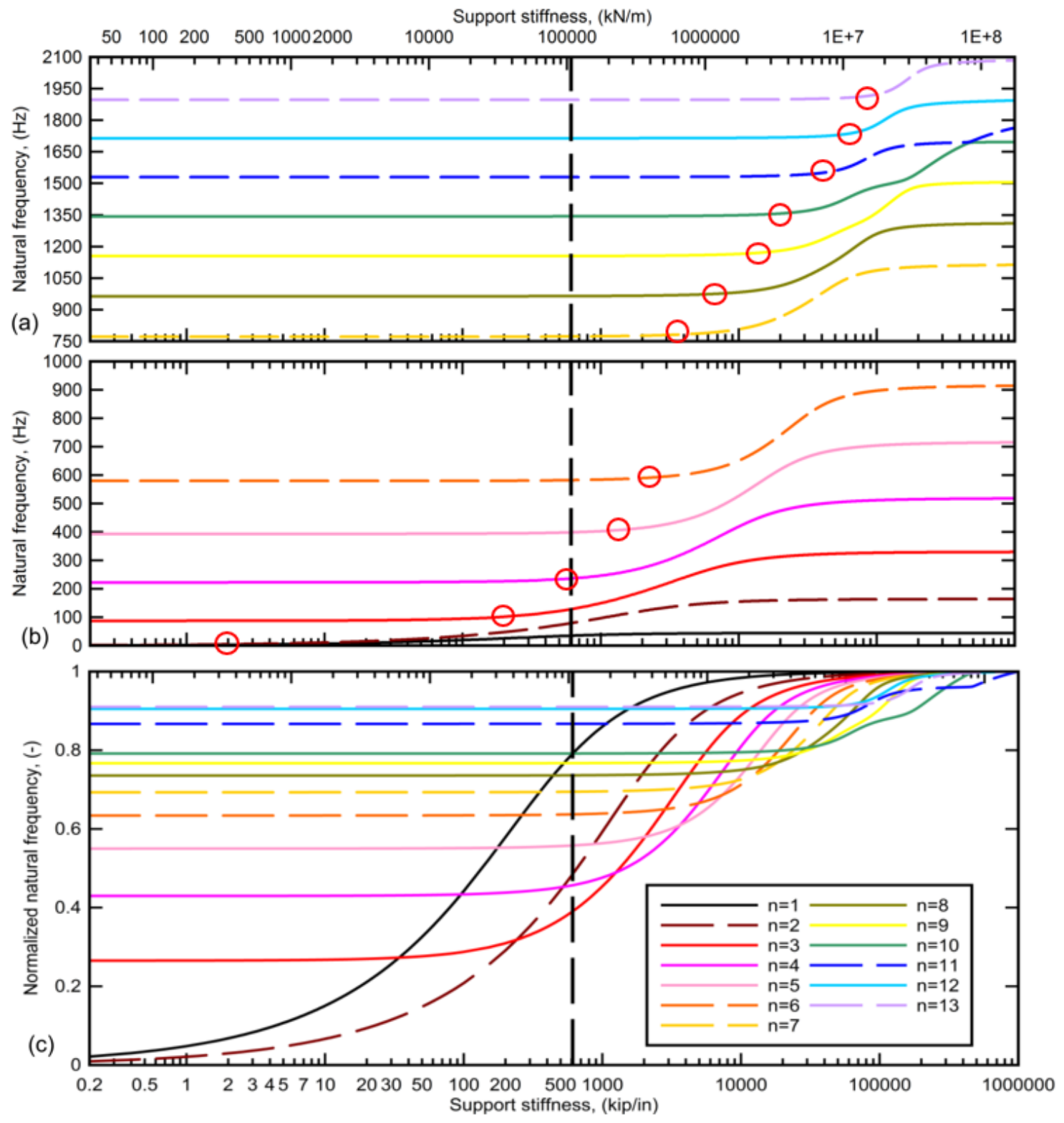

Figure 3-13. Natural vibration frequency for the first 13 modes vs. support stiffness; (a) non-linear regime, (b) linear regime and (c) normalized response including both regimes. The black dashed vertical line denotes the support stiffnesses estimated for the reinforced concrete girder used in this study. Note that the $\mathrm{x}$-axis is on a log scale. 
Furthermore, the ratio of the reduction in natural frequency due to change the support's stiffness from rigid to free-free case, is related to mode number where this ratio decreases with increasing mode order, as shown in Figure 3-13.c. This is true for all modes except the second mode, which is most effected by the stiffness of support. The effect of support stiffness on the shape of the second mode is selected for further discussion. Figure 3-14 shows the shape of the second mode for a range of support stiffnesses. It is evident that the mode shape changes from a three-node case for rigid supports to a two-node case for free (= no) supports. The two-node mode shape represents the case where the girder vibrates freely, i.e. the girder does barely deform compared to the deflections experienced at the supports. This situation appears when the stiffness of support is much lower than the girder stiffness. The three-node mode shape is exhibited for rigid supports.

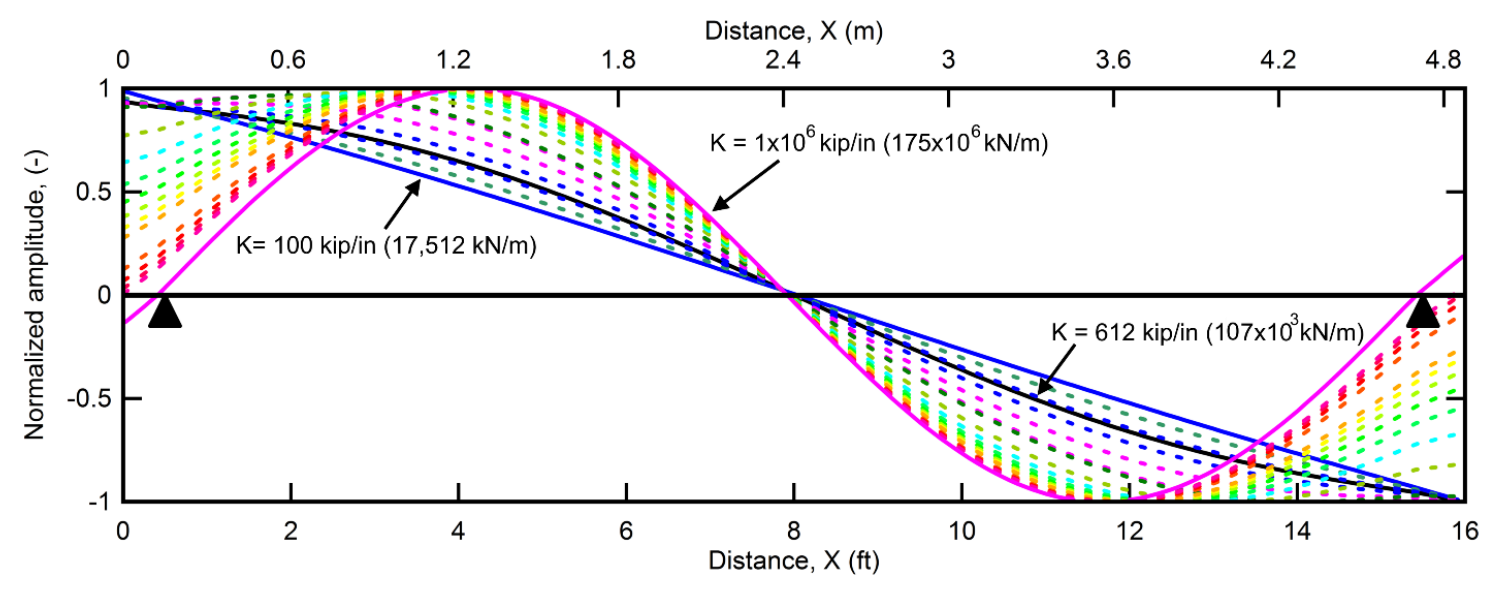

Figure 3-14. Mode shape of second mode for varying support stiffness. The black sold line represents the reinforced concrete girder used in this study. 


\subsubsection{Discussion}

The numerical model was a useful tool to help distinguish the natural vibration frequencies from the vibration response. However, there were some additional frequency peaks that appeared in the FRF as highlighted by the black circles in Figure 3-8. These frequencies are not related to the flexural vibration modes since the numerical model could not predict them. Additionally, they are not related to the compression modes of the steel support because they were affected by the stiffness of the girder. In other words, they decreased with the decreasing stiffness of the girder due to cracks (as discussed in Section 5.2). As a result, these frequencies can be associated with torsional modes. These frequencies did not appear in the used numerical model since it is two-dimensional and can thus not exhibit torsional behavior.

In the numerical model, including the effect of shear deformations had a significant effect on improving the model's accuracy. When the model did not consider shear deformations of the girder, its results revealed a large error as compared with the experimental results. The results of that model are not presented in this paper for brevity.

On the other hand, the effect of support stiffness had a significant influence on the dynamic response of the girder by adding new natural modes and affecting the natural vibration frequencies of the other modes. The most accurate way to study the effects of support stiffness is by comparing the experimental results with the numerical model of simply supported beam case (see Section 5.1.3) where this model is named " $2^{\text {nd }}$ numerical model" in this study. The results of comparison are listed in Table 3-2. The mode shapes were 
compared to the number of nodes in each mode. Below are some key points observed by comparing experimental and $2^{\text {nd }}$ numerical model results:

1- The experimental first and fourth modes are associated with the first and second modes of the $2^{\text {nd }}$ numerical model based on the similarity between their mode shapes. Their natural frequencies were substantially lower due to the effect of elastic supports.

2- The elastic supports introduce two new modes (i.e., $2^{\text {nd }}$ and $3^{\text {rd }}$ modes) that can be observed in both the experimental results as well as the numerical model. However, the $2^{\text {nd }}$ numerical model is unable to predict those.

3- After the $3^{\text {rd }}$ mode, the number of the nodes in the mode shapes evenly increased in both the experimental and in the $2^{\text {nd }}$ numerical model regardless of their frequency.

Table 3-2. Comparison of natural vibration frequencies between experimental and $2^{\text {nd }}$ numerical model results.

\begin{tabular}{|c|c|c|c|c|}
\hline \multicolumn{2}{|c|}{ Experimental } & \multicolumn{2}{|c|}{$2^{\text {nd }}$ numerical model } \\
\hline$f^{\#}(\mathrm{~Hz})$ & $n$ & $f(\mathrm{~Hz})$ & $n$ & Error $(\%)$ \\
\hline 35 & 1 & 44 & 1 & 20 \\
\hline 85 & 2 & - & - & - \\
\hline 132 & 3 & - & - & - \\
\hline 232 & 4 & 517 & 2 & 55 \\
\hline 412 & 5 & 714 & 3 & 42 \\
\hline 595 & 6 & 913 & 4 & 35 \\
\hline
\end{tabular}




\subsubsection{Effect of Cracking}

\subsubsection{Natural Frequency}

During performing the static test, as described in Section 3.3, flexural tension cracks appeared around mid-span. The applied load corresponds to approximately $56 \%$ of the ultimate load, which was estimated theoretically since the beam never loaded to failure.

Figure 3-15 shows the acceleration response in the frequency domain for the cracked girder side by side with the reference (= uncracked) girder. In addition, their natural frequencies are listed in Table 3-3. It can be observed that an unexpected increase in the natural frequency of the first two modes occurred. Although these cracks are clearly visible, they do not have a large influence on the vibration response for the first two modes since the frequency-based method has a limitation with regard to crack size, as discuss in Section 1. In addition, this increase in the natural vibration frequencies of these modes could be related to the effect of the elastic supports. As shown previously, support flexibility exerted a large influence on the natural frequency of the first mode and introduced a new second mode of vibration. 


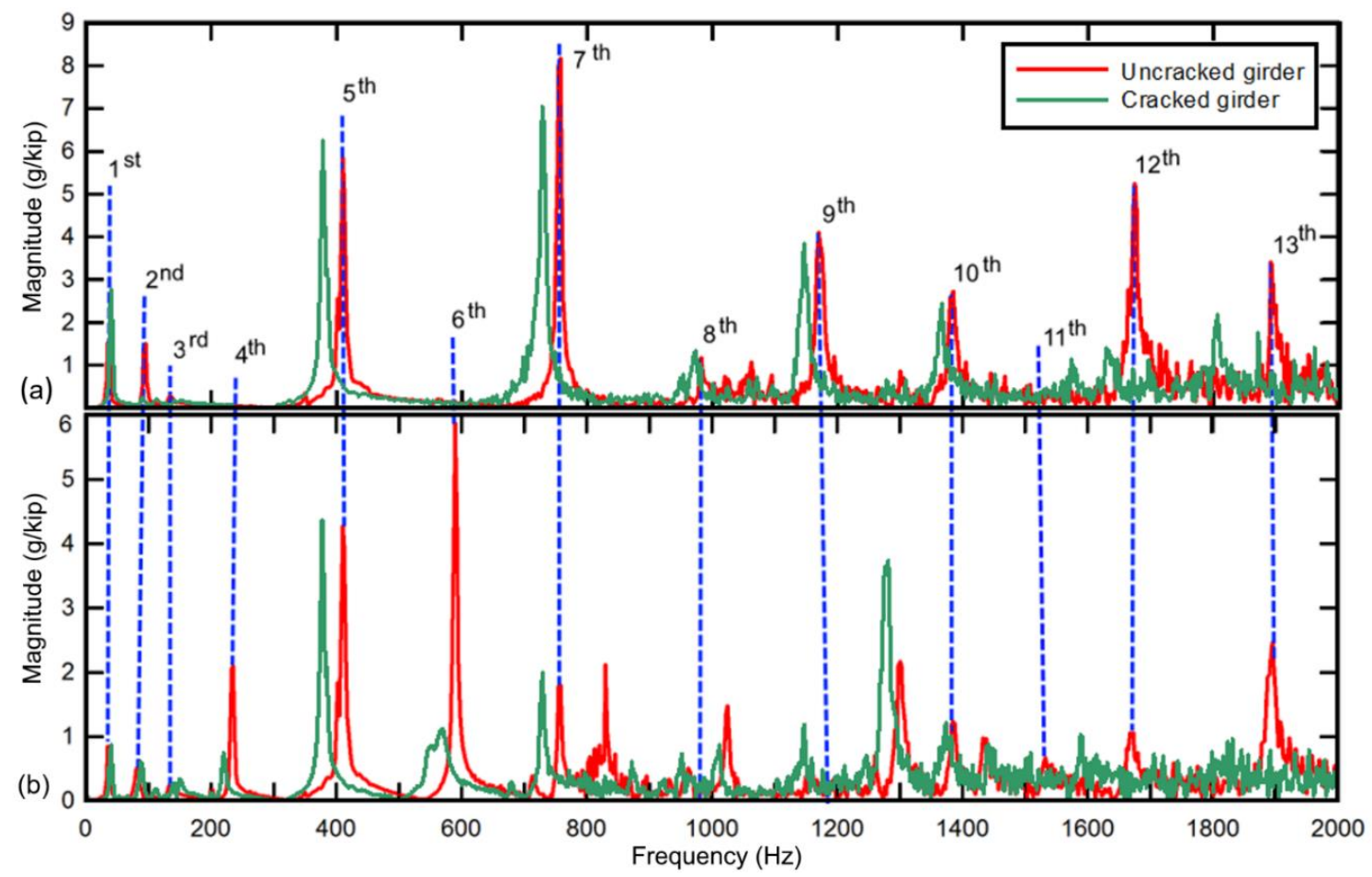

Figure 3-15. Four sample FRF for reference and cracked girders: (a) $x=x^{\prime}=8 \mathrm{ft}(2.438$ m) and (b) $x=x^{\prime}=3 \mathrm{ft}(0.914 \mathrm{~m})$.

On the other hand, the results demonstrate that there is a significant decrease in the natural frequencies for modes, $n>3$. This is expected since cracks decrease the stiffness of the girder locally. The reduction in the natural frequencies was observable for all of these modes and they can be clearly distinguished with reduction values between 12 and $45 \mathrm{~Hz}$. Therefore, for the linear regime, the natural frequencies of the higher order modes (between $3^{\text {rd }}$ and $\left.6^{\text {th }}\right)$ were found to be sensitive to localized cracking. Also, all modes in the nonlinear regime can be used for this purpose as they were found to be more sensitive to cracking. 


\subsubsection{Mode Shapes}

For the mode shapes, only the $1^{\text {st }}$ mode is presented and discussed here since all other mode shapes behaved in the same manner. In addition, the results from the mode shapes are reflected by the same results of earlier research [1],[36] and [37]. Figure 3-16 shows the $1^{\text {st }}$ mode for reference and the cracked girder in the actual and normalized response. It can be observed that the cracked girder exhibits higher flexibility compared to the reference one since the cracks reduce the girder's stiffness locally. Generally, both modes have the same shape function. Finally, the first mode shape can be used to detect cracking if reference data is available.
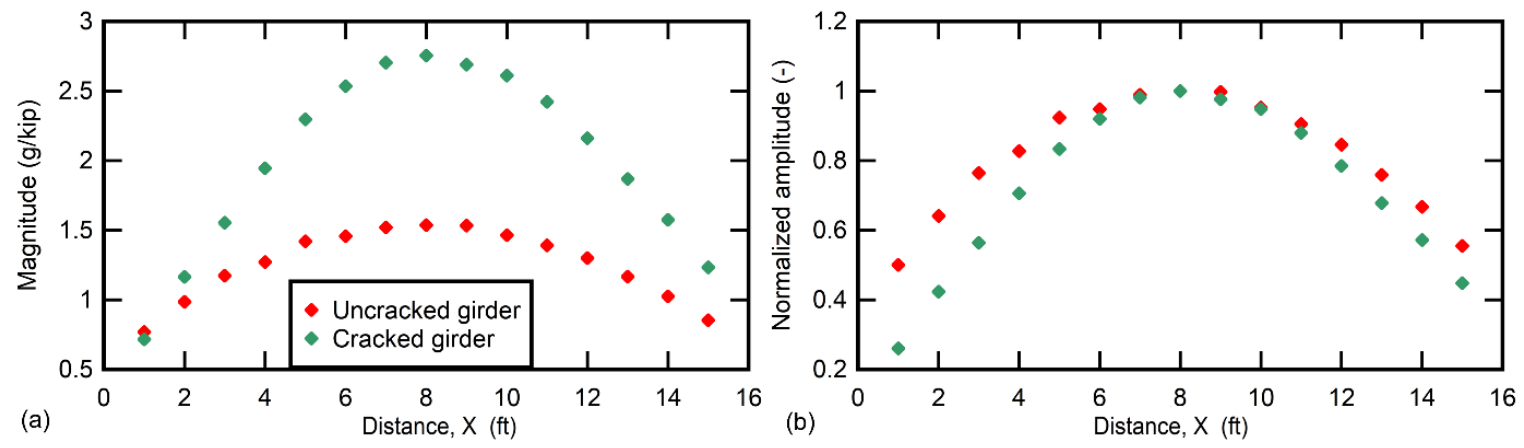

Figure 3-16. First mode shape for reference (red dots) and cracked (green dots) girders:

(a) actual and (b) normalized response. 
Table 3-3. Natural frequencies of reference and cracked girders.

\begin{tabular}{|c|c|c|c|c|}
\hline \multirow{3}{*}{ FRF regime } & & \multicolumn{2}{|c|}{ Frequency $(\mathrm{Hz})$} & \multirow{2}{*}{ Change } \\
\cline { 2 - 5 } & & Reference & Cracked & \\
\hline \multirow{5}{*}{ Linear } & 1 & 35.0 & 40.0 & 5.0 \\
\cline { 2 - 5 } & 2 & 77.5 & 87.0 & 9.5 \\
\cline { 2 - 5 } & 3 & 132 & 113 & -19.5 \\
\cline { 2 - 5 } & 4 & 232 & 220 & -12.0 \\
\cline { 2 - 5 } & 5 & 412 & 378 & -34.5 \\
\cline { 2 - 5 } & 6 & 595 & 570 & -25.0 \\
\hline \multirow{5}{*}{ Non-linear } & 7 & 757 & 730 & -27.0 \\
\cline { 2 - 5 } & 8 & 982 & 950 & -32.0 \\
\cline { 2 - 5 } & 9 & 1170 & 1145 & -25.0 \\
\cline { 2 - 5 } & 10 & 1382 & 1340 & -42.0 \\
\cline { 2 - 5 } & 11 & 1530 & 1500 & -30.0 \\
\cline { 2 - 5 } & 12 & 1675 & 1630 & -45.0 \\
\cline { 2 - 5 } & 13 & 1892 & 1850 & -42.0 \\
\hline
\end{tabular}

\subsubsection{Damage localization}

The modal flexibility method (see Introduction section) was utilized to locate damage in form of concrete cracking using Eq. 1 and 2. Figure 3-17 shows the flexibility change of the girder after introducing the flexural cracks where only the model parameters (mode shapes and natural frequency) of the first mode was used. It can be observed that the flexibility change varies by approximately $20 \%$ over the length of the girder with a significant increase around the mid-span location of the girder, which is where the cracking 
is located. The shape of this curve qualitatively matches the results presented by the researcher that introduced the flexibility method [24].

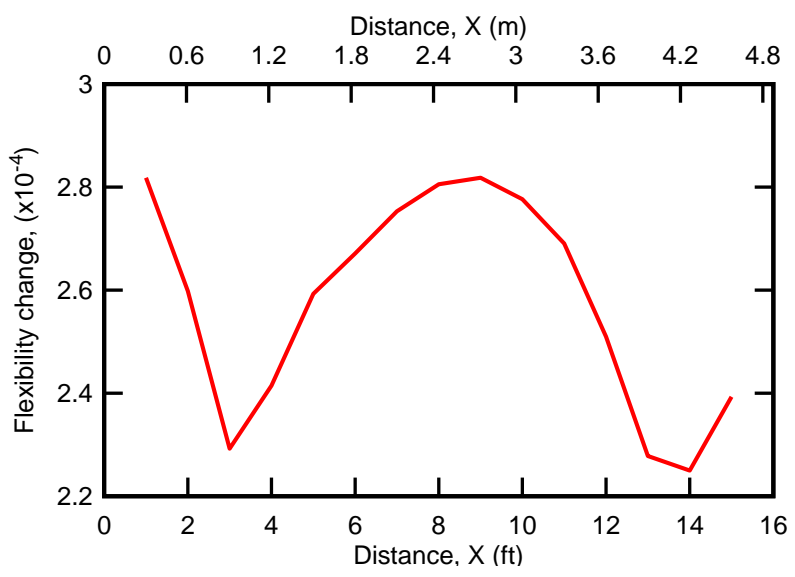

Figure 3-17. Flexibility change in mode 1 between undamaged and cracked girder.

\subsubsection{Discussion}

As demonstrated in the previous sections, using only the natural vibration frequency of the first mode gave the wrong indication for cracking. The shape of the first mode alone did also not indicate cracking correctly. This problem was stated in a number of previous research studies, e.g. [5] [6] and [7], and it presented as one of limitations of using a frequency-based approach. The modal parameters of the first mode are still useful when combining them as demonstrated by the results from the modal flexibility method. However, this method requires the full mode shapes, which can be challenging in the field, especially for large structures. On the other hand, using the natural vibration frequencies of the higher modes is effective to indict the presence damage for the case of exposed reinforced concrete members that are part of e.g. bridges or parking structures. 


\subsection{Conclusions}

By using the frequency response function (FRF), the natural vibration frequencies could be extracted from the experimental measurements up to the $13^{\text {th }}$ mode, but the mode shapes could be only extracted up to the $6^{\text {th }}$ mode because of the linearity limit in the FRF. These natural vibration frequencies and modes matched the numerical model predictions. In the numerical model, both support flexibility and shear deformations were considered. The numerical model provided a useful tool to help distinguish the natural frequencies from the experiential frequency response since there were additional frequencies that were not related to flexural modes.

Support flexibility influenced the dynamic characteristics of the reinforced concrete girder significantly. The effect was revealed by decreasing the natural frequency of the $1^{\text {st }}$ and $4^{\text {th }}$ mode from the experimental response where these modes were associated with the $1^{\text {st }}$ and $2^{\text {nd }}$ modes of the $2^{\text {nd }}$ numerical model for a simply-supported beam. Moreover, the elastic supports introduced two new intermediate modes, which can be completely associated to support flexibility because their mode shapes showed maximum amplitude at supports.

The first two natural frequencies could not be used to detect the significant flexural cracking in the reinforced concrete girder. This was due to governing effect of the elastic supports. However, their mode shapes could be used for this purpose. Additionally, the modal flexibility method could predict the location of flexural cracks by using the results

of the first mode (vibration natural frequency and the mode shape). Finally, the natural 
vibration frequencies of the non-linear regime were sensitive to cracking as they exhibited a significant reduction.

\section{Acknowledgement}

We would like to acknowledge the financial support received from the Higher Committee of Education Development in Iraq (HCED) and the Department of Civil and Environmental Engineering at Portland State University. The concrete girder used in this study was originally built for a research project to develop at a novel methodology for locating acoustic emissions during cracking [38] and we thank Dr. Stephan Gollob for letting us use the girder for this study. Finally, the support of Tom Bennett, Laboratory Manager in the department is greatly appreciated. 


\section{References}

[1] W. Fan, P. Qiao, Vibration-based damage identification methods: A review and comparative study, Structural Health Monitoring. 10 (2011) 83-111. doi:10.1177/1475921710365419.

[2] J.T. Kim, Y.S. Ryu, H.M. Cho, N. Stubbs, Damage identification in beam-type structures: Frequency-based method vs mode-shape-based method, Engineering Structures. 25 (2003) 57-67. doi:10.1016/S0141-0296(02)00118-9.

[3] a Z. Khan, A.B. Stanbridge, D.J. Ewins, Detecting damage in vibrating structures with a scanning LDV, Optics and Lasers in Engineering. 32 (2000) 583-592. doi:10.1016/S0143-8166(00)00004-X.

[4] O.S. Salawu, Detection of structural damage through changes in frequency: a review, Engineering Structures. 19 (1997) 718-723. doi:10.1016/S01410296(96)00149-6.

[5] C.M. Tan, Nonlinear vibrations of cracked reinforced concrete beams, University of Nottingham, 2003.

[6] C.R. Farrar, W.E. Baker, T.M. Bell, K.M. Cone, T.W. Darling, T.A. Duffey, A. Eklund, A. Migliori, Dynamic characterization and damage detection in the I-40 bridge over the Rio Grande, Los Alamos National Lab., NM (United States), 1994.

[7] B.J. Eccles, The use of non-linear vibrations in the health monitoring of reinforced 
concrete structures., (1999).

[8] P. Avitabile, Experimental modal analysis, Sound and Vibration. (2001) 1-11. http://www.ewp.rpi.edu/hartford/ ernesto/F2010/EP2/Materials4Students/Miller/ Modal_Analysis.pdf.

[9] E. V. Fernstrom, J.L. Carreiro, J.D. Rawn, K.A. Girmmelsman, K.A. Grimmelsman, Dynamic Characterization of a Truss Bridge by Falling Weight Deflectometer, Transportation Research Record: Journal of the Transportation Research Board, No. 2331, Transportation Research Board of the National Academies, Washington, D.C., 2013. 2321 (2013) 81-89. doi:10.3141/2331-08.

[10] C.R. Farrar, P.J. Cornwell, S.W. Doebling, M.B. Prime, Structural health monitoring studies of the Alamosa Canyon and I-40 bridges, Los Alamos National Lab., NM (US), 2000.

[11] M.M. Fayyadh, H. Abdul Razak, O.R. Khaleel, Differential effects of support conditions on dynamic parameters, in: Procedia Engineering, 2011: pp. 177-184. doi:10.1016/j.proeng.2011.07.021.

[12] T.G. Carne, C.R. Dohrmann, Support conditions, their effect on measured modal parameters, in: Proceedings-Spie the International Society for Optical Engineering, 1998: pp. 477-483. http://sem-proceedings.com/16i/sem.org-IMAC-XVI-16th-Int161403-Support-Conditions-Their-Effect-Measured-Modal-Parameters.pdf. 
[13] R.M. Lin, T.Y. Ng, Exact vibration modes of multiple-stepped beams with arbitrary steps and supports using elemental impedance method, Engineering Structures. 152 (2017) 24-34. doi:10.1016/J.ENGSTRUCT.2017.07.095.

[14] W.-X. Ren, G. De Roeck, Structural Damage Identification using Modal Data. I: Simulation Verification, Journal of Structural Engineering. 128 (2002) 87-95. doi:10.1061/(ASCE)0733-9445(2002)128:1(87).

[15] J. Maeck, M.A. Wahab, B. Peeters, G. De Roeck, J. De Visscher, W.P. De Wilde, J.-M. Ndambi, J. Vantomme, Damage identification in reinforced concrete structures by dynamic stiffness determination, Engineering Structures. 22 (2000) 1339-1349. doi:10.1016/S0141-0296(99)00074-7.

[16] W. Dai, M.O. Moroni, J.M. Roesset, M. Sarrazin, Effect of isolation pads and their stiffness on the dynamic characteristics of bridges, Engineering Structures. 28 (2006) 1298-1306. doi:10.1016/j.engstruct.2005.12.012.

[17] M.M. Fayyadh, H. Abdul Razak, Condition assessment of elastic bearing supports using vibration data, Construction and Building Materials. 30 (2012) 616-628. doi:10.1016/j.conbuildmat.2011.12.043.

[18] E. Aydin, Minimum dynamic response of cantilever beams supported By optimal elastic springs, Structural Engineering and Mechanics. 51 (2014) 377-402. doi:10.12989/sem.2014.51.3.377. 
[19] W.I. Hamad, J.S. Owen, M.F.M. Hussein, Modelling the degradation of vibration characteristics of reinforced concrete beams due to flexural damage, Structural Control and Health Monitoring. 22 (2015) 939-967. doi:10.1002/stc.1726.

[20] M. Dilena, A. Morassi, M. Perin, Dynamic identification of a reinforced concrete damaged bridge, Mechanical Systems and Signal Processing. 25 (2011) 2990-3009. doi:10.1016/j.ymssp.2011.05.016.

[21] S.P. Lele, S.K. Maiti, Modelling of transverse vibration of short beams for crack detection and measurement of crack extension, Journal of Sound and Vibration. 257 (2002) 559-583. doi:10.1006/jsvi.2002.5059.

[22] M. Dilena, A. Morassi, Vibrations of steel-concrete composite beams with partially degraded connection and applications to damage detection, Journal of Sound and Vibration. 320 (2009) 101-124. doi:10.1016/j.jsv.2008.07.022.

[23] P. Cornwell, S.W. Doebling, C.R. Farrar, Application of the strain energy damage detection method to plate-like structures, Journal of Sound and Vibration. 224 (1999) 359-374. doi:10.1006/jsvi.1999.2163.

[24] A.K. Pandey, M. Biswas, Damage detection in structures using changes in flexibility, Journal of Sound and Vibration. 169 (1994) 3-17. doi:10.1006/jsvi.1994.1002.

[25] H.W. Shih, D.P. Thambiratnam, T.H.T. Chan, Vibration based structural damage 
detection in flexural members using multi-criteria approach, Journal of Sound and Vibration. 323 (2009) 645-661. doi:10.1016/j.jsv.2009.01.019.

[26] L.N. Covert, Fast fourier transform-based spectral analysis, University of Alabama, 2003. http://library.ua.edu/vwebv/holdingsInfo?bibId=1632060.

[27] A. V Oppenheim, R.W. Schafer, J.R. Buck, Discrete Time Signal Processing, 1999.

[28] T. Irvine, An introduction to spectral functions, Vib. Publ. (2000) 1-15.

[29] J.C. Santamarina, D. Fratta, Discrete Signals and Inverse Problems: An Introduction for Engineers and Scientists, 2006. doi:10.1002/0470021896.

[30] The Mathworks Inc., MATLAB - MathWorks, Www.mathworks.com/products/matlab. (2016). doi:2016-11-26.

[31] S. Engineer, SCIA engineer manuals, 2013.

[32] T. Marwala, Finite-element-model updating using computional intelligence techniques: Applications to structural dynamics, 2010. doi:10.1007/978-1-84996323-7.

[33] C. Audet, J.E. Dennis, Analysis of Generalized Pattern Searches, SIAM Journal on Optimization. 13 (2002) 889-903. doi:10.1137/S1052623400378742.

[34] ACI Committee 318, Building Code Requirements for Structural Concrete (ACI 318-14) and Commentary (ACI 318R-14), 2014. doi:10.1016/0262-5075(85)90032- 
6.

[35] A.K. Chopra, Dynamics of structures: theory and applications to earthquake engineering, Pearson Education. (2007) 874. doi:10.1002/9781118599792.

[36] G.M. Owolabi, A.S.J. Swamidas, R. Seshadri, Crack detection in beams using changes in frequencies and amplitudes of frequency response functions, Journal of Sound and Vibration. 265 (2003) 1-22. doi:10.1016/S0022-460X(02)01264-6.

[37] F. Ubertini, A.L. Materazzi, A. D’Alessandro, S. Laflamme, Natural frequencies identification of a reinforced concrete beam using carbon nanotube cement-based sensors, Engineering $\quad$ Structures. $60 \quad$ (2014) 265-275. doi:10.1016/j.engstruct.2013.12.036.

[38] S. Gollob, Source localization of acoustic emissions using multi-segment paths based on a heterogeneous velocity model in structural concrete, ETH Zürich, 2017. doi:10.3929/ETHZ-A-010870031. 


\title{
Chapter Four:
}

\section{A Reference-Free Non-Destructive Testing Method to Detect Deterioration in Concrete Bridge Decks Based on Non-Linear Vibration Characteristics}

\author{
Ali Hafiz ${ }^{1, *}$, Anis $\operatorname{Raad}^{2}$, and Thomas Schumacher ${ }^{3}$
}

This paper will be submitted to the Journal of Mechanical Systems and Signal Processing.

\footnotetext{
${ }^{1} \mathrm{PhD}$ Candidate, Civil and Environmental Engineering, Portland State University 1930 SW 4th Avenue, Portland, OR 97201, USA, E-mail: hafiz@pdx.edu ${ }^{2}$ Graduate Student, Civil and Environmental Engineering, Portland State University 1930 SW 4th Avenue, Portland, OR 97201, USA, E-mail: araad@pdx.edu 3PhD, PE, Associate Professor, Civil and Environmental Engineering, Portland State University 1930 SW 4th Avenue, Portland, OR 97201, USA, E-mail:

thomas.schumacher@pdx.edu
} 


\title{
4. Chapter Four: A Reference-Free Non-Destructive Testing Method to Detect Deterioration in Concrete Bridge Decks Based on Non-Linear Vibration
}

\section{Characteristics}

\author{
Ali Hafiz ${ }^{1, *}$, Anis $\operatorname{Raad}^{2}$, and Thomas Schumacher ${ }^{3}$
}

\begin{abstract}
A number of non-destructive evaluation (NDE) methods have been developed in recent decades to detect deterioration such as delaminations in concrete bridge decks. These methods, namely visual inspection (i.e. hammer sounding and chain drag), impulse response testing, impact echo testing, ultrasonic (array) echo testing, and under certain conditions ground penetrating radar (GPR) can be used to detect and estimate the extent of delaminations. Since the early 1970s, researchers have also investigated using the dynamic response properties of a structure, which is generally referred to as the vibration-based method. For damage detection, the vibration-based method requires a comparison with reference data, which is unavailable in most cases. Generally, the vibration response due to an impact force can be measured using accelerometers. The frequency response function (FRF) is computed by dividing the measured response by the input force, both in the frequency domain. In this paper, we present a simple reference-free method based on impulse response (IR) testing to detect deterioration in concrete bridge decks using nonlinear vibration characteristics. The hypothesis is that for an undamaged deck, varying the impact force does not affect the corresponding FRFs for frequencies that lie within the accelerometer's operating range. On the other hand, the FRFs of a deteriorated slab change when the impact force is increased with the delamination resulting a non-linear vibration
\end{abstract}


response. Finite element modeling was first used to demonstrate that the method will work in theory. We then evaluated its performance on an in-service bridge deck. Finally, ultrahigh-pressure hydro-blasting was performed on the deck for rehabilitation, providing an opportunity to compare results.

Keyword: Bridge deck; concrete; delamination; deterioration; impulse response testing; non-linear vibration; nonlinearity index.

\subsection{Introduction and Background}

Highway infrastructure in the United States and around the world experience deterioration due to environmental conditions and increasing traffic volume [1]. Additionally, deterioration is caused by degradation in structural materials due to aging. The corrosion of steel bars and gradual degradation in concrete are the most common causes of deterioration in reinforced concrete structures. Accordingly, bridge engineers are typically concerned about four primary deterioration mechanisms: rebar corrosion, deck delamination, vertical cracks, and concrete degradation [2]. This project specifically focuses on deck deterioration and delamination.

Delamination is an advanced form of deterioration in reinforced concrete bridge decks resulting from corrosion of the embedded reinforcing steel bars (rebars), which is initiated by the presence of cracks in the concrete and sufficient moisture [3]. The rebars expand due to corrosion, leading to cracking and subsurface fracture planes within the concrete. A delamination is a crack parallel to the concrete surface. While they can exist at different planes between the reinforcing steel and the top surface of the concert deck, they are 
typically located at or just above the steel reinforcement layer [2]. With advancing corrosion, delaminations can progress to open spalls [2].

In recent decades, many non-destructive evaluation (NDE) methods have been developed to detect delaminations in concrete bridge decks. An ultrasonic stress pulse is used in techniques aiming for a high-frequency dynamic response (wave propagation), which include impact echo (IE), ultrasonic pulse echo (UPE), and ultrasonic surface wave (USW) testing. On the other hand, a low-frequency dynamic response is used in impulse response (IR) testing. In the latter method, specific characteristics of the dynamic response to a given impulse are evaluated to detect delaminations. In IR testing, an instrumented hammer is struck against the concrete surface to generate local vibrations, and the dynamic response is measured at a nearby location using a geophone or accelerometer. ASTM Standard C1740 provides guidance for evaluating the condition of concrete plates such as bridge decks using the IR method [4]. The frequency response function (FRF) is obtained by dividing the dynamic response by the impact force, where both signals are expressed in the frequency domain. The typical frequency range used to evaluate delamination ranges from 0 to $1 \mathrm{kHz}[4]$

In structural dynamics, modal analysis is the most popular approach for performing linearelastic structural system identification, where the modal parameters, i.e. natural vibration frequencies, mode shapes, and damping ratio, can be extracted and monitored over time [5]. Since these parameters are a function of the structural and material properties, they can be related to the initiation and propagation of damage [6]. Samman and Biswas [7][8]presented waveform-recognition techniques to detect damage in bridges and they 
applied these techniques to both laboratory and real-world conditions by detecting damage in a laboratory-sized bridge and a highway bridge. These techniques depend on a comparison between two dynamic signatures: one from an intact (= reference) state and the other from a state with a certain level of degradation. Zhou et al. [9] utilized vibrationbased damage detection (VBDD) methods to detect and localize low levels of damage in the deck of a two-girder, simply-supported bridge. They conducted their study using laboratory-based experimental and finite element analysis. The methods evaluated included the mode shape curvature method, the change in flexibility method, the damage index method, the change in uniform flexibility curvature method, and the change in mode shape method. They concluded that VBDD methods have excellent potential as structural health-monitoring tools for bridge decks. However, these methods require extracting the mode shapes, a process requiring multiple sensors. Additionally, there is difficulty in extracting the mode shapes for bride decks in the field. Kee et al. [10] used impact-echo (IE) testing in order to improve interpretation of the flexural vibration modes of delaminations detected in concrete bridge decks. This model was more accurate than conventional binary images for detecting the areal sizes of shallow delaminations. On the other hand, for deep delaminations, the conventional IE approach was more accurate. Finally, there are two challenges in using modal analysis methods for damage detection: first, it requires the dynamic response for the reference case, which is unavailable in most cases. Second, temperature variations can have a significant effect on the frequency response of the structure [11], and there is significant difficulty in distinguishing between the effects of temperature and damage. 
Generally, if a structural system fails to follow the principle of superposition, then it can be considered nonlinear [5][12][13], and linear-elastic modal analysis cannot be used to analyze the dynamic response. In reality, most structural systems show a certain level of nonlinear behavior [13]. The sources of nonlinearly can be summarized as [5]: (1) Geometric nonlinearity, when the structure exhibits large displacements, (2) material nonlinearity, when a material exhibits a nonlinear stress-strain response, (3) nonlinear boundary conditions, where imperfect boundary conditions cause nonlinear vibration, and (4) energy dissipation due to damping. This last phenomenon is still not fully understood.

For nonlinear vibrations, identification of a nonlinear structural system includes three steps. The first step is "Detection," where the excitation of nonlinearity in structural behavior is investigated. "Characterization" is the second step, where the source and location of nonlinearity is investigated, and how the source of nonlinearity behaves. The final step is "Parameter estimation." In this step, the coefficients of the nonlinearity are calculated, and their uncertainty quantified [5]. There are many identification methods that have been established in the preceding three decades, such as the restoring force surface method and NARMAX modeling [5][12].

Nonlinearity is important for damage detection of cases where damage changes the behavior of the structural form (initially) from linear to nonlinear [14]. Underwood et al. [15] investigated using nonlinear behavior for detecting and locating subsurface damage in composite materials by determining the frequency response function (FRF) of different input amplitudes without reference to previous historical reference measurements. Idriss et al. [16] found that nonlinear vibration parameters are much more sensitive to deboning 
damage in sandwich beams than linear vibration parameters. Zhao et al. [17] presented a new transmissibility analysis method for the detection and location of damage using the characteristics of nonlinear vibrations of structural multi-degree-of-freedom (MDOF) systems. Based on the nonlinear vibration response to an impact, Liu et al. [18] presented a new nondestructive testing method to predict the pretension force in membrane structures.

\subsection{Research Significance and Objective}

In this study, a Nonlinear Vibration Index (NVI) method is presented to detect damage in a reinforced concrete bridge deck using nonlinear vibration characteristics. This method does not require reference measurements for undamaged condition such as vibration base method. Therefore, it is considered as reference-free method. Additionally, this method does not require processing the data in a completed algorithm. Also, a frequency window is used in this method in order to reject the unwanted frequencies. Finally, although tests setup of Impulse Response (IR) is used NVI method, the data processing in NVI method is different.

In this study, a numerical model was used in order to explain the nonlinear vibration concept theoretically. The proposed method was applied to an in-service bridge deck slab. The deck had been visually inspected for delaminations prior to IR testing. The results shows the capability of the proposed method to detect deterioration in reinforced concrete bridge deck. 


\subsection{Proposed Nonlinear Vibration Index (NVI) Method}

The proposed method is based on the vibration response of a reinforced concrete deck in order to detect the deterioration or delamination. The same instruments that are used for impulse response (IR) testing and vibration-based methods are utilized here: A hammer impact is applied to the top surface of a bridge deck using an instrumented hammer and the vibration response at a nearby location measured with an accelerometer, as shown in Figure 4-1. Additionally, this approach requires applying at least two impact forces with varying magnitude at the same test location and measuring their vibration responses separately. Using the FRFs of these measurements, nonlinear behavior can be detected, which is indicative of damage. We refer to our proposed method as nonlinear vibration index (NVI) method.

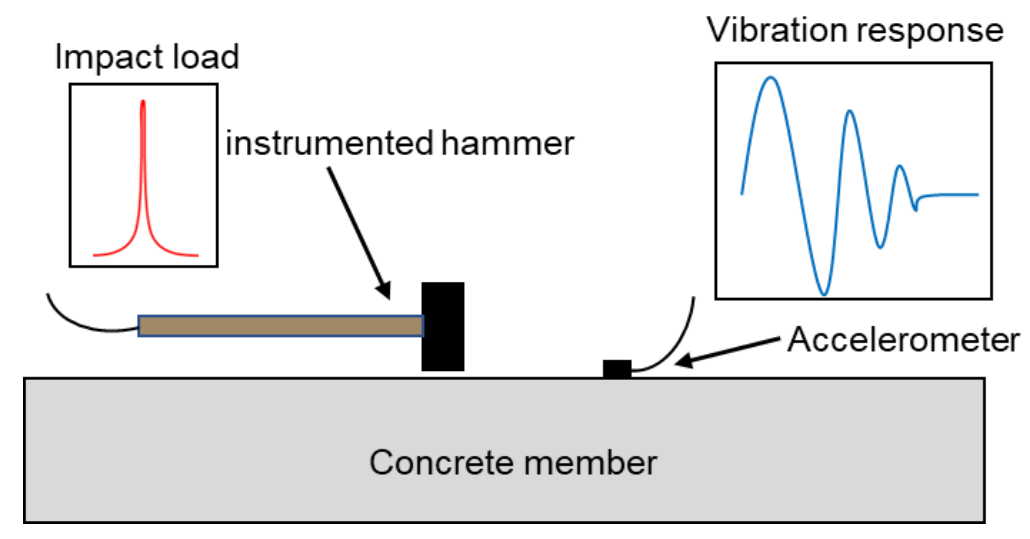

Figure 4-1. Illustration of impulse response (IR) test setup.

The principle of superposition plays a key role in investigating the excitation of the nonlinear vibration response of a concrete bridge deck, where only an undamaged linear structural system follows this principle. In other words, for an undamaged linear structural 
system, increasing the magnitude of the impact force does not change the FRF. In the case of a damaged system, which behaves nonlinear, the FRF is different for different impact forces. This feature was used to distinguish between undamaged linear and damaged nonlinear behavior.

In the proposed method, a bridge deck without deterioration or delamination is assumed to be a linear structural system, i.e. its FRF does not show any change due to an increase in the magnitude of the impact force. This is illustrated in Figure 4-2, where the FRFs of four increasing impact forces are shown from a select location on the bridge deck with no damage. Section 5 provides details about the bridge deck and data. From this figure, it can be observed that increasing the applied impact force, even doubling it, does not have a significant effect on the corresponding FRF, indicating linear behavior, which in turn indicates that no damage is present in the system.
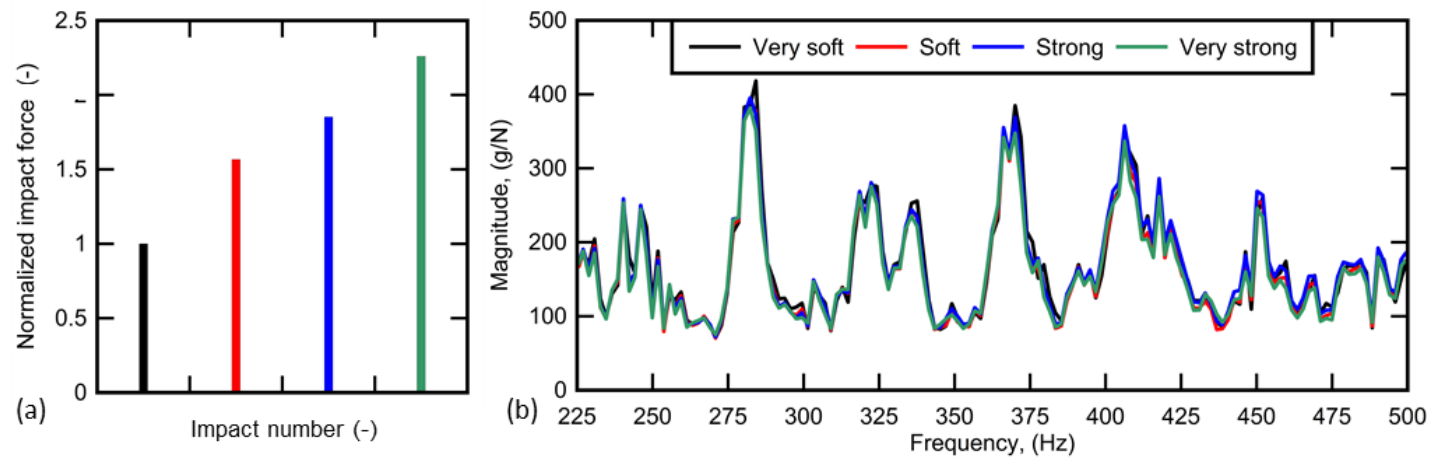

Figure 4-2. Sample for test location A1 (see Figure 4-9) on the selected bridge deck; (a) Impact forces and (b) FRFs.

In contrast, our hypothesis that if any area of a bridge deck fails to follow the principle of superposition, deterioration or delamination can be assumed to be present. The observed nonlinearity is assumed to be caused by crack boundary interaction. 
A number of methods exist to determine a parameter that represents the nonlinearity effect, see e.g. Idriss et al. [16] , Zhao et al. [17] and Liu et al. [18]. For linearization identification methods, the correlation coefficient or root mean square are typically used to estimate the nonlinearity parameter. Assuming two different impact forces (i.e. soft and strong), the proposed NVI is computed as follows:

$$
\begin{gathered}
F R F=H(f)=\frac{Y(f)}{X(f)}=\frac{G_{x y}(f)}{G_{x x}(f)} \\
\operatorname{COV}\left(H_{0}, H_{i}\right)(f)=\frac{1}{f-1} \sum_{J=1}^{f}\left(H_{0}-\mu_{H_{0}}\right)\left(H_{i}-\mu_{H_{i}}\right) \\
\rho_{H_{0}, H_{i}}(f)=\rho(f)=\frac{\operatorname{CoV}\left(H_{0}, H_{i}\right)(f)}{\sigma_{H_{0}} \sigma_{H_{i}}}=\frac{\sigma_{H_{0}, H_{i}}}{\sigma_{H_{0}} \sigma_{H_{i}}} \\
R^{2}(f)=\rho(f)^{2} \\
N V I=\frac{\sum_{f_{1}}^{f_{2} R^{2}(f)}}{f_{2}-f_{1}}
\end{gathered}
$$

where $Y(f)$ and $X(f)$ are the frequency domain representations of the response of the system and the impact force, respectively, $H_{0}$ and $H_{i}$ are the FRFs due to soft and strong impact forces, respectively, $\mathrm{COV}\left(H_{0}\right.$ and $\left.H_{i}\right)$ is the covariance between $H_{0}$ and $H_{i}, \rho$ is the correlation coefficient, $f_{1}$ and $f 2$ are the lower and upper limits of the selected frequency window, respectively, and $N V I$ is the nonlinear vibration index, which is a scalar indicating the level of nonlinearity of the structural system. NVI takes values between one and zero. When $H_{0}$ is equal to $H_{i}$, then NVI $=1$, implying the structural system is linear; otherwise, the structural system shows a certain level of nonlinearity.

Figure 4-3 shows an example coefficient of determination, $R^{2}$ as a function of the frequency. This coefficient was determined by comparing the FRFs of the very soft and 
very strong impact forces introduced in Figure 4-2. Finally, the normalized area under the coefficient of determination- frequency curve represents the nonlinear vibration index (NVI), which for this case is 0.98 .

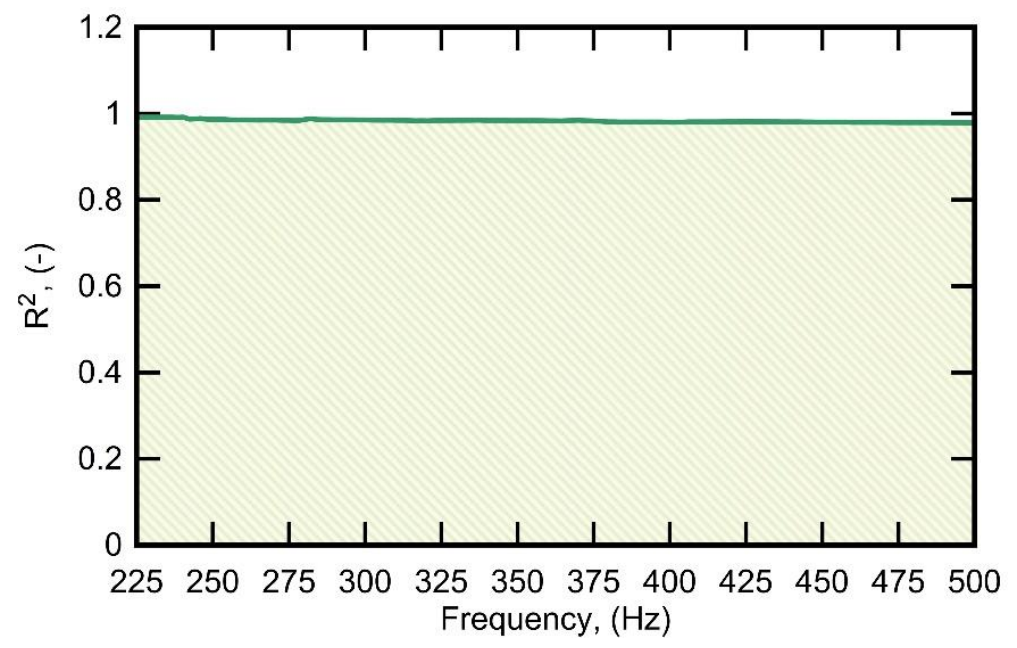

Figure 4-3. Example $R^{2}$ for FRFs very soft and very strong vs. frequency.

\subsection{Numerical Study}

\subsubsection{Modeling}

A finite element model was created to simulate the dynamic response of concrete bridge decks with and without delaminations theoretically. The objective was to study the effect of delaminations on the dynamic response and how they cause a nonlinear response. A concrete bridge deck was modeled as a simply-supported 2D beam using ABAQUS [19]. The model was created using quadrilateral elements, as shown in Figure 4-4. The span length is $1000 \mathrm{~mm}$ (39.4 in) and the depth is $240 \mathrm{~mm}$ (9.45 in). The material assigned for the deck is concrete with a modulus of elasticity, $E_{c}=23,520 \mathrm{MPa}(3,410 \mathrm{ksi})$ and a mass density, $\rho=2400 \mathrm{~kg} / \mathrm{m}^{3}\left(150 \mathrm{lb} / \mathrm{ft}^{3}\right)$. An impact force modeled after one observed in the 
field measurements (see Section 5) was applied as a distributed impact load over a length of $40 \mathrm{~mm}$, which corresponds to the diameter of the hammer tip. The acceleration response was measured at a point located $45 \mathrm{~mm}$ (1.77 in) from the applied impact force.

Two separate beams were modeled, referred to as Model 1 and 2: Model 1 represents the reinforced concrete beam without delaminations, i.e. an intact (or reference) beam. Model 2 represents the same beam as in Model 1 but with a delamination, which was modeled as a gap with the following dimensions: $0.5 \mathrm{~mm}$ (0.02 in) width and $800 \mathrm{~mm}$ (31.54 in) length, located in the center of the beam at a depth of $15 \mathrm{~mm}(0.59 \mathrm{in})$ (see Figure 4-4). In both models, eight impact forces were applied to the beams where the peak value of the impact force varied from 0.5 to $15 \mathrm{kN}$ ( 0.11 to $3.37 \mathrm{kip}$ ). This range was selected based on the actual forces measured in the field (see Section 5). A dynamic explicit step routine with a simulation time of 1 second was used. The dynamic response of all 16 simulations was analyzed and is discussed in the following section.

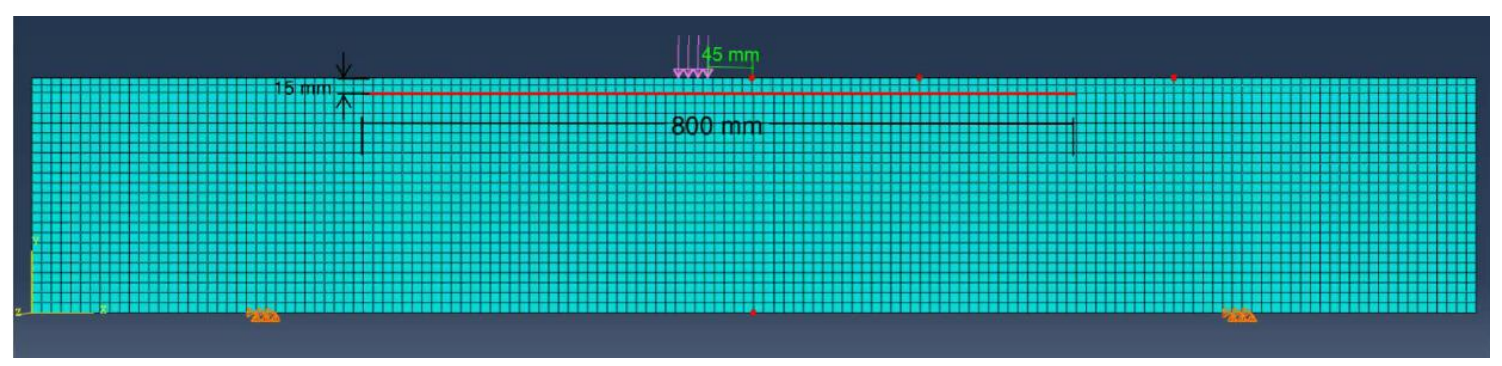

Figure 4-4. Illustration of the finite element model. The red line indicates the delamination (gap). The red point at the surface indicates the acceleration measurement point. The purple arrows indicate the distributed load applied on the deck. 


\subsubsection{Results and Discussion}

Figure 4-5 shows the FRF of the beam with and without delamination, i.e. Model 1 and Model 2), respectively, due to an impact force with a magnitude of $4 \mathrm{kN}$ (0.9 kip). Natural frequencies of the beam decrease because the delamination reduces the stiffness of the beam. Therefore, it can be observed that the delamination has a significant effect on the FRF.

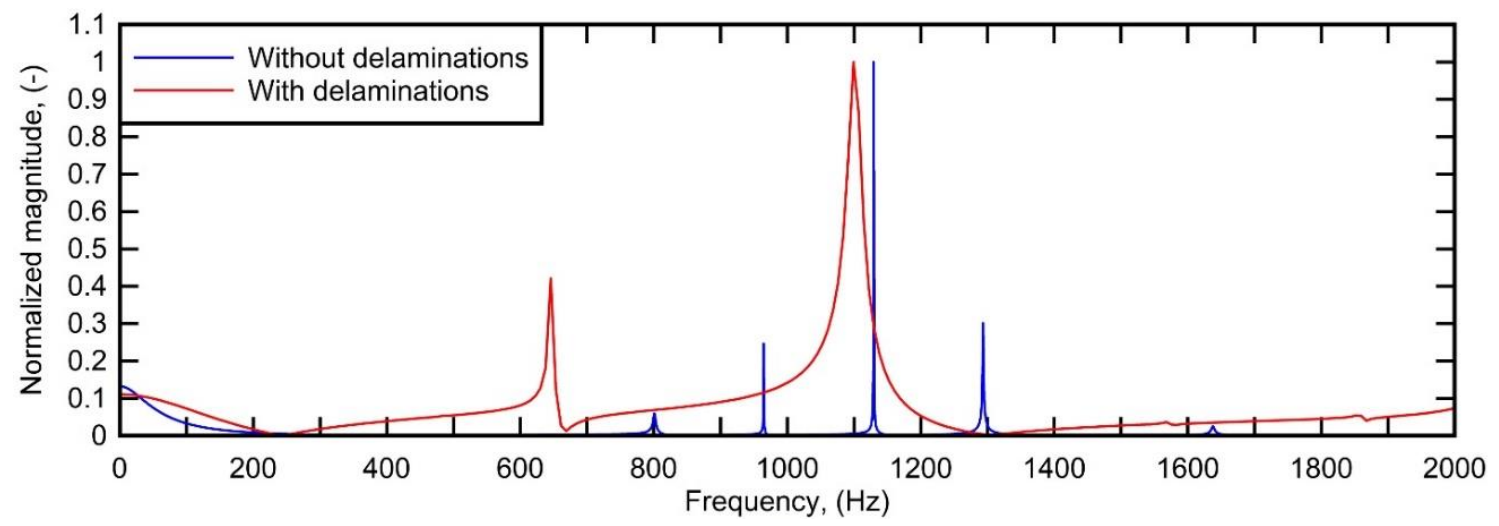

Figure 4-5. Two samples of FRFs for decks with and without delaminations; Magnitude

$$
\text { of impact force }=4 \mathrm{kN}(0.9 \mathrm{kip}) \text {. }
$$

The FRF response of the beam without delamination does not change due to increasing the impact force value ranging from 0.5 to $15 \mathrm{kN}$ (0.11 to $3.37 \mathrm{kip})$, as shown in Figure 4-6.a. On the other hand, increasing the value of the impact force has an influence on the FRF of the beam with delamination. This influence appears as a change in the magnitude of the FRF where the magnitude of the select peak decreased with increasing impact force, as shown in Figure 4-6.b. 

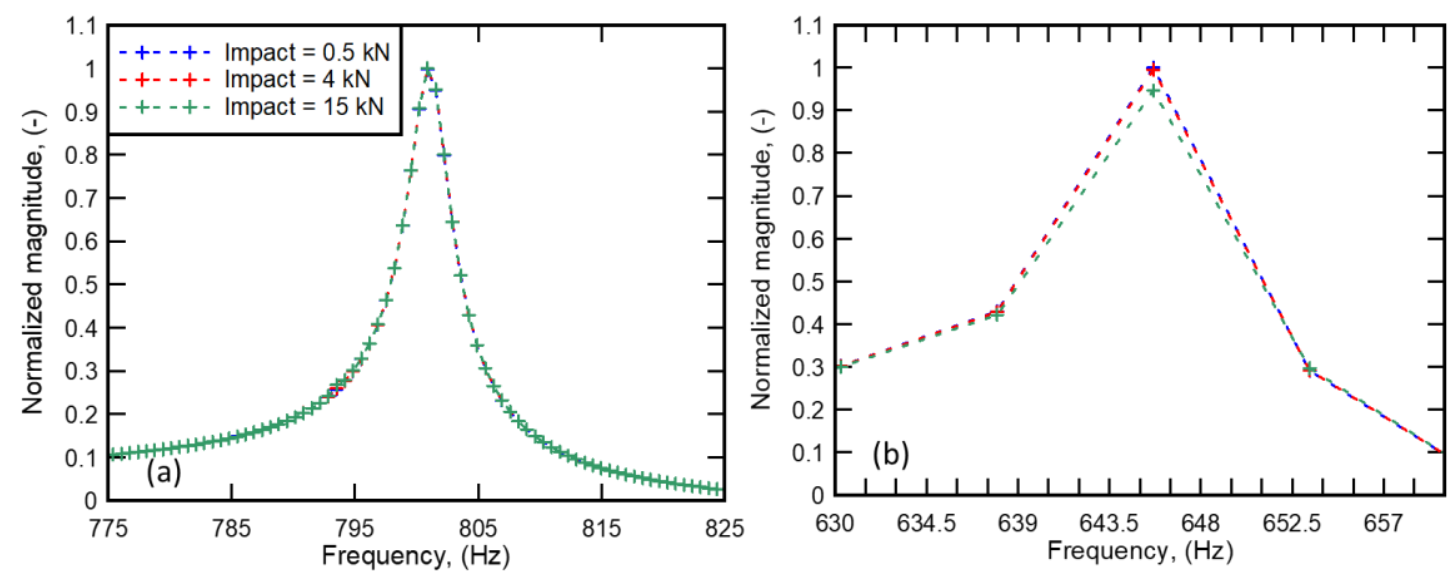

Figure 4-6. Three samples of FRF (first peak) for impact force magnitude $=0.5,4$ and 15

$\mathrm{kN}$ :

(a) Model 1 (reference) and (b) Model 2 (with delamination).

Figure 4-7 shows a comparison of the first peak in the FRF for both models as a function of the normalized impact force magnitude. For Model 1 (reference) it can be observed that there is a minor increase in the peak response, which might be associated with certain geometric nonlinearities associated with the boundary conditions or the uncertainty of the numerical solution by ABAQUS. Model 2 (with delamination), however, shows a clear decrease in the peak response after the load exceeds approximately $4 \mathrm{kN}$. This behavior can be associated with the contact interaction of the lower and upper boundaries of the gap, where the relative vibration deformations of these boundaries is larger than the gap width. These numerical simulations proof that changes of the FRF are sensitive to the presence of delaminations. It can be speculated that other types of deterioration and cracking will have a similar but smaller effect. 


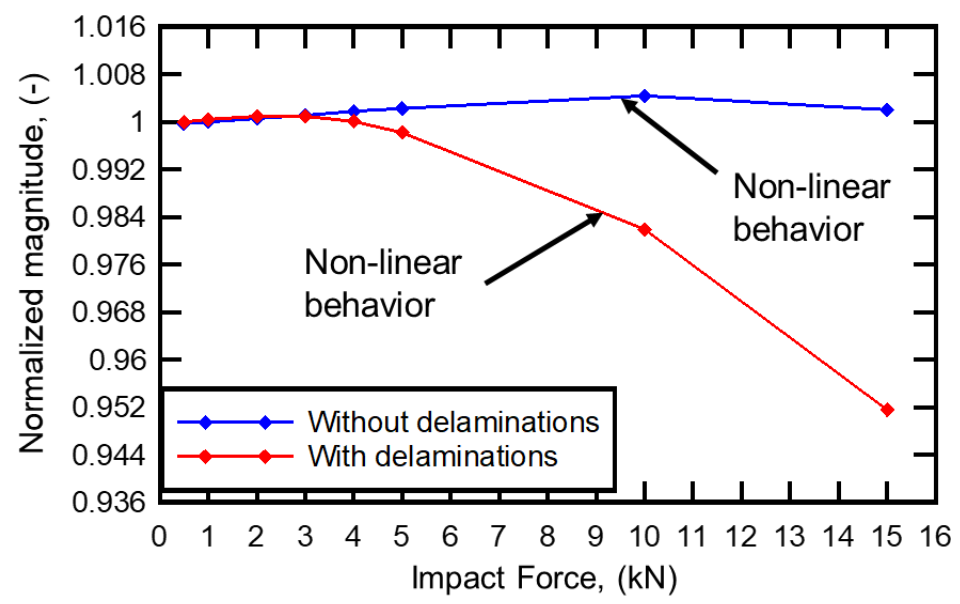

Figure 4-7. Maximum peak value of FRF corresponding to first peak frequency for both models vs. peak impact force value.

\subsection{Field Study}

\subsubsection{Description of Selected Bridge}

A 25 year old bridge in Branchport, NJ was selected to evaluate the proposed NVI method's ability to detect deteriorated areas in reinforced concrete bridge decks. The bridge, presented in Figure 4-8, has a total length of $216 \mathrm{ft}(65.83 \mathrm{~m})$ and is $37 \mathrm{ft}(11.28 \mathrm{~m})$ wide. The superstructure consists of six $36 \mathrm{ft}(10.97 \mathrm{~m})$ long two-span sections with steel girders carrying an 8.5 to 12 in (216 to $305 \mathrm{~mm}$ ) thick reinforced concrete deck, as shown in Figure 4-8.c. Due to the harsh environment combined with exposure of chlorides from seawater and deicing, the bridge deck exhibited severe visual distress. Five deck sections were severely deteriorated, showing visible signs of spalling, potholes, and in some locations exposure of the steel reinforcing bars. The deck selected for this study (see Figure 4-8.a and b) showed no visual distress and hammer sounding revealed only two small areas with delaminations. 

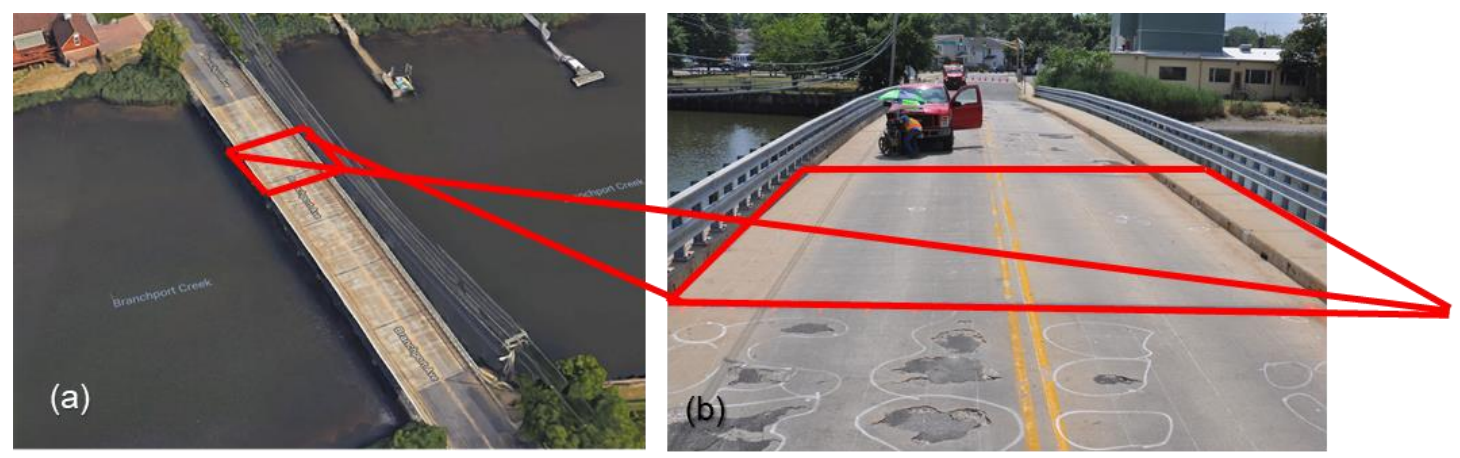

(c)

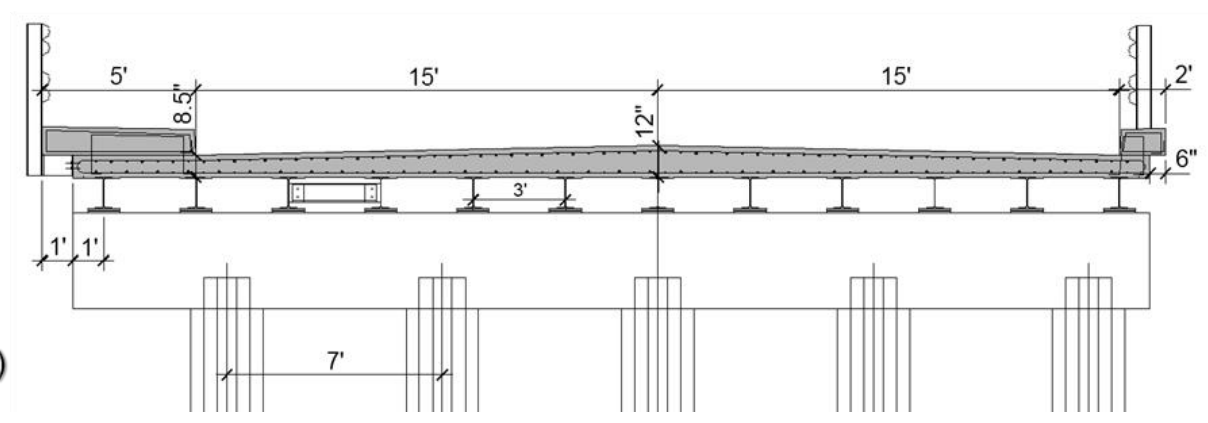

Figure 4-8. Bridge in Branchport, NJ: (a) Google map image showing selected slab (\#2) used as part of this study, (b) photo from a driver's perspective, and (c) cross-section with dimensions in (in).

Since the county had planned to rehabilitate the bridge deck, this represented an opportunity to evaluate a variety of NDT methods by comparing their results with the removed concrete. Some of the work is reported in [20]. The NDT surveys were completed in July 2011, hydro-blasting to remove surface as well as deteriorated concrete was performed in March 2013. Before new concrete was placed in July 2013, the depth of the removed concrete was measured on a $2 \times 2 \mathrm{ft}(0.61 \times 0.61 \mathrm{~m})$ grid.

\subsubsection{Test Setup and Procedure}

A typical impulse response (IR) test setup was used, as illustrated in Figure 4-1. The used hammer (PCB, Model 086D20) weighs $1.5 \mathrm{lb}(0.67 \mathrm{~kg})$ and has a 2 in $(51 \mathrm{~mm})$ diameter hard- 
plastic hammer tip (1500 lb-peak (6.67 kN-peak)). It is equipped with a piezoelectric load cell connected to a signal amplifier/conditioner to measure the generated impact force. The vibration response was measured using a capacitive MEMS accelerometer (Silicon Designs-Model-2260-010) that has a flat frequency response within $3 \mathrm{~dB}$ over the range of 0 to $1 \mathrm{kHz}$. Both input (force) and output (acceleration) signals were recorded using a highspeed transient recorder (Elsys, Model TraNET 204s) at a sampling frequency of $500 \mathrm{kHz}$.

The two-lane traffic portion of Deck \#2, measuring 30 x $36 \mathrm{ft}(9.14 \times 10.97 \mathrm{~m})$, was divided into a $2 \times 2 \mathrm{ft}(610 \times 610 \mathrm{~mm})$ test grid, resulting in 270 test locations, as shown in Figure 4-9.a. Two locations were selected for coring and are highlighted by solid black circles. Hammer impacts were applied at each test point manually four times with different intensities, referred to as very soft, soft, strong, and very strong, as illustrated in Figure 4-9.b.

(a)

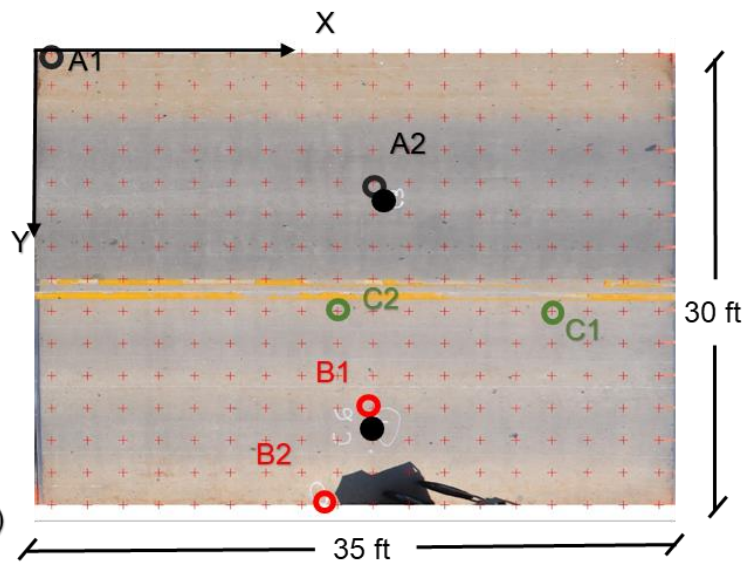

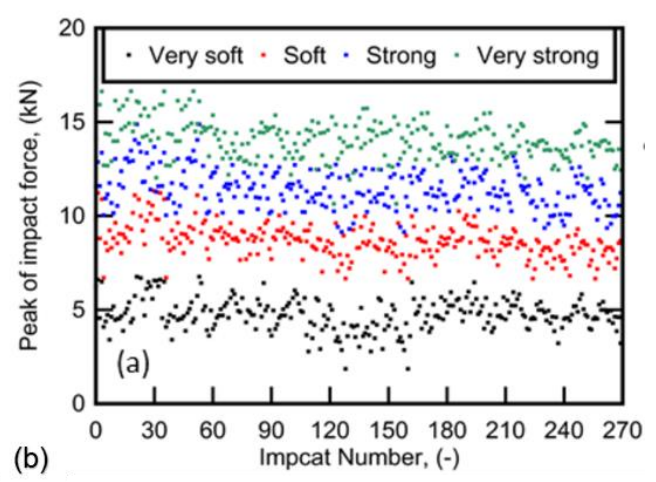

Figure 4-9. (a) Plan view photo of Deck \#2 with test grid (red '+'), sample results (A1, B1, B2, C1, C2), and cores (full black circles) and (b) peak impact forces for all 270 test locations. 
Figure 4-10 shows sample time histories of impact forces with different levels of magnitude and the corresponding acceleration responses.
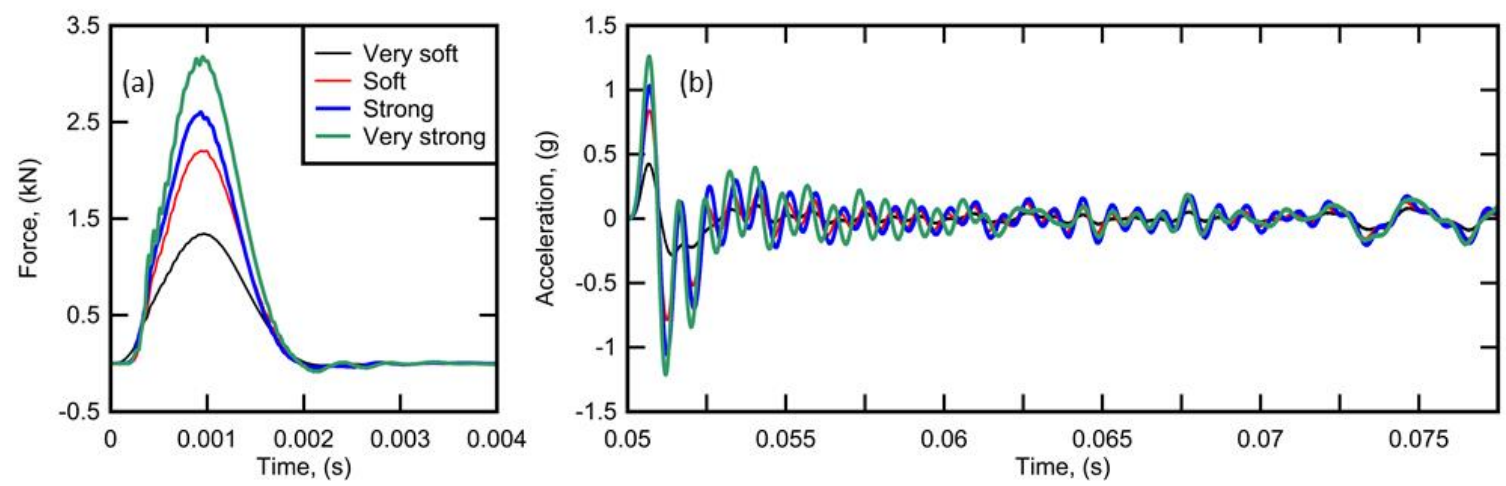

Figure 4-10. Samples of: (a) Four impact forces and (b) four corresponding acceleration responses for one select test point.

\subsubsection{Results and Discussion}

\subsubsection{Sources of Nonlinearity}

A structural member may exhibit nonlinear vibrations due to a number of causes. For the type of structural system investigated in this study, the causes may be limited to two: material nonlinearity and crack boundary interaction. There are two causes that lead to concrete behaving nonlinearly under a static or dynamic loads. First, the nonlinear relationship between the applied stress and resulting strain. In order to ensure that this is not the case in this study, the stresses generated from the impact forces were calculated and compared with the stress-strain relationship of the concrete. The generated stress for each impact force was calculated by dividing the peak of the force by the hammer tip area. Since the actual stress-strain relationship of the tested bridge was not available, the empirical Carreira and Chu equation was used [21]. Figure 4-11 shows this stress-strain relationship 
by assuming a conservative concrete compressive strength, $f_{c}{ }^{\prime}=3,000 \mathrm{psi}(20.7 \mathrm{MPa})$. It can be observed that all generated stresses lie within the linear limit, which is typically assumed to lie at $40 \%$ of $f_{c}$ ' (shown as black dashed line). The ranges of generated stresses for very soft and very strong impact forces are provided for reference. As a conclusion, in this study, the effect of the nonlinear stress-strain relationship of concrete can be excluded as a cause of nonlinear vibration.

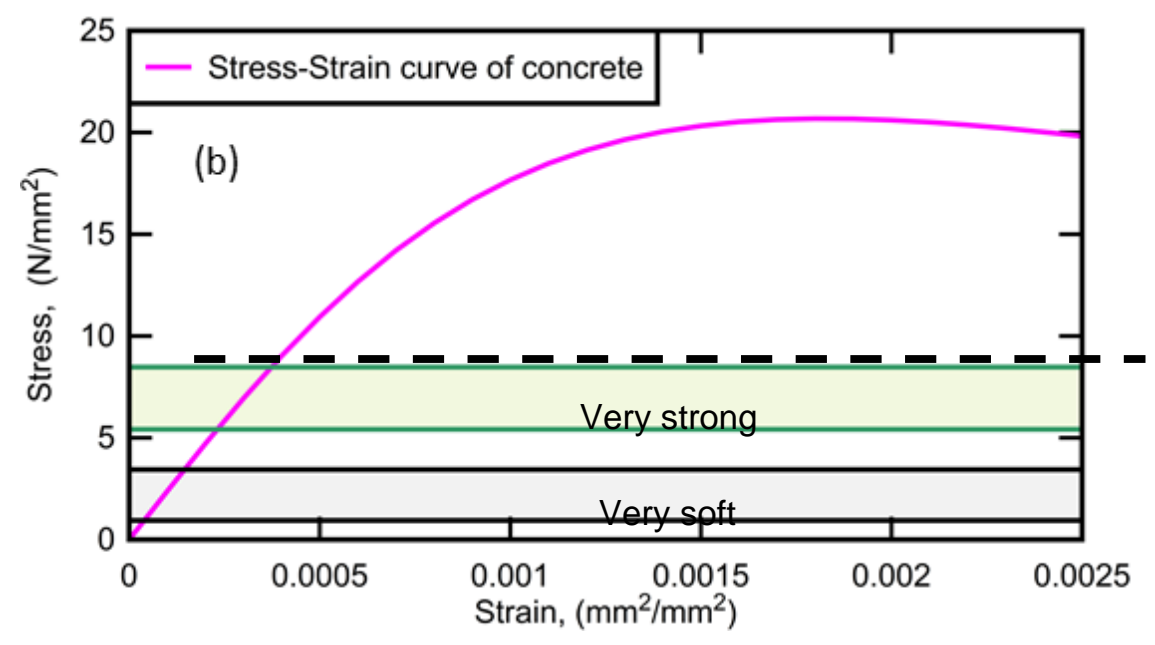

Figure 4-11 Empirical Stress-Strain relationship [21] and generated stress ranges due to very soft (grey) and very strong (green) impact forces. The black dashed line represents the assumed linearity limit for this concrete.

Concrete degradation is the second factor in leading the concrete to respond nonlinearly to a load (static or dynamic). Due to the effects of aging, the environment, exposure to chlorides, and live loads, distributed micro cracks can form inside the concrete. These cracks open and close during vibrations, which is referred to as crack breathing. Although the cracks are small in this case, they can still cause a nonlinear vibration response. 
Therefore, the proposed NVI method should theoretically be able to detect degradation of this type in a concrete bridge deck.

A shallow delamination in a concrete bridge deck is a discrete horizontal macro crack located between the top rebar mesh and the top surface. While a delamination is distinctly different from distributed micro cracks, the crack breathing model still applies; in fact, it can be hypothesized that it is much more pronounced for this case.

\subsubsection{Select NVI Results}

As shown in numerous investigations, the crack-boundary interaction of delamination can cause nonlinear vibrations due to the effects of the crack breathing phenomenon [22]. In this section, results from six test locations on Deck \#2 were selected and are discussed in detail to evaluate the proposed NVI method. These six test locations were divided into three groups (A, B, and C) according to the observed results from the proposed method, cores and visual inspection. and each group consists of two test locations (see Table 4-1). Note that "very soft" serves as the reference case for the three other impact forces (soft, strong, and very strong). In order to estimate the nonlinearity of test locations using the proposed method, a frequency range of 225 to $500 \mathrm{~Hz}$ was selected. The lower limit of this window was chosen to exclude low-frequency noise caused by traffic, wind, etc. The upper limit was selected to minimize the effect of nonlinearity of the used accelerometer. In a previous study the authors used the same instrumentation and found this type of nonlinear vibration response to start at approximately $600 \mathrm{~Hz}$ [23]. Therefore, the upper limit was conservatively set to $500 \mathrm{~Hz}$. 
Table 4-1. Six selected test location coordinates and their NVI values.

\begin{tabular}{|c|c|c|c|c|c|c|}
\hline Group & $\begin{array}{c}\text { Location } \\
\text { (see Figure }\end{array}$ & $\begin{array}{c}\mathrm{X} \\
\text { 4-9.a) }\end{array}$ & $\mathrm{ft}(\mathrm{m}))$ & $\mathrm{Y}$ & \multicolumn{3}{|c|}{ NVI value (-) } \\
\cline { 5 - 7 } & $\mathrm{ft}(\mathrm{m}))$ & & Soft & Strong & $\begin{array}{c}\text { Very } \\
\text { strong }\end{array}$ \\
\hline \multirow{2}{*}{$\mathrm{A}$} & $\mathrm{A} 1$ & $1(0.30)$ & $1(0.30)$ & 0.99 & 0.98 & 0.98 \\
\cline { 2 - 7 } & $\mathrm{A} 2$ & $19(5.79)$ & $9(2.74)$ & 0.98 & 0.98 & 0.97 \\
\hline \multirow{2}{*}{$\mathrm{B}$} & $\mathrm{B} 1$ & $19(5.79)$ & $23(7.01)$ & 0.63 & 0.49 & 0.44 \\
\cline { 2 - 7 } & $\mathrm{B} 2$ & $17(5.18)$ & $29(8.84)$ & 0.96 & 0.91 & 0.98 \\
\hline \multirow{2}{*}{$\mathrm{C}$} & $\mathrm{C} 1$ & $29(8.84)$ & $17(5.18)$ & 0.38 & 0.25 & 0.05 \\
\cline { 2 - 7 } & $\mathrm{C} 2$ & $17(5.18)$ & $17(5.18)$ & 0.89 & 0.88 & 0.86 \\
\hline
\end{tabular}

Group A represents two test locations that were not found to have any form of degradation by visual inspection. Figure 4-2 shows the FRF of test location A1, as well as the peak impact forces. Recall from the discussion in Section 3, although the impact force was more than doubled, this only had a very minor effect on the FRF, which means the system is linear. The FRF of test location A2 is also not significantly affected by the increase of the impact force, as can be observed in Figure 4-12. Since any structure will demonstrate a certain level of nonlinearity, $3 \%$ can be interpreted as the uncertainty in the NVI value for non-degraded locations in this study. The concrete core taken near test location A2 was further proof that this location is in healthy condition, as shown in Figure 4-12.a. In conclusion, areas on the bridge deck that do not show signs of nonlinear vibration behavior can be considered healthy, i.e. free of degradation or delaminations, which supports the hypothesis of our proposed method. 

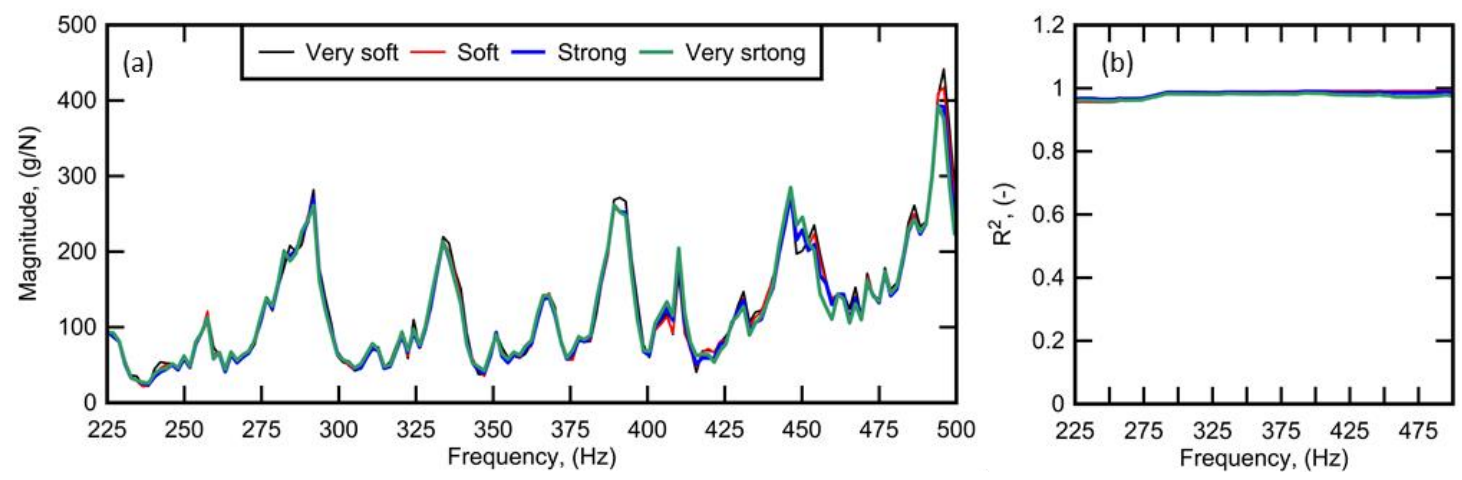

Figure 4-12. (a) FRF response of test location A2 and (b) $R^{2}$ - frequency relationship.
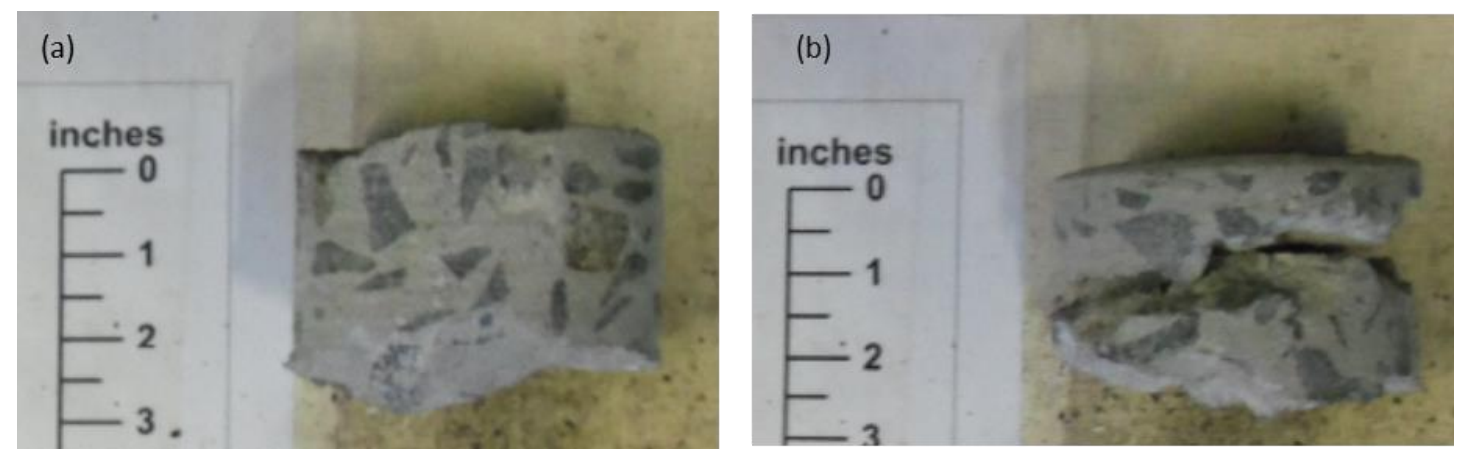

Figure 4-13. Photos of extracted concrete cores: (a) Cr1 (near A2) and (b) Cr2 (near B1).

Group B represents two test locations that were marked having delaminations according to visual inspection. The FRFs for the Group B locations are presented in Figs. 14 and 15. It can be observed that the FRFs are significantly affected with increasing impact force, leading to low $R^{2}$ functions. Additionally, along with increases in the intensity of the impact force, the change in the FRF increases resulting in a decrease in the NVI value, as shown in Table 4-1. This behavior is distinctly different from the one of Group A. These results also match the core taken near test location B1, which shows a horizontal crack, as shown in Figure 4-13.b. As a final conclusion, the Group B results are consistent with the hypothesis of our proposed method, which means it can be used to detect delaminations. 
The NVI values for test location $\mathrm{B} 2$ are not as low as for $\mathrm{B} 1$, which is where visual inspection found a small delaminated area.
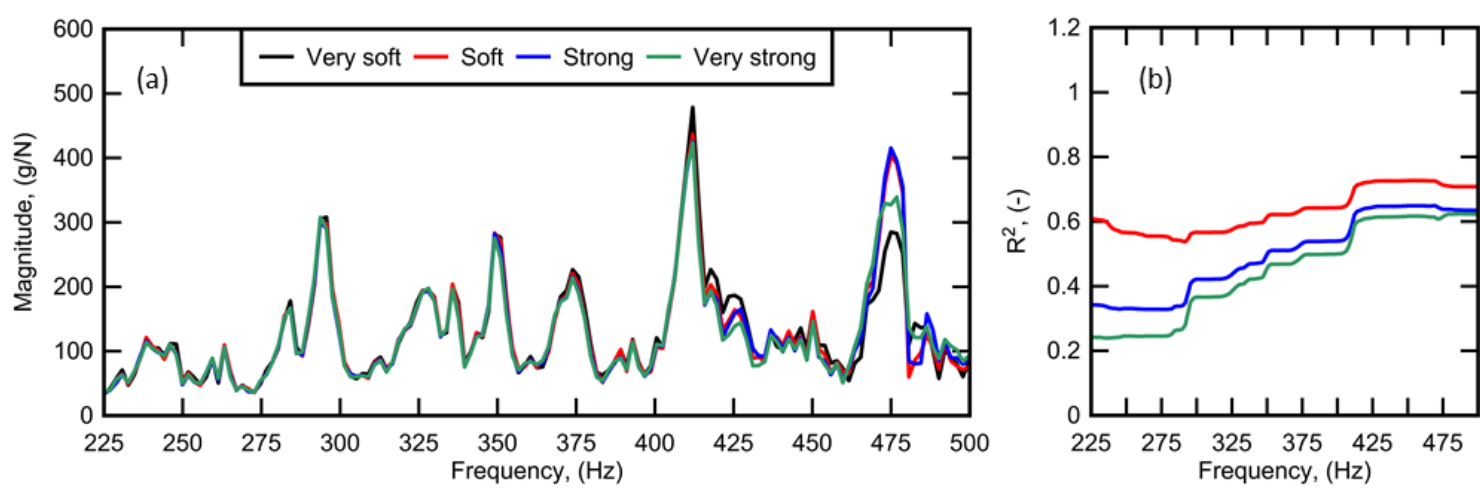

Figure 4-14. (a) FRF response of test location B1 and (b) $R^{2}$ - frequency relationship.
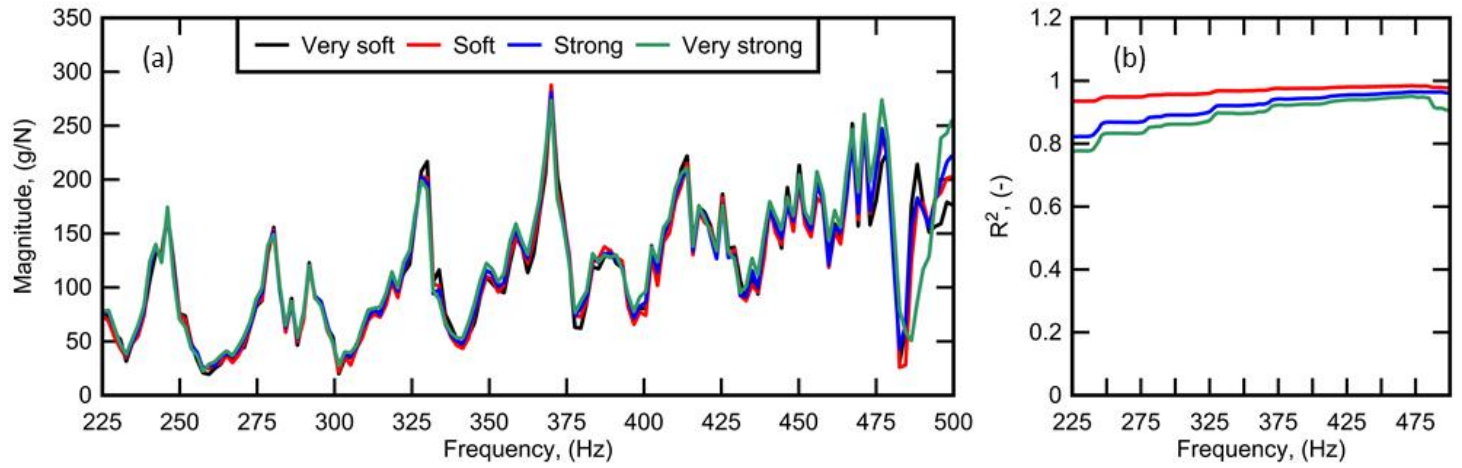

Figure 4-15. (a) FRF response of test location B2 and (b) $R^{2}$ - frequency relationship.

Group $\mathrm{C}$ represents two test locations that exhibited nonlinear vibration behavior, but where the visual inspection did not find any degradation or delaminations. The two associated test locations showed strong nonlinear vibration behavior, as shown in their FRFs (see Figs. 16 and 17). Unfortunately, no cores were available for the Group C test locations. However, the NVI results could be compared with the depth of the removed concrete after hydro-blasting was performed, which is discussed in more detail in Section 
5.3.3. The depth of removed concrete for these locations was approximately $1.6 \mathrm{in}(40 \mathrm{~mm})$ for $\mathrm{C} 1$ and $\mathrm{C} 2$, which can be considered relatively high. Assuming that hydro-jetting removes more depth when the concrete is degraded, they hypothesis that the NVI method can detect degradation is also supported.
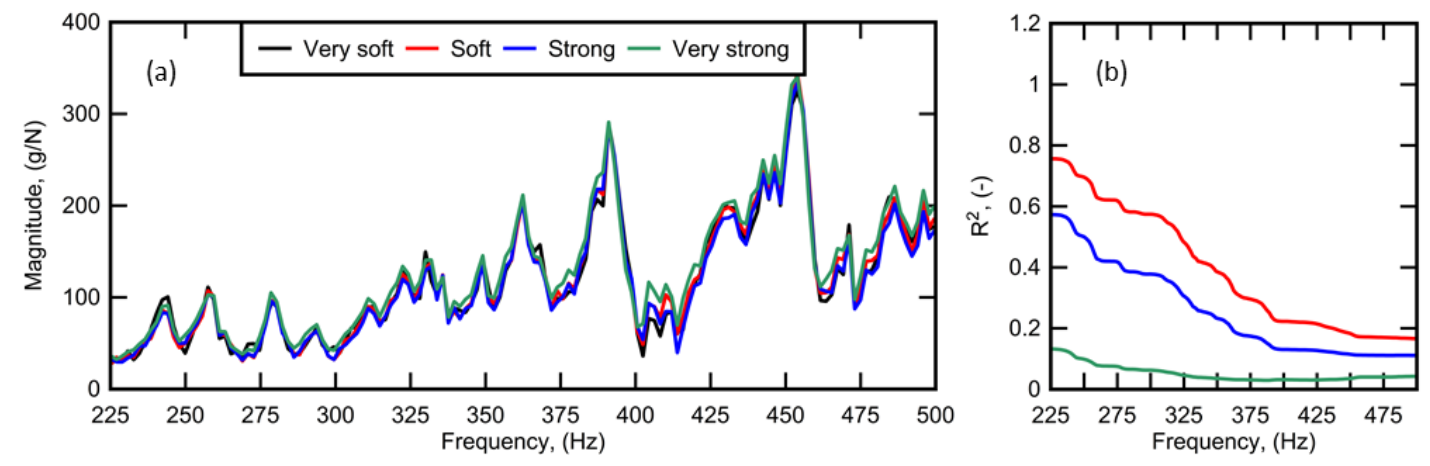

Figure 4-16. (a) FRF response of test location $\mathrm{C} 1$ and (b) $R^{2}$ - frequency relationship.
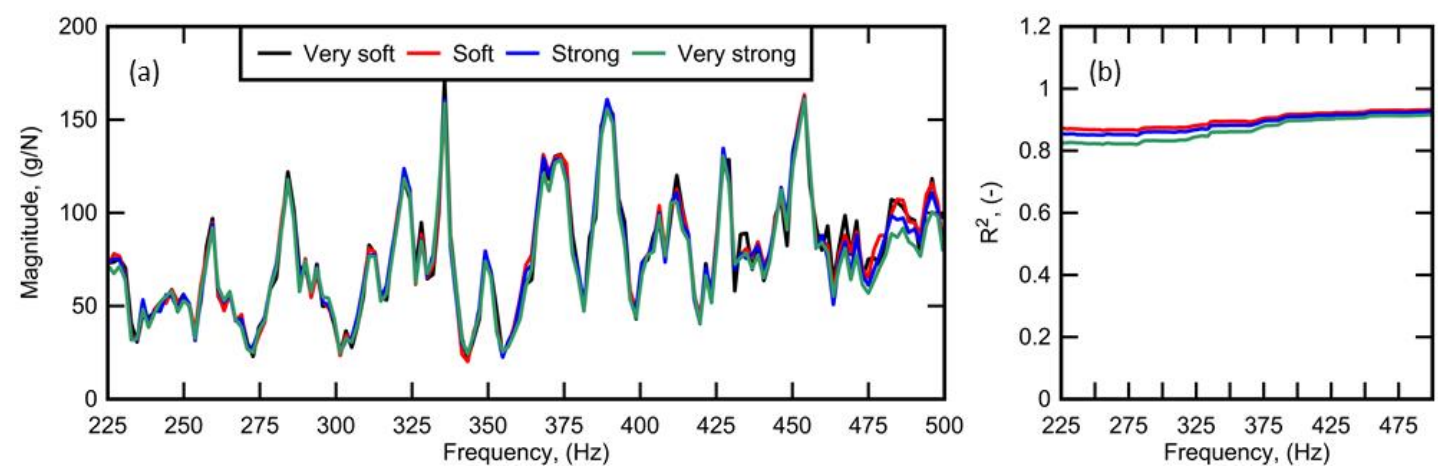

Figure 4-17. (a) FRF response of test location C2 and (b) $R^{2}$ - frequency relationship.

Since only two cores were available for the entire deck, a comparison between the NVI results and depth of removed concrete was the only way to evaluate the proposed method for all 270 test locations, which is discussed in the subsequent section. 


\subsubsection{Comparison of NVI and Removed Concrete for Entire Deck \#2}

Figure 4-18 shows a contour plot of the NVI values (a) and depth of concrete removed by hydro-blasting (b) across the entire Deck \#2. NVI values were computed between the very soft (= reference) and very strong impact forces. Both NVI results and depth of the removed concrete agree that there is a large degraded or delaminated area as highlighted by black boxes. Additionally, both figures show that the area highlighted by gray dashed boxes are in healthy condition. On the other hand, the NVI method missed a literal hole in the deck found after hydro-blasting, as highlighted by the red box. Also, the NVI values predicted degradation or delaminations in four areas (highlighted by blue boxes) that are not associated with a high depth of removed concrete. The discrepancies between NVI values and depth of removed concrete is likely due to the fact that removed concrete is not necessarily always an accurate predictor of degradation and delaminations. At the same time, total removed concrete is the likely the single most important quantity determining rehabilitation cost. 

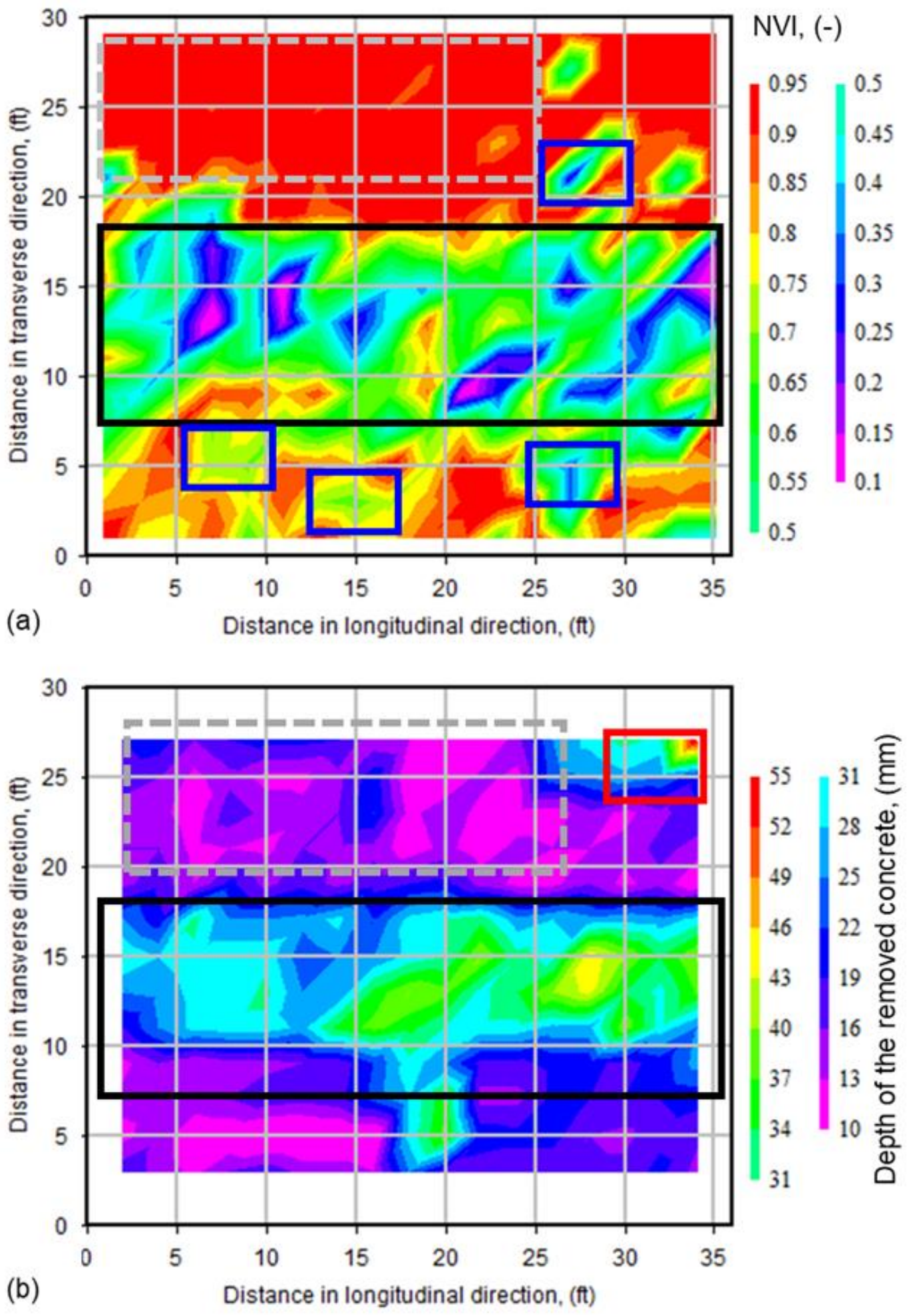

Figure 4-18. (a) NVI values and (b) depth of removed concrete for Deck \#2. 


\subsection{Conclusions}

The presented results demonstrate the potential for our proposed NVI method to detect degradation and delaminations in a reinforced concrete bridge deck. The NVI method is based on the concept of linear and nonlinear vibration response, which is determined by computing the frequency response functions (FRFs) for a set of increasing impact forces and comparing them. The hypothesis was that if the FRFs remain constant and change, this can be associated with healthy and degraded deck sections, respectively. A numerical study using a finite element model showed that nonlinear behavior was indeed exhibited for a deck with a delamination.

The proposed method was applied to an in-service bridge deck using impulse response testing equipment. The results of this field study are consistent with the proposed hypothesis. A comparison between NVI results and visual inspection and concrete cores for six test locations showed that:

1. NVI results were able to distinguish areas in the bridge deck that did not have degradation or delaminations. Additionally, NVI results were in excellent agreement with visual inspection and core test results.

2. A strong match was found between the results of the NVI method and visual inspection and cores for detecting areas that could have degradation or delaminations.

3. The NVI technique could detect degraded or delaminated areas that were missed by visual inspection. 
4. A comparison between NVI values and depth of the removed concrete showed acceptable agreement in terms of areas of degradation or delaminations.

It should be noted that the proposed method cannot distinguish the type of degradation. Also, it cannot predict the depth of delaminations or removed concrete. However, ongoing research is studying these limitations and trying to reduce the uncertainty of the predictions.

\section{Acknowledgment}

The authors thank the Higher Education Committee of Iraq for supporting the first author. Equipment was provided by the Department of Civil and Environmental Engineering at the University of Delaware. Access to the bridge as well as traffic management during testing was provided by Dr. Kaz Tabrizi and Dr. Manuel Celaya from Advanced Infrastructure Designs and Greg Bitsko from Cherry Weber \& Associates, which is greatly appreciated. 


\section{References}

[1] Scott, M., Rezaizadeh, A., Delahaza, A., Santos, C. G., Moore, M., Graybeal, B., and Washer, G., 2003, “A Comparison of Nondestructive Evaluation Methods for Bridge Deck Assessment," NDT and E International, pp. 245-255.

[2] Gucunski, N., and Council, N. R., 2013, Nondestructive Testing to Identify Concrete Bridge Deck Deterioration, Transportation Research Board.

[3] Zhang, G., Harichandran, R. S., and Ramuhalli, P., 2012, “Automatic Delamination Detection of Concrete Bridge Decks Using Impact Signals," Journal of Bridge Engineering, 17(6), pp. 951-954.

[4] ASTM C1740, 2016, Standard Practice for Evaluating the Condition of Concrete Plates Using the Impulse-Response Method, West Conshohocken, PA.

[5] Kerschen, G., Worden, K., Vakakis, A. F., and Golinval, J.-C., 2006, "Past, Present and Future of Nonlinear System Identification in Structural Dynamics," Mechanical Systems and Signal Processing, 20(3), pp. 505-592.

[6] Doebling, S. W., Farrar, C. R., and Prime, M. B., 1998, “A Summary Review of Vibration-Based Damage Identification Methods," The Shock and Vibration Digest, 30(2), pp. 91-105.

[7] Samman, M. M., and Biswas, M., 1994, "Vibration Testing for Nondestructive Evaluation of Bridges. II: Results," Journal of Structural Engineering, 120(1), pp. 290-306. 
[8] Samman, M. M., and Biswas, M., 1994, "Vibration Testing for Nondestructive Evaluation of Bridges. I: Theory," Journal of Structural Engineering, 120(1), pp. 269-289.

[9] Zhou, Z., Wegner, L. D., and Sparling, B. F., 2007, "Vibration-Based Detection of Small-Scale Damage on a Bridge Deck," Journal of Structural Engineering, 133(9), pp. 1257-1267.

[10] Kee, S.-H., and Gucunski, N., 2016, "Interpretation of Flexural Vibration Modes from Impact-Echo Testing,” Journal of Infrastructure Systems, 22(3), p. 4016009.

[11] Zhou, H. F., Ni, Y. Q., and Ko, J. M., 2011, "Eliminating Temperature Effect in Vibration-Based Structural Damage Detection," Journal of Engineering Mechanics, 137(12), pp. 785-796.

[12] Noël, J. P., and Kerschen, G., 2017, "Nonlinear System Identification in Structural Dynamics: 10 More Years of Progress," Mechanical Systems and Signal Processing, 83, pp. 2-35.

[13] Lin, R., 1991, "Identification of the Dynamic Characteristics of Nonlinear Structures," Imperial College London.

[14] Worden, K., and Tomlinson, G., 2001, "NONLINEARITY IN Detection , Identification and Modelling," Physics.

[15] Underwood, S. S., Meyer, J. J., and Adams, D. E., 2015, “Damage Localization in Composite Structures Using Nonlinear Vibration Response Properties," Journal of 
Vibration and Acoustics, 137(3), p. 031015.

[16] Idriss, M., E1 Mahi, A., and El Guerjouma, R., 2015, “Characterization of Sandwich Beams with Debonding by Linear and Nonlinear Vibration Method," Composite Structures, 120, pp. 200-207.

[17] Zhao, X. Y., Lang, Z. Q., Park, G., Farrar, C. R., Todd, M. D., Mao, Z., and Worden, K., 2015, “A New Transmissibility Analysis Method for Detection and Location of Damage via Nonlinear Features in MDOF Structural Systems," IEEE/ASME Transactions on Mechatronics, 20(4), pp. 1933-1947.

[18] Liu, C.-J., Todd, M. D., Zheng, Z.-L., and Wu, Y.-Y., 2017, “A Nondestructive Method for the Pretension Detection in Membrane Structures Based on Nonlinear Vibration Response to Impact," http://dx.doi.org.ezlibproxy1.ntu.edu.sg/10.1177/1475921716686171.

[19] Dassault Systèmes, 2012, “Abaqus 6.12,” Notes.

[20] Celaya, M., Schumacher, T., Tabrizi, K., Bitsko, G., and Shokouhi, P., 2014, "Field Verification of Nondestructive Testing Technologies for Condition Assessment of Concrete Bridge Decks: A Case Study," NDE/NDT for Structural Materials Technology for Highway \& Bridges, pp. 36-44.

[21] Carreira, D. J., and Chu, K.-H., 1985, "Stress-Strain Relationship for Plain Concrete in Compression," Journal Proceedings, pp. 797-804.

[22] Giannini, O., Casini, P., and Vestroni, F., 2014, "Nonlinear Harmonic Identification 
of Cracks in Structures," Conference Proceedings of the Society for Experimental Mechanics Series, pp. 207-217.

[23] Hafiz, A., and Schumacher, T., 2019, "Effects of Elastic Supports and Flexural Cracking on Low and High Order Modal Properties of a Reinforced Concrete Girder," Engineering Structures, 178. 


\section{Chapter Five: Conclusions and Outlook}

\subsection{Summary and Conclusion}

Condition evaluation of reinforced concrete members is the focus of this $\mathrm{PhD}$ dissertation research, as concrete is widely used as construction material for civil infrastructures. The dynamic response of reinforced concrete members was used to evaluate or monitor condition changes. Both the low and high frequency ranges of the dynamic response of reinforced concrete members were investigated assuming that both are essentially wave phenomena. While it is commonly understood that the capability to sense damage is limited by the investigated wavelength, this research shows that this is only true for conventional linear approaches such as time-of-flight ultrasound and linear vibrations. By studying diffuse (or coda) ultrasonic waves and non-linear vibration responses, new techniques capable of sensing minute internal changes in a material or low-level stiffness changes, respectively, can be developed. Digital signal processing (DSP) was employed throughout this dissertation research, in particular operating in the frequency domain of the recorded data. Thus, employing Fourier analysis is a core component in the mathematical procedures used in this work in order to calculate frequency response functions (FRFs) and magnitudesquared coherence (MSC). While researchers have developed many NDE methods and new sensors in the recent decades, developing more sensitive, accurate, and quantitative methods and tools is still in demand. In this PhD dissertation, two novel NDE techniques are proposed:

- Ultrasonic coda wave comparison (CWC) technique: This SHM technique makes use of the highly sensitive coda wave portion of a recorded ultrasonic signal to monitor 
condition changes in reinforced concrete members. Traditionally, only the time-offlight (TOF) has been considered (e.g. ultrasonic pulse velocity method) but this is not sensitive to minute and slowly-varying changes in concrete. Since the entire recorded signal is used for analysis, changes that are not in the direct wave travel path can also be detected. This dissertation developed a theoretical framework and demonstrated the technique's ability to monitor and characterize minute internal stress changes both in the laboratory as well as in the field. This study resulted in one published peer-reviewed journal paper and is presented in Chapter 2.

- Nonlinear vibration index (NVI) method: This reference-free NDT technique is based on the idea that internal degradation in a concrete member such as cracking results in a nonlinear dynamic response. A new test is proposed where an instrumented hammer is struck against the concrete surface with increasing levels of magnitude and both the impact force as well as the response of the system are recorded. The hypothesis was that if the system is undamaged, the frequency response function (FRF), should remain constant and independent of the impact force. With the introduction of degradation, however, the FRF changes. The proposed NVI method was explored numerically first, then evaluated on an in-service concrete bridge deck. This study resulted in one peerreviewed journal paper (to be submitted) and is presented in Chapter 4.

Additionally, the natural vibration response of a large-scale reinforced concrete beam was studied in the laboratory by means of a simple impulse response test using only one sensor location on the beam. This study showed that the elastic supports have a crucial influence 
on the modal parameters of the reinforced concrete girders, especially on the modal parameters of the lower modes. The natural frequencies of the higher modes were found to be much more sensitive to flexural cracking but might be difficult to distinguish without a numerical model. Finally, flexural cracking was detected by looking at the function of the mode shape and by means of the flexibility method. This study resulted in one published peer-reviewed journal paper and is presented in Chapter 3.

\subsection{Outlook and Recommended Future Work}

This $\mathrm{PhD}$ dissertation research established the fundamental basis for several new NDE techniques, which still have limitations before they can reliably be used in a real-world setting. One major aspect that should be studied in depth is the effects of temperature and humidity variations on the dynamic response. The presented work has either been based on short-term measurements where these environmental effects do not vary considerably or they have been limited due to a laboratory setting. The ultimate goal should be to evaluate the performance of any NDE method in a real-world setting. The author of this $\mathrm{PhD}$ dissertation can think of many useful applications for concrete structures that would help agencies make better decisions regarding maintenance and repair, for example:

- Monitoring for alkali-silica reaction (ASR) and carbonation.

- Estimation of residual and creep stresses after structural load testing.

- Rapid post-earthquake condition assessment tools

One way to minimize environmental effects and provide long-term durability of the monitoring system is by using embeddable sensors. Commercial embeddable sensors will 
be available soon and will open new avenues for research and development. Temperature and humidity should be monitored in conjunction with the dynamic response. Finally, new data analytics approaches such as machine learning should be explored and validated to help distinguish sensor measurement components and assign them to certain causes. This will require additional controlled and carefully planned laboratory experimentation to ensure accuracy and reliability of any advanced data analytics tools used. 